UNIVERSIDADE DE SÃO PAULO

FACULDADE DE ECONOMIA, ADMINISTRAÇÃO E CONTABILIDADE DEPARTAMENTO DE ECONOMIA PROGRAMA DE DOUTORADO EM ECONOMIA DO DESENVOLVIMENTO

\title{
Efeitos de Aposentadoria em Saúde e Mobilidade Ocupacional no Brasil
}

André Gal Mountian

Orientadora: Profa. Dra. Maria Dolores Montoya Diaz 
Prof. Dr. João Grandino Rodas

Reitor da Universidade de São Paulo

Prof. Dr. Reinaldo Guerreiro

Diretor da Faculdade de Economia, Administração e Contabilidade

Prof. Dr. Joaquim José Martins Guilhoto

Chefe do Departamento de Economia

Prof. Dr. Prof. Márcio Issao Nakane

Coordenador do Programa de Pós-Graduação em Economia 


\title{
Efeitos de Aposentadoria em Saúde e Mobilidade Ocupacional no Brasil
}

\author{
Tese apresentada ao Programa de Pós-Graduação \\ em Economia do Desenvolvimento da Faculdade \\ de Economia, Administração e Contabilidade da \\ Universidade de São Paulo, como parte dos \\ requisitos para obtenção do título de Doutor em \\ Ciências.
}

Orientadora: Profa. Dra. Maria Dolores Montoya Diaz

Versão Corrigida

São Paulo

2015 


\section{FICHA CATALOGRÁFICA}

\section{Elaborada pela Seção de Processamento Técnico do SBD/FEA/USP}

\section{Mountian, André Gal}

Efeitos de aposentadoria em saúde e mobilidade ocupacional no Brasil / André Gal Mountian. -- São Paulo, 2015

$95 \mathrm{p}$.

Tese (Doutorado) - Universidade de São Paulo, 2015.

Orientador: Maria Dolores Montoya Diaz.

1. Aposentadoria 2. Saúde 3. Trabalho por conta própria 4. Idoso 5. Econometria I. Universidade de São Paulo. Faculdade de Economia, Administração e Contabilidade. II. Título. 


\section{AGRADECIMENTOS}

A conclusão desse trabalho desperta em mim uma serie de sentimentos. De um lado, a satisfação de finalizar essa etapa da minha formação acadêmica, que foi um dos maiores desafios da minha trajetória profissional e intelectual. De outro, a sensação de que o aprendizado adquirido nesses anos, em todas as suas dimensões, marca o início de um novo caminho e de novas possibilidades de pesquisa e atuação profissional.

Nesse processo, muitas pessoas e instituições foram importantes para que o doutorado fosse possível. Em primeiro lugar, agradeço à minha orientadora, Maria Dolores Montoya Diaz, que teve um papel fundamental em todas as etapas da pesquisa, contribuindo na definição do tema de investigação e nas escolhas metodológicas utilizadas. Agradeço especialmente a sua paciência e dedicação à orientação. Sou grato também à professora Maria Cristina Cacciamali pela confiança depositada na aceitação do meu projeto de doutorado e pelas inspiradoras aulas de Economia do Trabalho, bem como aos professores do Programa de Economia do Desenvolvimento Pedro Garcia Duarte, Gilberto Tadeu Lima, Renato Colistete, Raúl Cristóvão e José Paulo Zeetano Chahad.

Agradeço aos professores Fernando Postali e Paula Pereda, que participaram das bancas de qualificação e de tese, pelas muitas contribuições realizadas, além da constante receptividade e compreensão com as minhas dúvidas. Agradeço também às professoras Flávia Mori e Regina Madalozzo pelos valiosos comentários na defesa de tese.

Sou grato à professora Maria Lucia Lebrão, pelo auxílio com os dados da SABE, ao Rafael Ribas, pela fundamental ajuda com o algoritmo de imputação da renda de aposentadoria e ao Luciano Machado, pelo auxílio com algoritmo de pseudo-painel. Não posso deixar de agradecer à sempre presente Andrea Lucchesi e ao Vinícius Mendes, amigos que me ajudaram muito nessa caminhada. Agradeço à CAPES, pelo período de apoio financeiro, ao Departamento de Economia da PUC/SP, instituição onde leciono e que me concedeu licença para eu concluir o doutorado, e à FEA/USP.

Importante lembrar da minha pequena, mas muito valorosa turma de doutorado em Economia do Desenvolvimento, André Carvalho, Aná Lélia, Carlândia, José Carlos e Guilherme de Oliveira, bem como dos funcionários da biblioteca, Crislaine, Janaína, Roberto, Valéria e André.

Agradeço aos amigos da vida e a família por todo o apoio e por compreenderem as minhas ausências na etapa final do doutorado, em especial às minhas irmãs, Daniela e Ilana. Finalizo dedicando essa tese aos meus pais, Sofia e Moissei, que tornaram tudo isso possível. 



\section{RESUMO}

A aposentadoria é uma instituição social que pode ter efeitos múltiplos e de longo prazo sobre o bem-estar individual. Essa tese investigou duas dimensões dessa questão, relacionadas à saúde e à inserção laboral de indivíduos mais velhos no Brasil. O objetivo desse trabalho é investigar os efeitos da aposentadoria sobre as condições de saúde e sobre a transição para o trabalho por conta própria no Brasil. A metodologia utilizada é econométrica e duas bases de dados foram utilizadas. A investigação da transição para o trabalho por conta própria utilizou a Pesquisa Mensal de Emprego (PME), entre os anos de 2002 a 2007, com trabalhadores na faixa de 50 a 69 anos de idade. A metodologia empregada foi a de pseudo-painel, que permitiu o tratamento de uma possível endogeneidade da decisão de trabalhar, além de possibilitar o uso de técnicas de dados em painel. Os resultados encontrados mostram que a renda de aposentadoria tem impacto sobre essa transição, em especial, para os menores quartis. No entanto, estar aposentado (dummy) não é significativo para explicar a transição ocupacional de interesse. Outros controles mostraram-se importantes, mas com diferentes impactos para homens e mulheres. Já a investigação dos efeitos de aposentadoria em saúde utilizou a Saúde Bem-Estar e Envelhecimento (SABE), base longitudinal com idosos no município de São Paulo. Foram estimados modelos de efeitos fixos e efeitos fixos com variável instrumental para levar em conta a possível simultaneidade entre a decisão de parar de trabalhar e a condição de saúde da pessoa. Foram encontradas evidências de que a aposentadoria melhora indicadores de mobilidade, especialmente para os homens.

Palavras-chave: Aposentadoria, Saúde, Trabalho por Conta Própria, Idoso, Econometria. 



\begin{abstract}
Retirement is a social institution that can have multiple and long-term effects on individual well-being. This thesis investigated two dimensions of this issue, related to health and labor insertion of older individuals in Brazil. The aim of this study is to investigate the effects of retirement on health and on the transition to self-employment in Brazil. The methodology used is econometric and two databases were used. The investigation of the transition to selfemployment used the Monthly Employment Survey (PME), between the years 2002-2007, with workers aged 50 to 69 years old. The methodology used was the pseudo-panel, allowing the treatment of a possible endogeneity of the decision to work, in addition to allowing the use of panel data techniques. The results show that retirement income has an impact on this transition, particularly for the lower quartiles. However, be retired (dummy) is not significant in explaining the occupational transition of interest. Other controls were important, but with different impacts on men and women. Already investigating the health effects of retirement used the Health Welfare and Ageing (SABE), longitudinal base with elderly in São Paulo. Fixed effects and fixed effects with instrumental models were estimated to take into account the possible simultaneity between the decision to stop working and the person's health condition. Evidence was found that retirement improves mobility indicators, especially for men.
\end{abstract}

Keywords: Retirement, Health, Self-Employment, elderly, Econometrics. 


\section{LISTA DE TABELAS}

Tabela 1. Indicadores de envelhecimento populacional, 1950-2050

Tabela 2. Regras de elegibilidade para aposentadoria

Tabela 3. Características sociodemográficas da PEA idosa, segundo status de aposentadoria, 2013

Tabela 4. Posição na ocupação da população idosa, segundo status de aposentadoria, 2013 .. 34

Tabela 5. Autopercepção de saúde. PEA idosa, PEA pura e PEA aposentada. 34

Tabela 6. Estatísticas descritivas. 53

Tabela 7 Transição ocupacional dos trabalhadores formais e informais entre $t$ e $t+1$ 55

Tabela 8. Determinantes da transição para o trabalho por conta própria entre homens e mulheres. 57

Tabela 9. Indicadores de envelhecimento populacional, por grupo de países 63

Tabela 10 Painel desbalanceado da amostra selecionada da SABE: total de observações por ano e distribuição dos indivíduos no painel...... 73

Tabela 11. Indicador Geral de Saúde 76

Tabela 12. Indicadores de saúde investigados .77

Tabela 13. Variáveis de controle. 79

Tabela 14 Média e desvio padrão por sexo. 80

Tabela 15. Estatísticas descritivas para aposentados e trabalhadores 82

Tabela 16. Efeito da aposentadoria nos indicadores de saúde 83

Tabela 17. Primeiro estágio, coeficientes para a decisão e aposentadoria. 85

Tabela 18. Coortes de nascimento. 97 


\section{LISTA DE GRÁFICOS E FIGURAS}

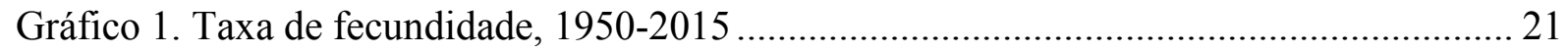

Gráfico 2. Estrutura Etária do Brasil, 1950-2050 _................................................................... 24

Gráfico 3. Quantidade de benefícios concedidos, segundo grupos de espécie, 1983-2011 .... 26

Gráfico 4. Taxa de participação de homens entre 60 e 64 anos de idade, 1960-2008 ............. 27

Gráfico 5. Proporção de idosos na população e proporção de idosos na PEA.......................... 31

Gráfico 6. Nível de atividade de idosos, por gênero, 1981-2013 .......................................... 31

Gráfico 7. Posição na ocupação das pessoas com 60 anos ou mais de idade no Brasil, 201332

Gráfico 8. Proporção de trabalhadores por conta-própria em relação aos ocupados, por faixa

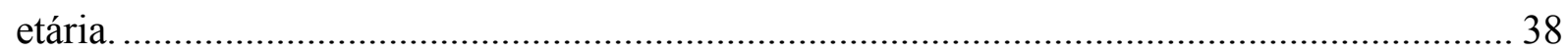

Gráfico 9. Número de observações por coorte ...................................................................... 52 


\section{LISTA DE ABREVIATURAS E SIGLAS}

HRS: Health and Retirement Study

IBGE: Instituto Brasileiro de Geografia e Estatística

INSS: Instituto $\mathrm{Na}$

OMS: Organização Mundial de Saúde

ONU: Organização das Nações Unidas

PEA: População Economicamente Ativa

PME: Pesquisa Mensal de Emprego

PNAD: Pesquisa Nacional por Amostras de Domicílios

RGPS: Regime Geral de Previdência Social

RPS: Regime Próprio da Previdência Social

SABE: Saúde, Bem-Estar e Envelhecimento

SHARE: Survey of Health, Ageing and Retirement in Europe

TEE: Transição da Estrutura Etária 


\section{SUMÁRIO}

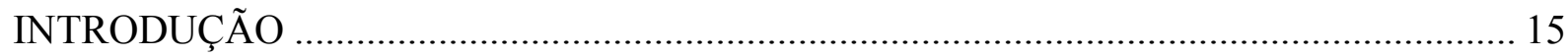

1. Aposentadoria, mercado de trabalho e saúde de idosos no Brasil ..................................... 19

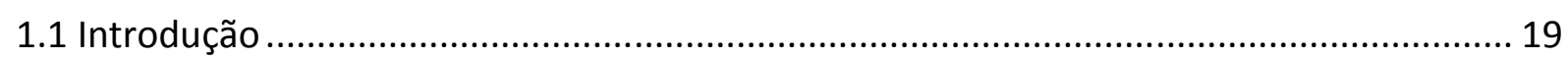

1.2 Desafios do envelhecimento populacional no Brasil .................................................. 21

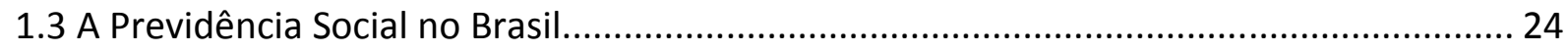

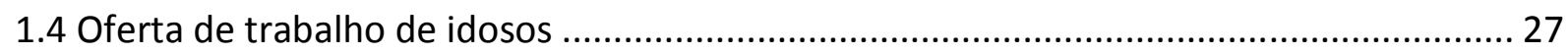

1.5 Inserção econômica e estado de saúde dos idosos no Brasil .......................................... 30

2. EFEITOS DA APOSENTADORIA NA TRANSIÇÃO PARA O TRABALHO POR CONTA PRÓPRIA NO BRASIL

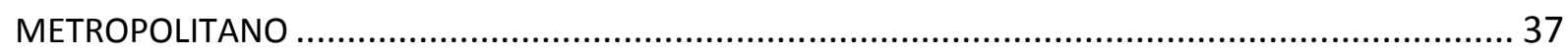

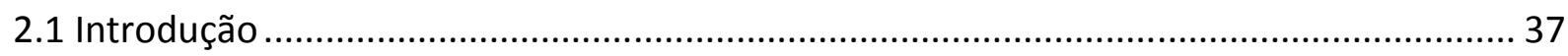

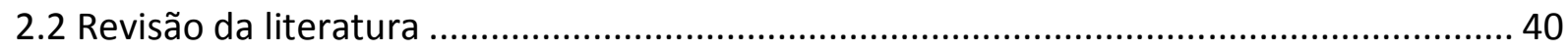

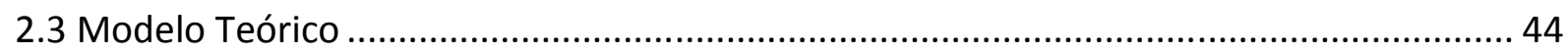

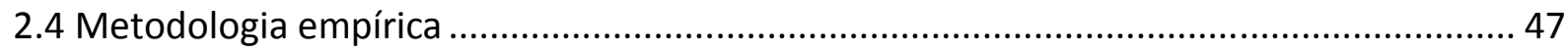

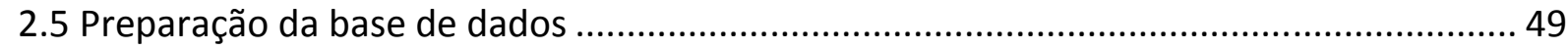

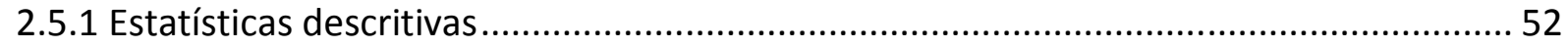

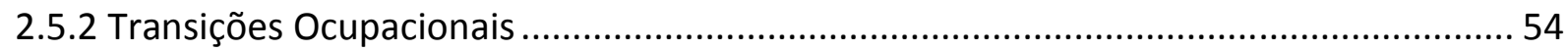

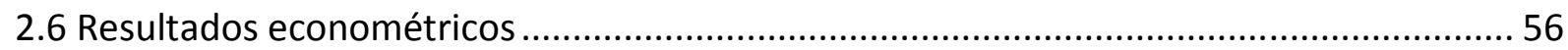

3. Os Efeitos da Aposentadoria na Saúde dos Idosos na Cidade de São Paulo ....................... 63

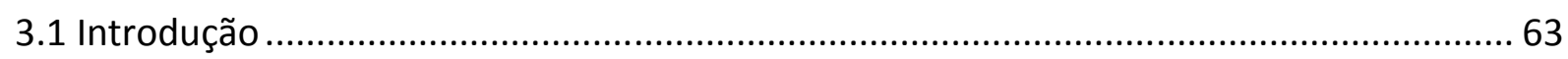

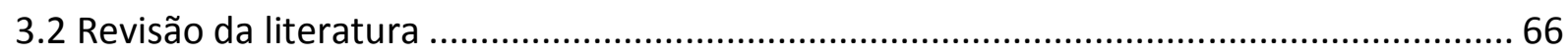

3.3 Função de produção de saúde e a decisão de aposentadoria ........................................ 68

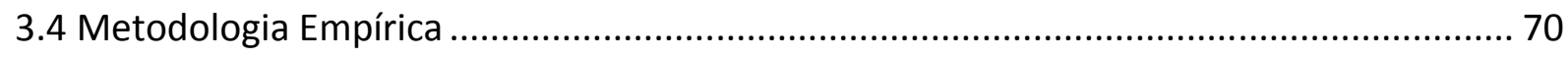

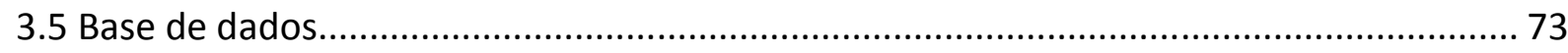

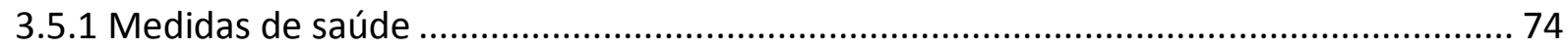

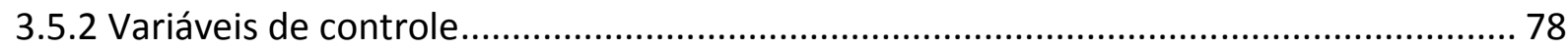




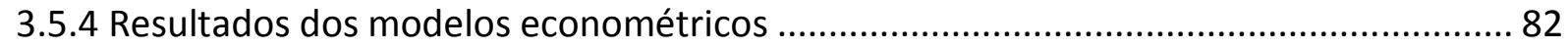

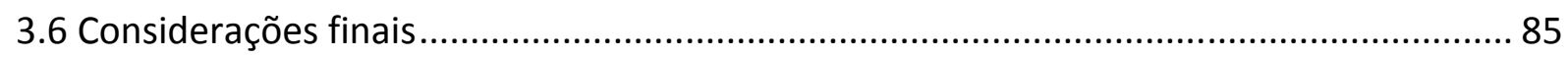

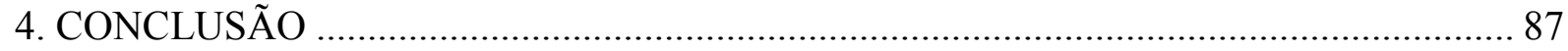

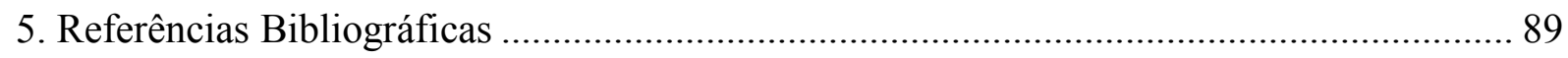

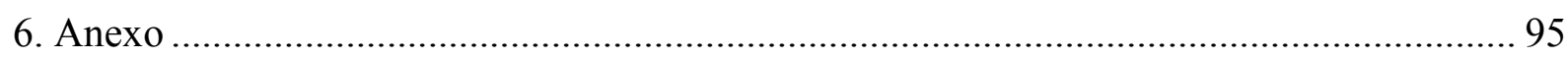




\section{INTRODUÇÃO}

O conceito de aposentadoria está relacionado com distintos fenômenos. Do ponto de vista instrumental, trata-se da forma pela qual as sociedades regulam a sucessão em diferentes espaços, como no mercado de trabalho e na família, além de satisfazer a inclinação das pessoas de retirar-se das atividades econômicas (EKERDT, 2010). Do ponto de vista individual, a aposentadoria representa uma fase de transição entre o mundo do trabalho e outra etapa da vida a ser construída, que envolve uma redefinição dos papéis sociais e com possíveis efeitos sobre a saúde das pessoas (COE; ZAMARRO, 2011). Por último, da perspectiva institucional, a aposentadoria constitui-se como um elemento fundante do Estado de Bem Estar Social, provendo seguro contra riscos sociais relacionados à velhice, doença e acidente de trabalho (LLOYD-SHERLOCK, 2000).

A partir da década de 1980, alguns dos fundamentos dos sistemas previdenciários mudaram de forma profunda, fato que, embora não questione as funções instrumentais da aposentadoria, contesta a sua atual configuração (EKERDT, 2010). A natureza e a organização do trabalho mudaram, tornando os empregos menos fisicamente demandantes, porém mais instáveis e inseguros (KALLEBERG et al, 2000). A taxa de participação das mulheres no mercado de trabalho aumentou nas últimas décadas, com repercussões sobre a renda e a dinâmica das famílias. Além disso, as tendências demográficas para sociedades mais envelhecidas têm implicações fiscais sobre os sistemas de previdência social (GRUBER; WISE, 1998).

De acordo com Ekerdt (2010), essas questões introduziram nuances na fronteira entre trabalho e aposentadoria, e engendraram linhas de investigação, novas e necessárias para a compreensão do fenômeno da aposentadoria. Nessa nova agenda, destaca-se o trabalho de idosos, que deve ter uma participação maior na população economicamente ativa (PEA) devido ao envelhecimento populacional e aos incentivos das políticas públicas para que as pessoas continuem trabalhando em idades avançadas. Nesse sentido, há evidências de que parte dos idosos retorna à força de trabalho após um período de inatividade e que muitos trabalhadores, em especial nos Estados Unidos, se aposentam de forma gradual, utilizando empregos de curta duração (bridge jobs) entre o emprego de carreira full time e a saída definitiva do mercado de trabalho (CAHILL; GIANDREA; QUINN, 2006). Essas variações sugerem que os limites entre aposentadoria e o trabalho estão sendo redefinidos. 
Outra linha de pesquisa destacada por Ekerdt (2010) diz respeito à experiência de estar aposentado, ou seja, aos estilos de vida adotados pelas pessoas que saem definitivamente do mercado de trabalho e à maneira pela qual experimentam essa nova fase da vida. Os efeitos da decisão de aposentadoria sobre o bem-estar individual, em especial sobre os indicadores de saúde, constituem uma agenda de pesquisa promissora, uma vez que a aposentadoria representa um período relativamente grande na vida das pessoas graças ao aumento da expectativa de vida.

As duas linhas de investigação destacadas acima, mercado de trabalho de idosos e a experiência de estar aposentado, revelam que o escopo da agenda de pesquisa sobre aposentadoria está se ampliando e levam em consideração possíveis efeitos sobre o bem-estar individual, por meio de conexões com saúde, histórico laboral, estrutura familiar etc. $\mathrm{O}$ caráter interdisciplinar - envolvendo áreas de conhecimento como Economia, Medicina, Gerontologia e Ciências Sociais - e o subsídio de detalhadas bases de dados longitudinais com pessoas acima de 50 anos, são outras características dessa agenda de pesquisa.

Essa tese se insere nessa perspectiva de análise e tem dois objetivos gerais:

(i) determinar os impactos da aposentadoria sobre a transição para o trabalho por conta própria no Brasil metropolitano. Mais especificamente, deseja-se testar a hipótese de que possuir renda de aposentadoria favorece a abertura de um negócio próprio;

(ii) determinar os impactos da aposentadoria sobre a saúde de idosos residentes no município de São Paulo. Ou seja, pretende-se determinar se as pessoas que continuam trabalhando possuem uma condição de saúde melhor, avaliada a partir de um conjunto de indicadores, do que aqueles que pararam de trabalhar.

Essas questões são de grande relevância para um país como o Brasil, que tem uma população que envelhece rapidamente, e que precisa constituir um conjunto de políticas públicas que apoiem esse processo de envelhecimento. No Brasil, assim como nos demais países em desenvolvimento, há poucos trabalhos dessa natureza, fato que pode ser justificado pela pouca disponibilidade de dados com perfil multidisciplinar, necessário para o estudo de saúde e inserção laboral de idosos. Além disso, esse tipo de investigação pode funcionar como subsídio para as discussões que envolvem as reformas no sistema previdenciário brasileiro. Mais especificamente, os debates sobre as reformas não deve ficar restrito aos impactos fiscais, mas precisam levar em conta os potenciais impactos sobre os resultados do mercado de trabalho e sobre a saúde das pessoas.

A metodologia de análise utilizada na tese baseia-se no instrumental de Microeconometria. Ou seja, a partir da disponibilidade de microdados e da descrição do 
comportamento dos indivíduos fornecidos pelos modelos microeconômicos, utilizou-se modelos econométricos para estimar os parâmetros de interesse. Procurou-se dialogar com os trabalhos já existentes, e com outras áreas do conhecimento que discutem questões similares.

A tese está dividida em cinco partes, incluindo essa Introdução. O primeiro capítulo apresenta um conjunto de fatos estilizados sobre o envelhecimento populacional, a inserção laboral e a saúde de idosos no Brasil. O objetivo desse capítulo é fornecer um quadro analítico que subsidie as discussões posteriores na pesquisa.

O segundo capítulo investiga os determinantes da transição do trabalhado assalariado, formal ou informal, para o trabalho por conta própria. A base de dados utilizada foi a Pesquisa Mensal de Emprego (PME), entre 2002 e 2007, em seis regiões metropolitanas do Brasil. Foram investigadas as transições para o trabalho por conta própria entre indivíduos na faixa de 50 a 69 anos de idade, com ênfase para o papel da renda de aposentadoria nesse processo. Essa análise baseou-se na construção de um pseudo-painel ao nível dos indivíduos, que permitiu levar em conta a possível endogeneidade da decisão de trabalhar.

O terceiro capítulo investiga os impactos da aposentadoria na saúde dos idosos residentes no município de São Paulo. A base de dados utilizada é a Saúde, Bem Estar e Envelhecimento (SABE). Foram investigados os efeitos e os mecanismos pelos quais a aposentadoria pode impactar a saúde das pessoas. Para levar em conta a simultaneidade entre a decisão de se aposentar e a condição de saúde da pessoa, foram utilizados os modelos de efeito fixo e efeito fixo com variável instrumental. O quarto capítulo conclui a pesquisa. 


\section{APOSENTADORIA, MERCADO DE TRABALHO E SAÚDE DE IDOSOS NO BRASIL}

\subsection{Introdução}

A investigação sobre o estado de saúde e a inserção laboral de idosos necessita de uma explicação prévia sobre o conceito de idoso e suas especificidades. A Organização Mundial de Saúde (OMS) concebe como idosas as pessoas com 60 anos ou mais de idade, se residirem em países em desenvolvimento, e com 65 anos ou mais, se residirem em países desenvolvidos. Essa classificação é corroborada no Brasil pelo Estatuto do Idoso, aprovado em 2003 (BRASIL, 2003).

Camarano (2013) avalia que o conteúdo dessa classificação etária pressupõe que a partir de determinada idade as pessoas começariam a apresentar sinais de incapacidade física e mental que a diferenciam da população mais jovem ${ }^{1}$. No entanto, por essa classificação, um indivíduo pode ser considerado idoso pela sua idade, mas não possuir os atributos usualmente associados à velhice, como obsolescência e incapacidade. Essas pessoas receberiam os benefícios da política social, sem necessitar, e sofreriam constrangimentos no mercado de trabalho, como a existência de aposentadoria compulsória.

O aumento da expectativa de vida e os papeis sociais desempenhados pelos idosos sugerem que esse conceito precisa ser rediscutido no Brasil. Em 2010, a expectativa de vida de uma pessoa com 60 anos era cerca de 23 anos, fase da vida superior à infância e a adolescência juntas. Dessa forma, o conceito de idoso abarca um conjunto heterogêneo de pessoas, com distintas faixas etárias (incluindo o grupo mais idoso com 60 anos ou mais) e níveis de vulnerabilidade ${ }^{2}$ (CAMARANO, 2013).

Lloyd-Sherlock (2004) argumenta que a percepção da velhice fundamenta as políticas voltadas a esse segmento populacional. $\mathrm{O}$ autor identificou duas visões extremas sobre a velhice no debate internacional. A primeira e predominante visão associa a velhice com aspectos negativos, como dependência e vulnerabilidade. Segundo essa concepção, o envelhecimento é positivo do ponto de vista individual, mas representa uma ameaça ao desenvolvimento econômico, pois os idosos seriam inerentemente improdutivos e suas necessidades reduziriam os recursos econômicos disponíveis. As políticas públicas baseadas nesse tipo de concepção tendem a reforçar a dependência das pessoas mais velhas e a

\footnotetext{
1 A denominação de idoso não se refere somente características biológicas, mas localiza o indivíduo em diferentes esferas da vida social, como no trabalho e na família (CAMARANO, 2013).

${ }^{2}$ Para tornar esse subgrupo populacional mais homogêneo, Camarano (2013) defende que a idade que define idoso aumente para 65 anos no Brasil.
} 
considerar que os idosos representam um fardo aos mais jovens, devido aos gastos com saúde e previdência (CAMARANO, 2004)

No entanto, outra concepção vem ganhado espaço a partir da década de 1990, enfatizando que o envelhecimento não pode ser associado a uma fase de declínio individual. Ao contrário, o aumento da expectativa de vida e a elevação da cobertura previdenciária têm levado os idosos a desempenharem novos papéis sociais. Lloyd-Sherlock (2004) destaca que a contribuição econômica das pessoas mais velhas inclui o prosseguindo das atividades econômicas, a importância da renda de aposentadoria e da residência aos familiares, o cuidado com os netos, além de envolver a participação nas decisões da família e da comunidade. Essa visão de velhice fundamenta a adoção de políticas que estimulam o desenvolvimento das capacidades das pessoas mais velhas, conhecidas como políticas de envelhecimento ativo ${ }^{3}$.

Do ponto de vista das políticas públicas, a primeira Assembleia da Organização das Nações Unidas (ONU) sobre Envelhecimento ocorrida em 1982, em Viena, é considerada o marco inicial da agenda internacional das políticas para a população idosa. Até então, o tema do envelhecimento era visto como secundário na ONU e em outras agências internacionais, como a Organização Internacional do Trabalho (OIT), da Organização Mundial de Saúde (OMS), e da Organização para a Educação, Ciência e Cultura (UNESCO). O objetivo do Plano de Viena era garantir segurança econômica e social aos idosos e foi centrado nas condições de envelhecimento dos países desenvolvidos, com ênfase em recomendações que promoviam a independência física e financeira dos idosos (CAMARANO; PASINATO, 2004).

A segunda Assembleia da ONU sobre Envelhecimento ocorreu em 2002, em Madri, em um contexto econômico e social distinto, e dedicou maior atenção ao envelhecimento em curso nos países em desenvolvimento. O Plano de Madri consiste em um conjunto de recomendações aos países membros, com foco em três eixos: participação ativa dos idosos na sociedade e na luta contra a pobreza, promoção de envelhecimento saudável e criação de um eterno propício ao envelhecimento. Camarano e Pasinato (2004) destacam que uma das maiores contribuições do Plano de Madri está na percepção de que os idosos podem dar uma contribuição ativa para a sociedade, ou seja, contraria a ideia de que o envelhecimento populacional representa uma ameaça ao desenvolvimento econômico.

\footnotetext{
${ }^{3}$ Lloyd-Skerlock (2004) argumenta que essa concepção de velhice, apesar de representar um importante contraponto ao paradigma negativo de envelhecimento, negligencia que uma parcela dos idosos realmente possui vulnerabilidades e dependências, e que não seriam suscetíveis às políticas de envelhecimento ativo. Nesse sentido, o autor destaca que ambas as concepções são equivocadas, pois compreendem a experiência do envelhecimento como homogênea.
} 


\subsection{Desafios do envelhecimento populacional no Brasil}

O envelhecimento populacional representa uma das maiores conquistas do século XX e é uma tendência consolidada em quase todas as regiões do mundo. Esse evento encontra-se mais aprofundado nos países desenvolvidos, embora a maioria dos idosos do mundo resida nos países em desenvolvimento desde a década de 1950 (UNITED NATIONS, 2013).

O fenômeno do envelhecimento populacional é usualmente compreendido como o estágio final do processo de transição demográfica. Nesse modelo, o início da transição é marcado por quedas nas taxas de mortalidade que, via de regra, conduzem ao alargamento da base da pirâmide etária, ou seja, à redução da idade média da população. Na etapa final, as taxas de fecundidade declinam de maneira consistente, levando ao estreitamento da pirâmide etária e a uma maior preponderância das coortes mais velhas na população (LLOYDSHERLOCK, 2010). No entanto, de acordo com Lloyd-Sherlock (2010), as tendências descritas pelo modelo de transição demográfica não podem ser interpretadas de forma linear, pois o momento e o ritmo de crescimento das taxas de mortalidade e fecundidade dependem da interação entre as condições socioeconômicas, culturais e institucionais dos países.

Palloni e Peláez (2003) afirmam que o momento demográfico dos países da América Latina e Caribe baseia-se em um padrão de crescimento populacional experimentado a partir da década de 1940, quando houve uma queda brusca na taxa de mortalidade e, após 1970, quando as taxas de fecundidade começaram a declinar rapidamente. O Gráfico 1 compara a taxa de fecundidade do Brasil com a dos países desenvolvidos e mostra que, embora tendam a convergir, o ritmo da queda é consideravelmente mais elevado no Brasil. Os autores argumentam que, embora os indicadores de envelhecimento apontem para valores similares aos vivenciados pelos países desenvolvidos, o processo de envelhecimento da região tem uma serie de particularidades. Nessas sociedades, a mortalidade e a fecundidade diminuíram em um curto intervalo de tempo, em oposição aos países da Europa Ocidental e da América do Norte, que experimentaram quedas mais graduais. Como consequência, a velocidade do envelhecimento nos países da região será pelos menos duas vezes maior que em outras partes do mundo (PALLONI e PELÁEZ, 2003).

Gráfico 1. Taxa de fecundidade, 1950-2015 


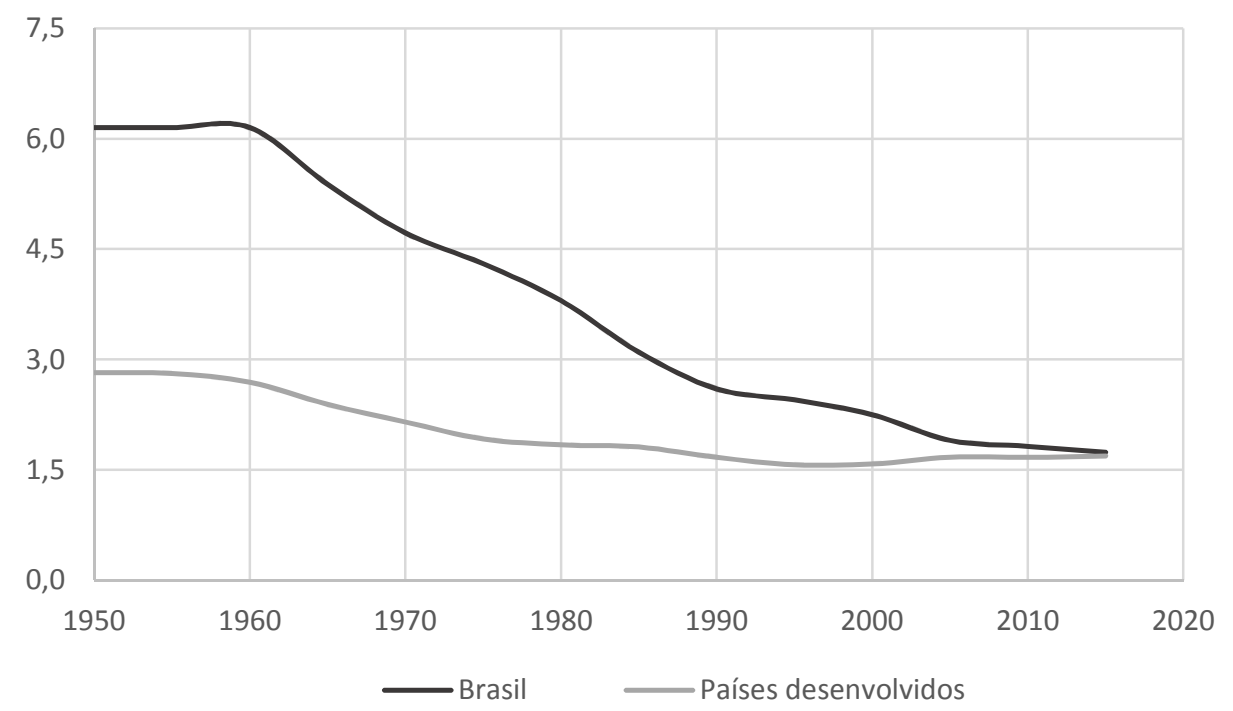

Fonte: UNITED NATIONS (2015)

A Tabela 1 apresenta três indicadores usuais de envelhecimento, a proporção de pessoas com 60 anos ou mais de idade, a idade média da população e a razão de dependência, para os anos de 1950, 2015 e 2050. Esses indicadores confirmam que o envelhecimento encontra-se em um estágio mais aprofundado nos países desenvolvidos, mas que essa diferença deve diminuir nas próximas décadas. Em particular, em 2015, as pessoas com 60 anos ou mais de idade representam $24 \%$ da população dos países desenvolvidos e $12 \%$ da população brasileira. Já em 2050, as projeções mostram que $29 \%$ da população do Brasil será composta por idosos, proporção próxima à projetada para os países desenvolvidos. Trajetória similar é prevista para a idade média do Brasil, que deve alcançar 45 anos em 2050, valor similar a dos países desenvolvidos.

Tabela 1. Indicadores de envelhecimento populacional, 1950-2050

\begin{tabular}{|c|c|c|c|c|c|c|c|c|c|}
\hline \multirow[b]{2}{*}{ Países } & \multicolumn{3}{|c|}{ Proporção de idosos (\%)* } & \multicolumn{3}{|c|}{ Idade mediana } & \multicolumn{3}{|c|}{ Razão de dependência** } \\
\hline & 1950 & 2015 & 2050 & 1950 & 2015 & 2050 & 1950 & 2015 & 2050 \\
\hline Desenvolvidos & 12 & 24 & 33 & 29 & 41 & 45 & 12 & 27 & 46 \\
\hline Em desenvolvimento & 6 & 10 & 20 & 21 & 28 & 35 & 7 & 10 & 23 \\
\hline \multicolumn{10}{|l|}{ Entre os países } \\
\hline \multicolumn{10}{|l|}{ em desenvolvimento: } \\
\hline América Latina & 6 & 11 & 26 & 20 & 29 & 41 & 6 & 11 & 31 \\
\hline Brasil & 5 & 12 & 29 & 19 & 31 & 45 & 5 & 11 & 37 \\
\hline Ásia & 7 & 12 & 25 & 22 & 30 & 40 & 7 & 11 & 28 \\
\hline África & 5 & 5 & 9 & 19 & 19 & 25 & 6 & 6 & 10 \\
\hline
\end{tabular}

Fonte: UNITED NATIONS (2015)

* Considerando idosos as pessoas com 60 anos ou mais; ** razão entre inativos idosos (65 anos ou mais em relação aos ativos (15 a 64 anos) vezes 100.

A razão de dependência reflete a disponibilidade de inativos idosos (65 anos ou mais) em relação aos ativos (15 a 64 anos) na população e é uma medida da capacidade de uma sociedade realizar transferências para as pessoas mais velhas. Em 2015, a razão de 
dependência do Brasil é de 11, indicando que para cada 100 ativos, há 11 inativos idosos na população. A projeção é que essa razão triplique nas próximas décadas, podendo comprometer a capacidade do país financiar transferências intergeracionais no futuro.

Tendo em vista o curto período de tempo em que as taxas de mortalidade e fecundidade declinaram nos países latino-americanos, essas nações não conseguiram construir instituições de suporte ao envelhecimento. O calendário estreito do envelhecimento na região ocorreu em meio a contextos sociais e econômicos frágeis que dificultavam o acesso a serviços de saúde e de apoio aos mais velhos. Esse processo difere do ocorrido nos países desenvolvidos, cujo desenvolvimento econômico social já estava assegurado quando as demandas de uma sociedade que envelhecia surgiram (PALLONI e PELÁEZ, 2003). Além do frágil contexto institucional, Palloni e Peláez (2003) sugerem que a natureza do envelhecimento na América Latina e Caribe tem implicações sobre a saúde das pessoas que completarão 60 anos de idade depois de 2000. Isso porque a redução da mortalidade na região ocorreu, pelo menos em parte, graças à revolução médica e de saúde pública, mas sem melhorias nas condições de vida (moradia, saneamento básico etc.). Isso significa que os ganhos de sobrevida devem-se ao tratamento e a recuperação de doenças, mas que a contínua exposição a doenças na infância e na vida adulta poderia conduzir a um estado de saúde mais frágil na velhice.

O aumento da proporção de idosos na população brasileira está associado ao processo mais amplo de transição da estrutura etária (TEE) do país, ou seja, à mudança no tamanho relativo das diversas coortes devido ao rápido declínio da fecundidade, e traz oportunidades e desafios importantes para as políticas públicas brasileiras (WONG; CARVALHO, 2006). O Gráfico 2 apresenta a evolução de três grandes grupos etários ( 0 a 14 anos, 15 a 64 anos e 65 anos ou mais), entre 1950 e 2050, e mostra que a participação de ativos (15 e 64 anos) deve aumentar até cerca de 2025. Isso significa a existência de um bônus demográfico, segundo o qual a proporção de ativos cresce a uma taxa maior que a de inativos, fenômeno que acabará por volta de 2025, momento em que a proporção de pessoas mais velhas do que 65 anos ainda representará uma parcela pequena da população ${ }^{4}$. Nas décadas seguintes, a TEE aponta para uma sociedade com taxas crescentes de pessoas mais velhas e com uma menor participação da população economicamente ativa. De acordo com Wong e Carvalho (2006), a conclusão lógica dessa tendência é que as gerações mais novas atuais, que formarão a PEA futura, precisam receber grandes investimentos, especialmente em educação e saúde, para elevar a

\footnotetext{
${ }^{4}$ O país atingirá por volta de 2025 a mais baixa Razão de Dependência, pelo menos desde seu primeiro censo demográfico, em 1872 (WONG; CARVALHO, 2006).
} 
sua produtividade, não somente para melhorar a sua qualidade de vida futura, mas para sustentar as transferências à crescente população mais velha.

Gráfico 2. Estrutura Etária do Brasil, 1950-2050

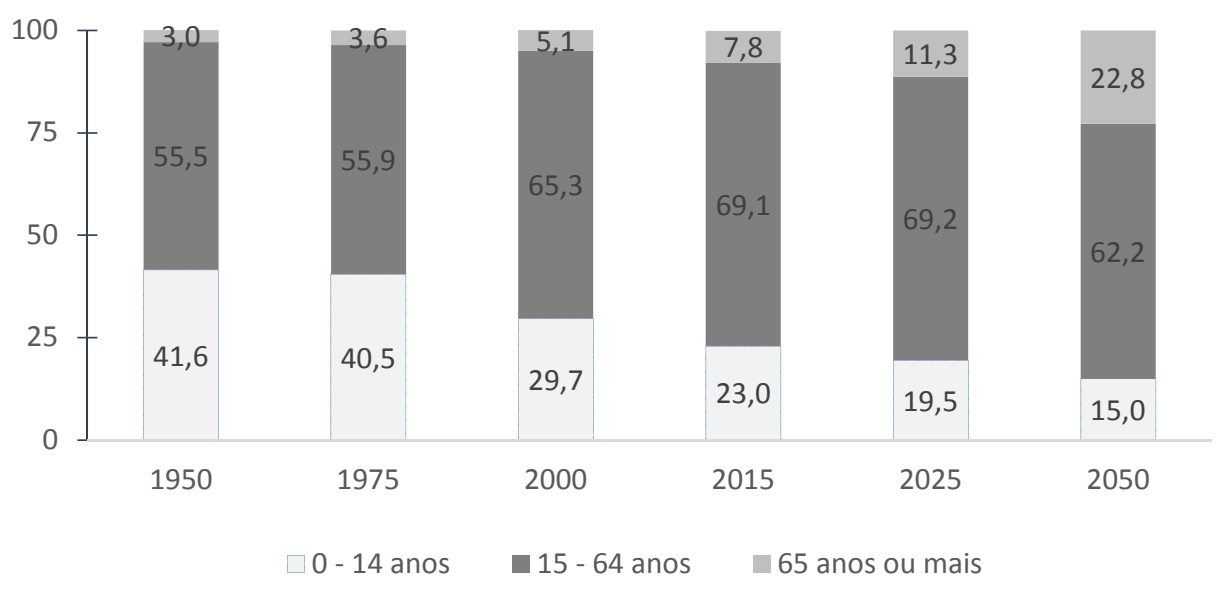

Fonte: UNITED NATIONS (2015)

Nesse sentido, as políticas públicas precisam levar em conta a atual TEE do Brasil, pois o peso relativo das distintas coortes no gasto público vai mudar nas próximas décadas. Analisando as receitas e despesas por cada faixa etária entre 2000 e 2050, Wong e Carvalho (2006) mostraram que a origem dos impostos concentra-se nas idades centrais da PEA, entre 30 e 49 anos durante todo esse período. Já a composição etária do gasto público é distinta e concentrada nas coortes com 60 anos ou mais de idade. Em 2000, cerca de 38\% da despesa pública era direcionada para essa parcela da população, valor que deve alcançar 49\% em 2025 e $67 \%$ em 2050, caso o padrão da despesa pública não se altere.

\subsection{A Previdência Social no Brasil}

A Previdência Social desenvolveu-se no Brasil ao longo do século XX em um contexto de grandes transformações econômicas, sociais e políticas. A primeira política pública de caráter previdenciário no Brasil originou-se em 1923, com a criação da Lei Eloy Chaves, que previa a criação de Caixas de Aposentadoria e Pensões destinadas aos funcionários das empresas de estradas de ferro. Tratou-se de um aparato institucional de filiação compulsória, que provia seguro contra velhice, enfermidades ou morte dos beneficiários (BRASIL, 2009).

$\mathrm{Na}$ década seguinte foram criados os Institutos de Aposentadoria e Pensão, que eram organizados por categorias profissionais e restritos aos trabalhadores urbanos. Os Institutos funcionavam conforme a lógica coorporativa do governo Getúlio Vargas, que aumentou significativamente a cobertura previdenciária no período (BRASIL, 2007). No entanto, o 
modelo dos Institutos era muito heterogêneo, com padrões de benefícios e contribuições distintos entre as categorias profissionais, e criava desigualdades de acesso a essa política social. Em 1960, a Lei Orgânica da Previdência Social (LOAS) uniformizou a legislação que era extensiva aos Institutos, a partir de critérios únicos e de filiação obrigatória aos trabalhadores não vinculados a algum regime próprio de aposentadoria. Já a unificação da gestão ocorreu somente em 1966, com a criação do Instituto Nacional de Previdência Social (INPS).

Ao longo da década de 1970 houve a criação de novas agências de Estado ligadas às Previdência Social, como a Empresa de Processamento de Dados da Previdência Social (DATAPREV), o Instituto Nacional de Assistência Médica da Previdência Social (INAMPS), o Instituto Nacional de Previdência Social (INPS) e o próprio Ministério da Previdência e Assistência Social, instituído em 1974. Além disso, em 1971, foi criado Programa de Assistência ao Trabalhador Rural (FUNRURAL), que concedia ao trabalhador rural aposentadoria por velhice e invalidez, pensão por morte e outros benefícios (BRASIL, 2007).

Na Constituição de 1988 foi criado o conceito da Seguridade Social, composta pela Previdência Social, Saúde e Assistência Social, e estabelecidos os princípios básicos, dentre os quais: universalidade da cobertura, equiparação dos benefícios para os trabalhadores rurais, adoção do salário mínimo como piso dos benefícios, descentralização da administração e incidência da contribuição sobre múltiplos setores da economia (BRASIL, 2007).

A estrutura atual da Previdência no Brasil é composta por três grandes regimes: o Regime Geral da Previdência Social (RGPS), que atende aos trabalhadores do setor privado, o Regime Próprio dos Servidores Públicos (RPSP) e o Regime Complementar (RC), cuja filiação é voluntária e é complementar ao RGPS/INSS.

Tabela 2. Regras de elegibilidade para aposentadoria

\begin{tabular}{|c|c|c|c|c|}
\hline \multirow[t]{2}{*}{ Aposentadoria } & \multicolumn{2}{|c|}{ Homens } & \multicolumn{2}{|c|}{ Mulheres } \\
\hline & RGPS* & $\mathrm{RPSP} * *$ & RGPS & RPSP \\
\hline Idade (urbano) & 65 & 60 & 60 & 55 \\
\hline Idade (rural) & 60 & - & 55 & - \\
\hline Tempo de contribuição & 35 & - & 30 & - \\
\hline Compulsória & - & 70 & - & 70 \\
\hline
\end{tabular}

O RGPS e o RPSP possuem regras distintas de elegibilidade, como mostrado na Tabela 2. No caso do RGPS é possível requerer os benefícios por tempo de contribuição (35 anos para os homens e 30 para as mulheres), ou por idade (65 anos para os homens e 60 anos 
para as mulheres na área urbana, ou 60 anos para os homens e 55 anos para as mulheres na área urbana). Dessa forma, no Brasil não existe idade mínima para requerer benefícios de aposentadoria por tempo de contribuição. Já pelo Regime RPSP é possível requerer aposentadoria por idade (60 anos para os homens e 55 anos para as mulheres), além de existir um mecanismo de aposentadoria compulsória aos 70 anos para ambos os sexos. Na Reforma da Previdência de 1997 foi instituído o fator previdenciário, que é um mecanismo para inibir aposentadorias precoces (dado que não existe idade mínima de aposentadoria por tempo de contribuição), que depende da idade do indivíduo, do tempo de contribuição, da expectativa de vida do país e da alíquota de contribuição

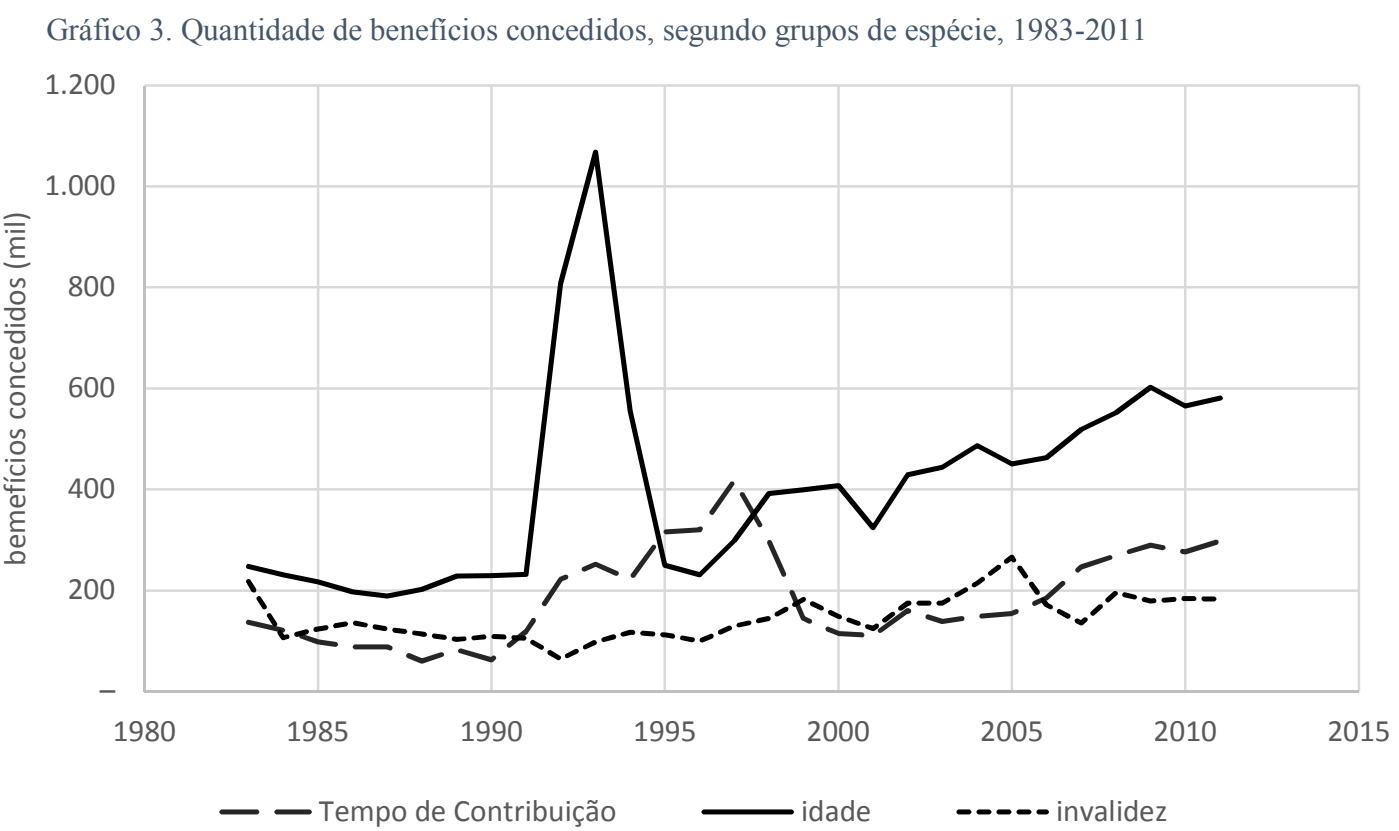

Fonte: BRASIL (2013)

Há evidências de que as regras de elegibilidade alteram a propensão dos indivíduos de requer os benefícios previdenciários (FURTADO, 2005; GRUBER; WISE, 1998). O Gráfíco 3 mostra a quantidade de benefícios concedidos em três modalidades, aposentadoria por idade, tempo de contribuição e invalidez. Observa-se que os benefícios concedidos por idade e tempo de contribuição têm uma tendência de crescimento no período considerado. Além disso, o crescimento observado no início da década de 1990 refere-se às mudanças estabelecidas na Constituição de 1988, cuja implementação somente ocorreu em 1991 (LIBERATO, 2003).

Um capítulo à parte em relação aos desafios que o envelhecimento populacional impõe à sociedade brasileira diz respeito aos gastos com a Previdência Social. De um lado, Caetano e Miranda (2009) indicam que a extensão da Previdência Social brasileira é bastante evoluída, mesmo quando comparada com a de países desenvolvidos e de estrutura populacional mais 
envelhecida. De outro lado, e ainda em comparação internacional, os autores mostraram que o Brasil gasta muito com previdência em relação à sua estrutura demográfica, ou seja, que previdência do país está superdimensionada.

\subsection{Oferta de trabalho de idosos}

Os determinantes da oferta de trabalho de idosos têm sido investigados na literatura nacional e internacional. Busca-se os motivos que levam as pessoas mais velhas a continuar trabalhando ou a retornar ao mercado de trabalho após um período de inatividade. Essa linha de investigação foi estimulada pela queda expressiva na taxa de participação dos trabalhadores mais velhos, especialmente entre os homens residentes nos países desenvolvidos, entre as décadas de 1960 e 1990. O Gráfico 4 mostra que, em 1960, o nível de atividade dos homens entre 60 e 64 anos de idade era próximo de 70\% na França e cerca de 80\% nos Estados Unidos, Inglaterra, Holanda e Japão. Já em 1990, essa taxa caiu para o conjunto dos países desenvolvidos, aproximando-se de 55\% nos Estados Unidos e Inglaterra e de $20 \%$ na França e na Holanda. Posteriormente, essas taxas aumentaram em alguns desses países, mas em um patamar inferir ao inicial.

Essa queda brusca no nível de atividade dos homens ocorreu devido aos incentivos engendrados pelos sistemas de aposentadoria (GRUBER; WISE, 1998). Há três características dos sistemas de previdência que afetam a decisão de aposentadoria dos trabalhadores mais velhos (FURTADO, 2005; OECD, 2004): idade mínima de elegibilidade, valor da aposentadoria e taxa de reposição e imposto implícito ${ }^{5}$.

Gráfico 4. Taxa de participação de homens entre 60 e 64 anos de idade, 1960-2008

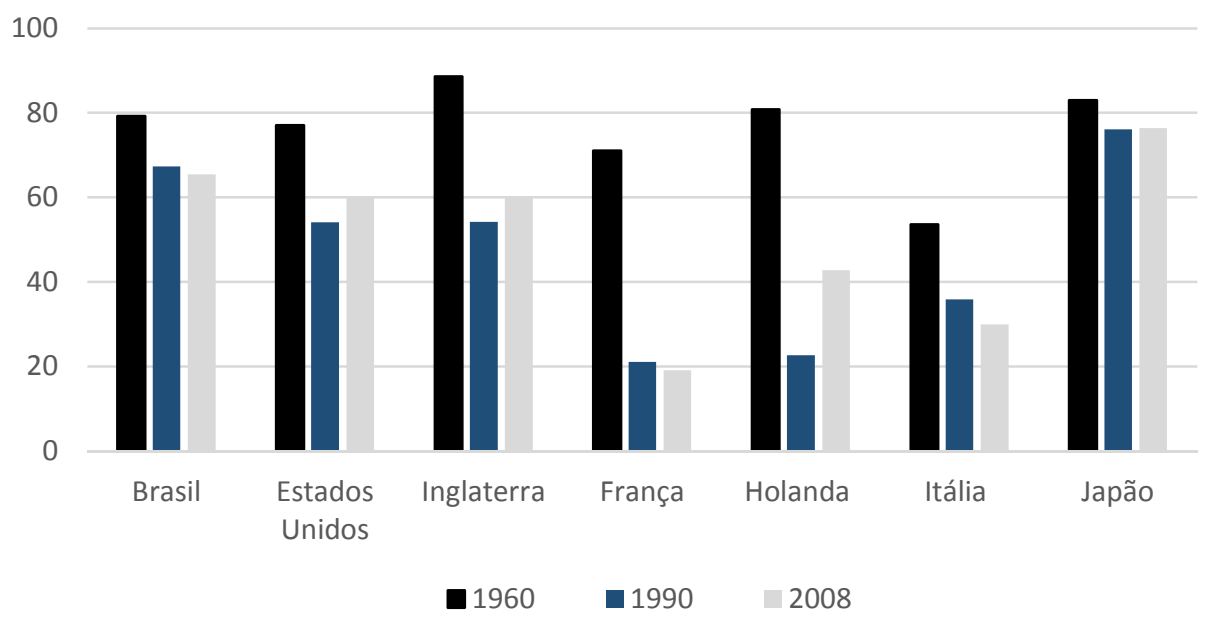

\footnotetext{
5 A taxa de reposição é a fração entre valor presente da aposentadoria e o rendimento corrente. Assim, quanto maior a taxa de reposição, maior o incentivo para a aposentadoria e a saída do mercado de trabalho. Já o imposto implícito leva em conta os benefícios que o trabalhador deixará de receber enquanto não se aposentar, bem como as contribuições que pagará enquanto não se aposentar.
} 
Fonte: ILO (2015)

Nos países em desenvolvimento, embora a participação dos indivíduos mais velhos seja maior, devido a cobertura previdenciária ser mais restritiva e oferecer menores benefícios, também há forte preocupação com a repercussão do envelhecimento populacional nos sistemas públicos de saúde e aposentadoria ${ }^{6}$ (METE e SCHULTZ, 2002).

As análises empíricas sobre oferta de trabalho costumam considerar que o número de horas de trabalho escolhido pelo indivíduo é função do salário que lhe é oferecido no mercado de trabalho, da sua renda não salarial, e de outras variáveis exógenas. (BORJAS, 2008). Na perspectiva dos trabalhadores mais velhos, um conjunto de variáveis exógenas costuma ser incluída no sentido de captar as particularidades dessa etapa da vida laboral. Destaca-se, em primeiro lugar, a idade do indivíduo, variável muito presente nas pesquisas da área, e que exerce um impacto negativo na participação do idoso na força de trabalho. $\mathrm{O}$ avanço da idade costuma estar relacionado com o aumento de dificuldades físicas e mentais e com a diminuição da capacidade para o trabalho. Além disso, a partir de determinada faixa etária, a maioria das pessoas recebe ou é elegível para receber aposentadoria, que também exerce influência negativa sobre o nível de atividade do idoso (PÉREZ et al, 2006).

O nível de escolaridade dos indivíduos é considerado com frequência na literatura e, ao contrário da idade, exerce um impacto positivo na participação laboral dos idosos. Por exemplo, Haider e Loughran (2009), ao pesquisarem trabalhadores com 50 anos ou mais de idade nos Estados Unidos, mostraram evidências de que o emprego nas idades mais avançadas concentra-se nos indivíduos mais educados ${ }^{7}$. O estado conjugal também é uma variável importante e, de acordo com Pérez (2006), seu efeito é diferente entre homens e mulheres. Os homens casados têm maior probabilidade de um ciclo de trabalho clássico, onde a vida laboral ocorre continuamente em empregos de jornada completa, até a saída definitiva do mercado de trabalho com a aposentadoria. Já as mulheres solteiras tendem a ficar mais tempo no mercado de trabalho, em relação às casadas.

Com relação à renda do idoso, a literatura tem sugerido que a renda não salarial, como aposentadoria e aluguel, pode exercer um impacto positivo sobre a transição do nível de atividade do indivíduo, e sobre o trabalho em tempo parcial. A renda salarial, embora diminua

\footnotetext{
${ }^{6}$ Nos Estados Unidos houve uma reversão recente na tendência de queda na taxa de participação dos idosos no mercado de trabalho. No entanto, não há consenso se essa reversão é temporária ou permanente. (HAIDER e LOUGHRAN, 2009).

${ }^{7}$ Haider e Loughran (2009, p.115-117) mostraram com dados dos Estados Unidos que na faixa dos 50-58 anos, $53 \%$ daqueles que não terminaram os estudos trabalhavam, enquanto $83 \%$ dos que tinham mais do que a graduação trabalhavam. Já na faixa dos 71-73 anos apenas $8 \%$ trabalhavam entre aqueles que não terminaram os estudos, contra $22 \%$ daqueles com formação avançada.
} 
com a idade, exerce um impacto positivo sobre a decisão de trabalho (BENÍTEZ-SILVA, 2000; PÉREZ, 2006). De outro lado, Haider e Loughran (2009) mostram que o trabalho entre os idosos está concentrado nos indivíduos mais ricos, ou seja, a probabilidade de um idoso que está no quintil superior de riqueza trabalhar é maior do que um idoso que se encontra no primeiro quintil. Isso poderia ser explicado pelo fato de que os indivíduos que continuaram trabalhando puderam acumular mais riqueza no passado. As características da ocupação também desempenham um papel importante na decisão de trabalho do idoso. Haider e Loughran (2009) argumentam que a flexibilidade de horário é importante para o idoso e que os trabalhadores mais velhos são mais propensos aos trabalhos por conta própria e de tempo parcial.

A condição de saúde é uma das dimensões mais relevantes da vida do idoso e pode ter um impacto decisivo sobre a sua participação no mercado de trabalho. Um indicador único de saúde costuma aparecer nas equações que descrevem a oferta de trabalho dos indivíduos mais velhos, que é a saúde autorreportada. Essa é uma variável subjetiva, baseada na avaliação do próprio indivíduo sobre o seu estado atual de saúde. De acordo com Kalwij e Vermeulen (2008), essa variável é potencialmente endógena, uma vez que o indivíduo poderia justificar a sua não participação no mercado de trabalho reportando uma saúde pior do que o seu verdadeiro status de saúde. Nesse caso, segundo os autores, haveria uma superestimação do impacto da saúde autorreportada no emprego. Além disso, a endogeneidade pode surgir de um problema de erro de medida. A literatura tem tratado a possível endogeneidade da saúde autorreportada basicamente de duas formas distintas: por meio da instrumentalização (Pérez et al, 2006), ou como um problema de variável omitida (Kalwij e Vermeulen, 2008). De qualquer forma, esses trabalhos incluem variáveis objetivas, no sentido de captar o estado de saúde do idoso com respeito a doenças crônicas, dificuldades motoras, doenças mentais e dificuldades cognitivas.

Além dos determinantes discutidos anteriormente, a literatura vem considerando outro conjunto de fatores para a condição de atividade do idoso, relacionados à qualidade do emprego. Haider e Loughran (2009) argumentam que a questão mais importante sobre a oferta de trabalho de idosos talvez seja: por que os idosos trabalham ou por que não trabalham? Nesse sentido, os autores questionam em que medida os idosos trabalham simplesmente por que gostam da ocupação. Ou seja, poderia o trabalho ser considerado uma forma de prazer ou divertimento para os idosos que continuam trabalhando? Ou, da mesma forma, será que os idosos que não estão trabalhando estão com dificuldades em encontrar um emprego prazeroso? Para sustentar essa afirmação, Haider e Loughran (2009) mostram que o 
nível de salário cai com a idade, mesmo para os indivíduos que trabalham em tempo integral. Ao mesmo tempo, os idosos que trabalhavam reportaram alta satisfação no emprego e grande flexibilidade no horário de trabalho. Uma possível interpretação para esse fato, segundo os autores, é que os idosos estariam dispostos a um trabalho prazeroso, mesmo a expensas de menor retorno financeiro. Em uma linha de investigação parecida, Groot (1999), ao avaliar a tendência de queda na taxa de participação dos trabalhadores mais velhos na Europa, sugere que houve mudanças na experiência do trabalho nas últimas décadas, que acarretaram uma piora na satisfação no trabalho e um consequente processo de aposentadoria precoce. Dessa forma, essa vertente da literatura tem buscado avaliar o impacto da qualidade do emprego na oferta de trabalho de idosos. Schnalzenberger et al (2011), por exemplo, mostraram que a insatisfação no emprego entre os trabalhadores com 55 anos ou mais de idade é bom preditor para a saída precoce do emprego, estimulando aposentadoria parcial $^{8}$ ou integral, mas também para a saída definitiva da força de trabalho, especialmente para as mulheres.

\subsection{Inserção econômica e estado de saúde dos idosos no Brasil}

O envelhecimento populacional do Brasil se reflete no aumento da participação dos idosos na PEA. O Gráfico 5 mostra a evolução da proporção de idosos na população e na PEA, entre 1981 e 2013, utilizando a Pesquisa Nacional por Amostras de Domicílios (PNAD). Os dados mostram que as pessoas com 60 anos ou mais de idade representam uma parcela crescente da população, tendo dobrado a sua participação no período considerado, alcançando cerca de $13 \%$ em 2013. A participação de idosos na PEA também aumentou no período considerado, representando cerca de 6,7\% da força de trabalho em 2013. De acordo com Wajnman (2004), as projeções indicam que em 2020 aproximadamente 10\% da PEA masculina e 6\% da PEA feminina serão compostas por idosos, representando um importante desafio para o mercado de trabalho brasileiro, que deve desenhar políticas para atender as especificidades produtivas dessa parcela da população.

\footnotetext{
${ }^{8}$ Os autores chamaram de aposentadoria parcial aquele caso em que o indivíduo recebe o benefício do governo e, ao mesmo tempo, continua trabalhando.
} 


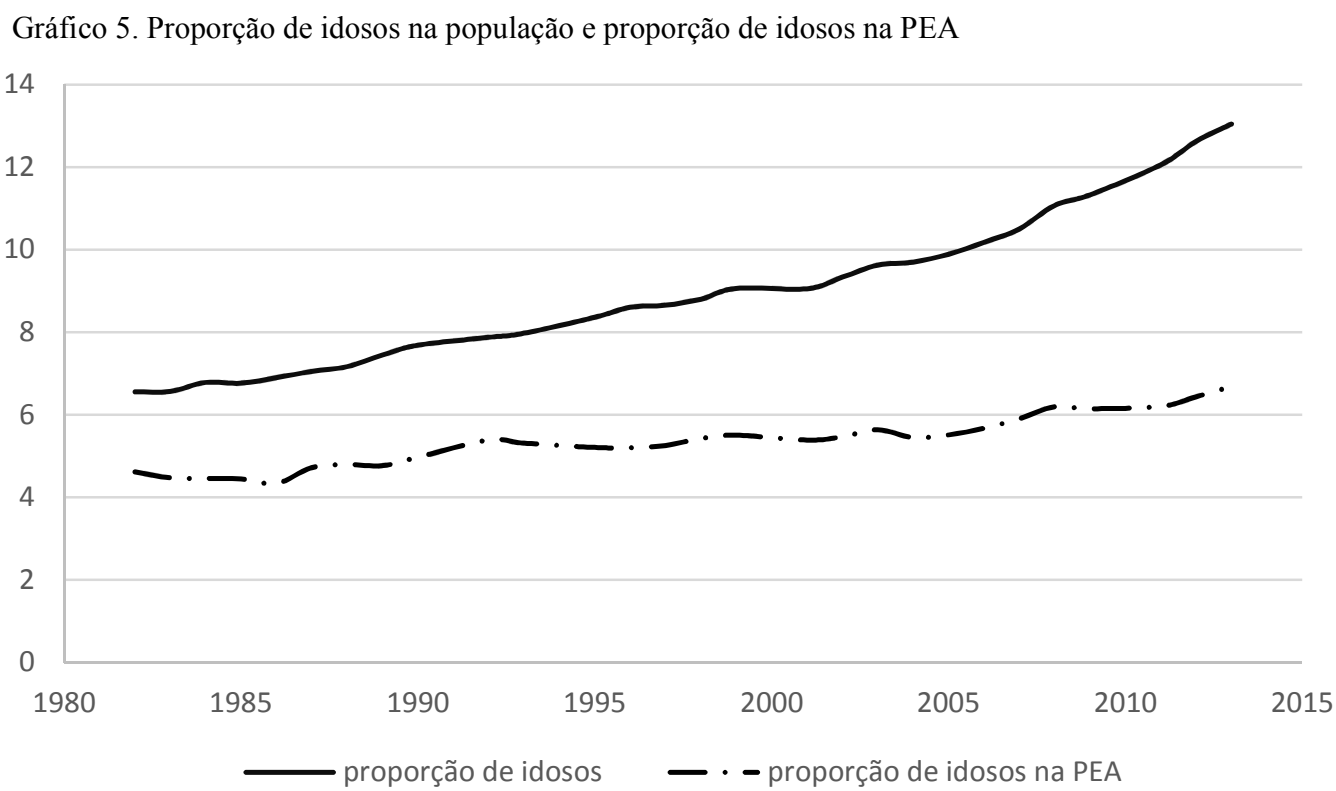

Fonte: IBGE (2014a). Elaborado pelo autor com base na PNAD (1981 a 2013)

Considerando especificamente o comportamento laboral da população idosa, a taxa de participação no mercado de trabalho apresenta um padrão distinto entre homens e mulheres, especialmente nas coortes mais velhas. O Gráfico 6 mostra que o nível de atividade dos idosos no Brasil apresentou um leve declínio no período considerado, alcançando cerca de 24\% em 2013. O nível de atividade dos homens idosos apresentou uma queda no período considerado, porém permanece em níveis altos quando comparado aos países desenvolvidos, como destacado no Gráfico 4. Já a taxa de participação das mulheres apresentou um aumento, possivelmente devido ao efeito coorte, pois as gerações mais novas têm um nível de participação mais elevado.

Gráfico 6. Nivel de atividade de idosos, por gênero, 1981-2013

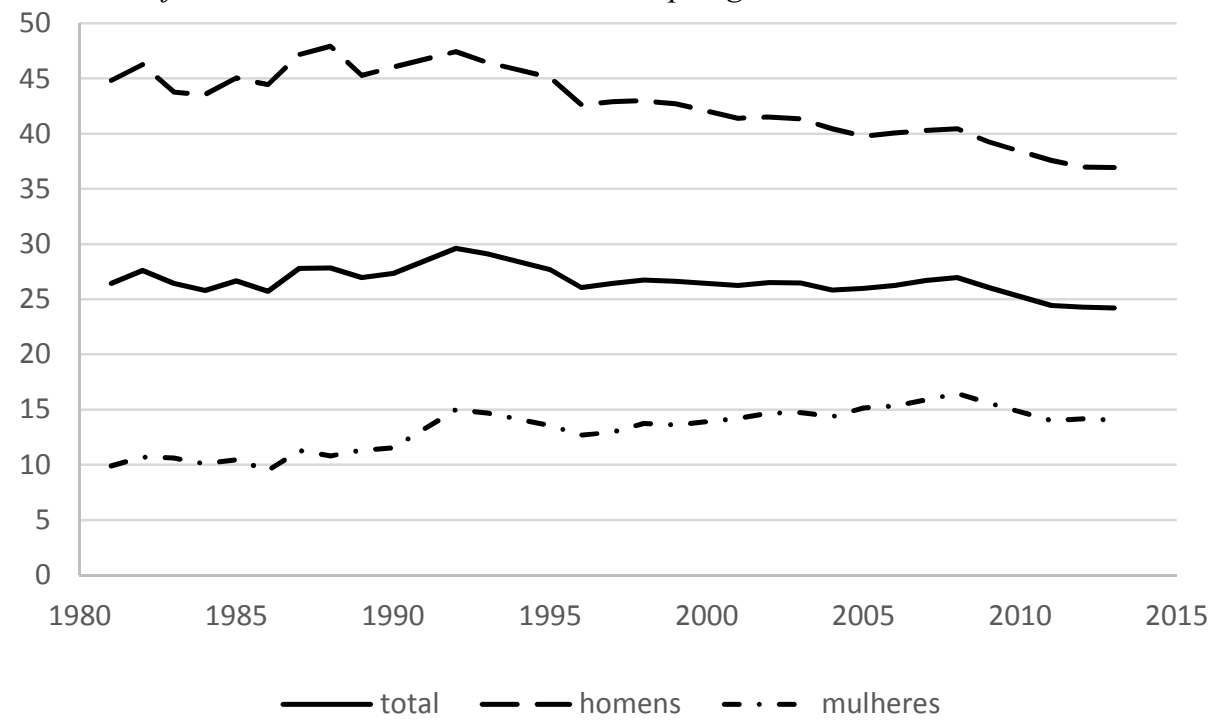

Fonte: IBGE (2014a). Elaborado pelo autor com base na PNAD (1981 a 2013) 
A inserção produtiva dos trabalhadores idosos no Brasil é marcada pela preponderância do trabalho por conta própria. O Erro! Fonte de referência não encontrada. apresenta a evolução da posição na ocupação ao longo da estrutura etária com a PNAD de 2013. Entre as coortes mais jovens, uma baixa proporção de trabalhadores está ocupada como conta própria. Essa taxa cresce de forma consistente, alcançando cerca de $42 \%$ entre os ocupados com 60 anos de idade e $60 \%$ entre os trabalhadores com 70 anos de idade. Esse padrão de crescimento do trabalho autônomo com a idade é observado em outros países e parece indicar que existe uma relação entre a natureza da ocupação por conta própria e a oferta de trabalho de idosos. Questões como autonomia no trabalho e jornada de trabalho flexível são valorizadas pelas pessoas mais velhas e podem constituir uma vantagem para essa parcela da população (ZISSIMOPOULOS; KAROLY,2007).

Gráfico 7. Posição na ocupação das pessoas com 60 anos ou mais de idade no Brasil, 2013

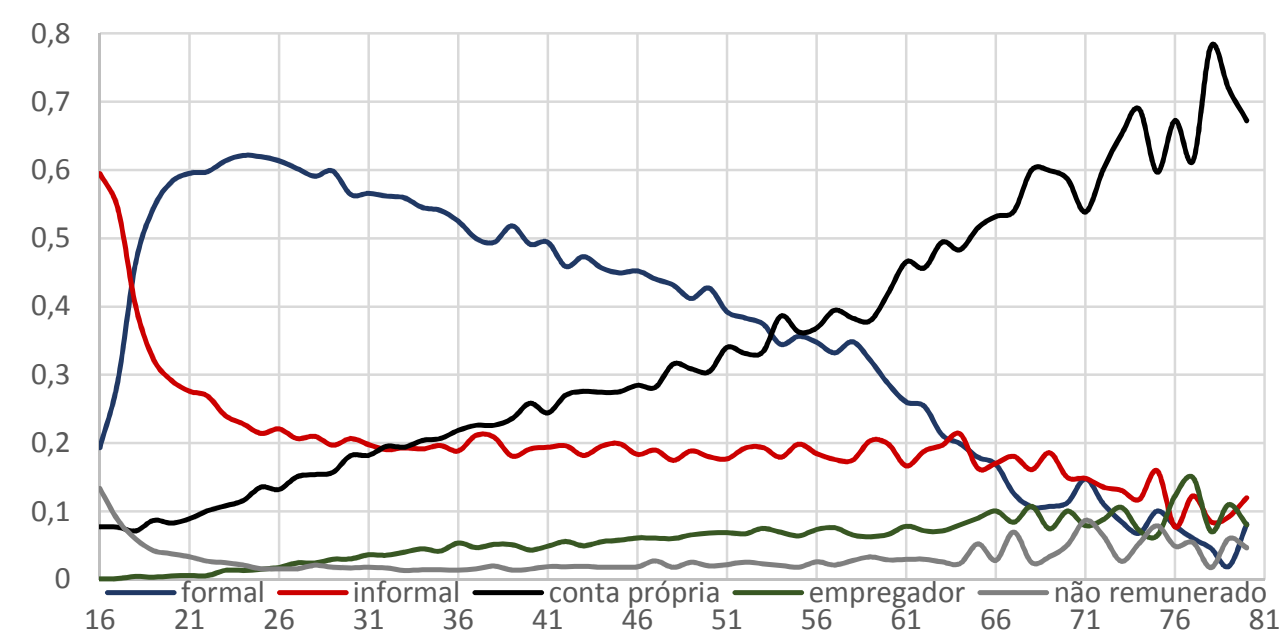

Fonte: IBGE (2014a). Elaborado pelo autor com base na PNAD (2013)

A PEA idosa pode ser decomposta em dois subgrupos: a PEA pura, formada pelos idosos economicamente ativos não aposentados, e pela PEA aposentada, formado pelos idosos economicamente ativos e que recebem renda de aposentadoria (CAMARANO, 2001). É importante compreender o comportamento desses dois subgrupos populacionais, no sentido de identificar possíveis explicações para a decisão de trabalhar, especialmente das pessoas aposentadas.

Uma das principais características da PEA idosa no Brasil é a alta taxa de participação de aposentados no mercado de trabalho, representando cerca de 58\% da PEA idosa masculina e 64\% da PEA idosa feminina em 2013. O aumento da PEA aposentada nas últimas décadas 
reflete o aumento da cobertura previdenciária, o aumento da longevidade e a melhora nas condições de saúde que permitem que as pessoas permaneçam ativas no mercado de trabalho em idades mais avançadas (CAMARANO, 2001).

Tabela 3. Características sociodemográficas da PEA idosa, segundo status de aposentadoria, 2013

\begin{tabular}{lcc}
\hline & Não aposentado (\%) & Aposentado (\%) \\
\hline Feminino & 35.8 & 34.1 \\
Masculino & 64.2 & 65.9 \\
Chefe & 70.3 & 74.3 \\
Não branco & 51.2 & 47.7 \\
Branco & 48.8 & 52.3 \\
Rural & 11.6 & 37.9 \\
Urbano & 88.4 & 62.1 \\
& Não aposentado (média) & Aposentado (média) \\
Estudo & 7.1 & 5.7 \\
Idade & 63.6 & 67.7 \\
Rendimento do trabalho principal & 1861 & 1242 \\
Horas de trabalho & 38.0 & 31.4 \\
Renda domiciliar per capita & 1548 & 1719 \\
\hline \hline Fonte: IBGE (2014a). Elaborado pelo autor com base na PNAD (2013)
\end{tabular}

A Tabela 3 apresenta algumas características sociodemográficas da PEA idosa, separadamente para aposentados e não aposentados, a partir dos dados da PNAD de 2013. Os homens constituem a maior parte da PEA idosa, tanto para aposentados quanto para não aposentados. Da mesma forma, os chefes de famílias têm predominância e ambos os estados aposentadoria, mas em especial entre os aposentados (74\%), revelando a importância do benefício previdenciário para a renda familiar (CAMARANO, 2001). Os trabalhadores do setor urbano constituem $88 \%$ da PEA não aposentada e $62 \%$ da PEA não aposentada. Possivelmente, a proporção relativamente alta dos trabalhadores rurais na PEA não aposentada deve-se às regas de elegibilidade da aposentadoria rural.

A segunda parte da Tabela 3 mostra que os trabalhadores idosos não aposentados têm, em média, maior escolaridade, rendimento e jornada de trabalho do que os aposentados. Queiroz et al (2009) argumenta que os trabalhadores aposentados podem utilizar o trabalho como forma de complemento da renda familiar, ou seja, aceitando menores salários, de modo que o trabalhador idoso não aposentado tenha que concorrer por empregos com melhores salários e que exigem maior escolaridade. A hipótese de uso do trabalho como complemento de renda pelos aposentados é corroborada pela menor jornada semanal de trabalho. Como era de se esperar, a idade média da PEA não aposentada é inferior à da PEA não aposentada. 
Tabela 4. Posição na ocupação da população idosa, segundo status de aposentadoria, 2013

\begin{tabular}{lll}
\hline & não aposentado (\%) & Aposentado (\%) \\
\hline Empregado com carteira de trabalho assinada & 19.0 & 8.6 \\
Militar & 0.1 & 0.0 \\
Funcionário público estatutário & 10.6 & 1.8 \\
Outro empregado sem carteira de trabalho assinada & 10.2 & 7.9 \\
Trabalhador doméstico com carteira de trabalho assinada & 2.7 & 0.7 \\
Trabalhador doméstico sem carteira de trabalho assinada & 5.8 & 3.5 \\
Conta própria & 38.8 & 39.8 \\
Empregador & 5.8 & 6.6 \\
Trabalhador na produção para o próprio consumo & 5.4 & 26.5 \\
Trabalhador na construção para o próprio uso & 0.1 & 0.6 \\
Não remunerado & 1.5 & 3.9 \\
\hline \hline
\end{tabular}

Fonte: IBGE (2014a). Elaborado pelo autor com base na PNAD (2013)

Com relação à posição na ocupação, os dados da

Tabela 4 confirmam a preponderância do trabalho por conta própria entre os idosos brasileiros, para ambos os estados de aposentadoria. Entre os trabalhadores com carteira assinada, há maior proporção de não aposentados. Além disso, observa-se que a proporção de trabalhadores informais na PEA pura é maior do que na PEA idosa. Esse resultado pode indicar que a renda de aposentadoria permite ao trabalhador idoso maior possibilidade de escolha ocupacional, uma vez que o trabalho sem carteira assinada não possui os benefícios do trabalho formal e tampouco a autonomia e flexibilidade do trabalho autônomo.

Tabela 5. Autopercepção de saúde. PEA idosa, PEA pura e PEA aposentada

\begin{tabular}{|c|c|c|c|c|c|c|}
\hline & \multicolumn{3}{|c|}{ Homens } & \multicolumn{3}{|c|}{ Mulheres } \\
\hline & PEA pura & PEA aposentada & Inativos & PEA pura & PEA aposentada & Inativos \\
\hline \multicolumn{7}{|l|}{2003} \\
\hline Muito boa & 12.1 & 9.5 & 6.9 & 9.1 & 8.5 & 6.9 \\
\hline Boa & 43.8 & 42.4 & 32.2 & 40.4 & 38.5 & 33.2 \\
\hline Regular & 36.8 & 40.6 & 42.4 & 41.3 & 44.6 & 44.7 \\
\hline Ruim & 6.3 & 6.8 & 14.5 & 7.3 & 7.6 & 12.4 \\
\hline Muito ruim & 1.0 & 0.7 & 4.0 & 1.9 & 0.8 & 2.8 \\
\hline \multicolumn{7}{|l|}{2008} \\
\hline Muito boa & 12.2 & 9.6 & 6.6 & 11.7 & 9.8 & 6.5 \\
\hline Boa & 44.7 & 42.7 & 32.1 & 42.6 & 41.9 & 36.1 \\
\hline Regular & 34.2 & 40.4 & 42.6 & 37.5 & 39.5 & 42.9 \\
\hline Ruim & 7.7 & 6.6 & 14.5 & 6.5 & 7.3 & 11.1 \\
\hline Muito ruim & 1.3 & 0.7 & 4.3 & 1.7 & 1.5 & 3.4 \\
\hline
\end{tabular}

Fonte: IBGE (2014a). Elaborado pelo autor com base na PNAD (2003 e 2008)

Por último, cabe destacar as condições de saúde da população idosa, pois essa é uma dimensão importante da oferta de trabalho dessa faixa etária. Os dados da Tabela 5 apresentam os resultados da autopercepção de saúde para a PEA pura, PEA aposentada e para os inativos, para os anos de 2003 e 2008. Os dados mostram que, em média, os inativos têm 
um estado de saúde mais deteriorado do que os ativos, aposentados ou não, tanto para os homens, quanto para as mulheres. Entre os homens, em 2008, enquanto 42,8\% da PEA pura e $42,7 \%$ da PEA aposentada declararam que têm uma saúde bom, apenas 32,1\% dos inativos respondeu essa opção. Não é possível inferir qualquer causalidade com a Tabela 5, mas sugere-se que a saúde é um fator preponderante para a decisão de trabalhar, pois o estado de saúde reportado pela PEA pura e pela PEA idosa são similares, para ambos os gêneros. 


\section{EFEITOS DA APOSENTADORIA NA TRANSIÇÃO PARA O TRABALHO POR CONTA PRÓPRIA NO BRASIL METROPOLITANO}

\subsection{Introdução}

Os indivíduos que trabalham explorando seu próprio empreendimento, denominados genericamente nesse capítulo como trabalhadores por conta própria ou autônomos, representam uma parcela importante da força de trabalho no Brasil, constituindo a inserção de aproximadamente $24 \%$ dos ocupados em $2013^{9}$ (IBGE, 2014b).

Essa forma de inserção laboral compreende um grupo heterogêneo de pessoas, envolvendo trabalhadores autônomos com diferentes níveis de qualificação, pessoas que contribuem e não contribuem para a previdência social e proprietários de firmas de distintos tamanhos. No entanto, apesar dessas diferenças, uma característica em comum nesse subgrupo populacional é a sobrerrepresentação de indivíduos mais velhos; enquanto os trabalhadores com 50 anos ou mais de idade representam cerca de $22 \%$ da força de trabalho total ocupada, essa proporção aumenta para cerca de $36 \%$ no subgrupo populacional conta própria (IBGE, 2014b).

O Gráfico 8 mostra a proporção de trabalhadores por conta própria em relação ao total de ocupados, em algumas faixas etárias, para os anos de 2003 e 2013. Percebe-se que essa proporção aumenta de forma gradual com a idade, ultrapassando 35\% dos ocupados na faixa de 51 a 55 anos de idade, e alcançando cerca de $45 \%$ na faixa de 61 a 65 anos, em ambos os anos. Embora a proporção de trabalhadores autônomos seja maior em 2003 do que em 2013, em todas os intervalos etários, essa diferença tende a diminuir nas idades mais avançadas, sugerindo que existe uma relação próxima entre a natureza dessa atividade econômica e a participação laboral de indivíduos mais velhos. Além disso, o ritmo de crescimento da proporção de trabalhadores autônomos intensifica-se entre 61 a 65 anos, em especial no ano de 2013, que é faixa em que os trabalhadores do setor privado tornam-se elegíveis para aposentadoria por idade.

\footnotetext{
${ }^{9}$ De acordo com IBGE (2014b), o trabalhador por conta própria é o indivíduo que trabalha explorando seu próprio empreendimento, sozinho ou com sócio, sem empregar ninguém, e contando ou não com ajuda de trabalhador não remunerado. Já o empregador trabalha explorando o seu próprio empreendimento, mas com pelo menos um empregado contratado. Esse capítulo denominará os trabalhadores por conta própria e os empregadores genericamente de trabalhadores por conta própria (ou autônomos), pois todos estão ocupados de forma não assalariada. Segundo a classificação do IBGE (2014), há cerca de 15,9 milhões de trabalhadores por conta própria urbanos, representando 19,3\% da força de trabalho, e 3,4 milhões de empregadores urbanos, constituindo $4 \%$ da força de trabalho (IBGE, 2013).
} 
Gráfico 8. Proporção de trabalhadores por conta-própria em relação aos ocupados, por faixa etária.

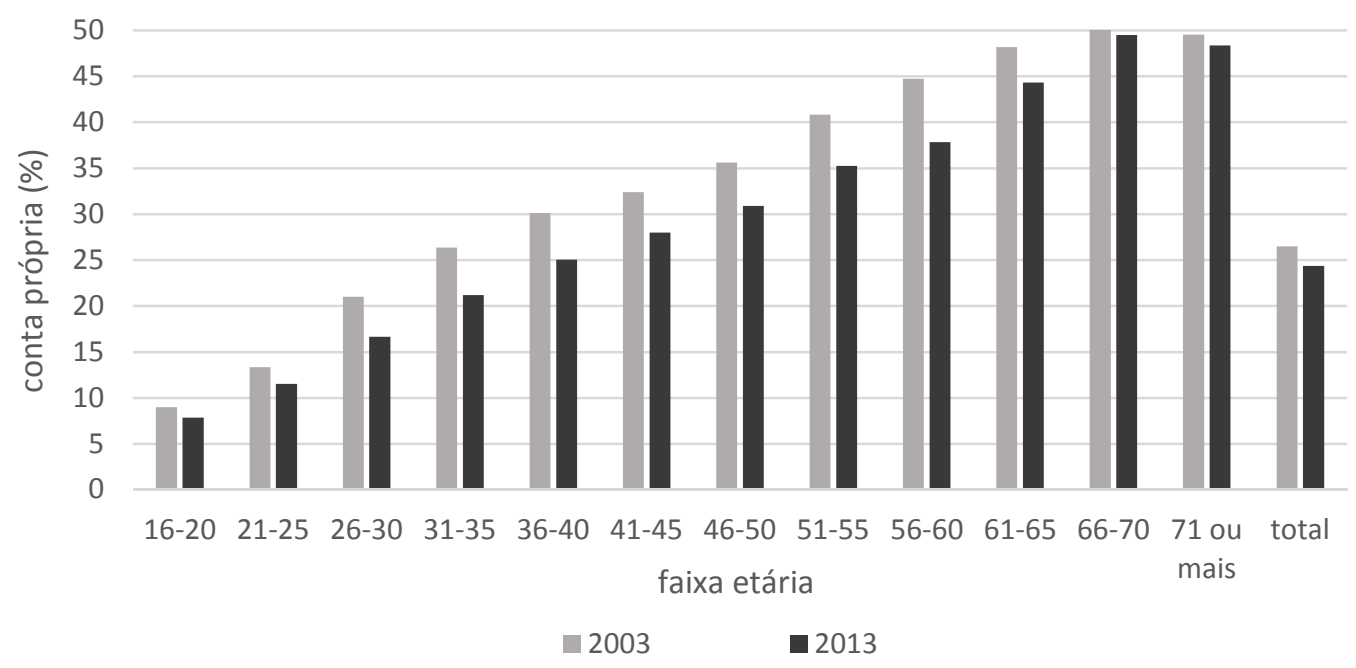

Fonte: IBGE (2014b). Elaborado pelo autor com base na PME (2003 e 2013)

A dependência do trabalho autônomo em relação à idade tem sido identificada no mercado de trabalho de países desenvolvidos (BLANCHFLOWER; OSWALD, 1998; BLANCHFLOWER, 2000) e de países em desenvolvimento (MEL et al, 2008; NARITA, 2014). No final da carreira laboral, a prevalência dessa escolha ocupacional deve-se ao aumento das transições para o trabalho por conta própria entre as pessoas mais velhas, ou a menor taxa de aposentadoria dos trabalhadores autônomos em relação aos assalariados (FUCHS, 1981; ZISSIMOPOULOS; KAROLY, 2007).

A transição do assalariamento para o trabalho autônomo pode trazer implicações para o bem-estar das pessoas mais velhas. Em primeiro lugar, os rendimentos do empreendimento próprio são mais instáveis e envolvem maiores riscos do que a remuneração salarial, podendo comprometer os benefícios previdenciários, correntes e futuros, e outros ativos financeiros acumulados durante a vida (ZISSIMOPOULOS; KAROLY, 2007). O trabalho assalariado também pode oferecer benefícios aos empregados, como seguro saúde, que são importantes para os indivíduos mais velhos. De outro lado, o trabalho por conta própria oferece maior autonomia e flexibilidade do que o trabalho assalariado, e há evidências de que os trabalhadores autônomos reportam um maior nível de satisfação no trabalho do que os empregados (BLANCHFLOWER, 2000). Além disso, o trabalho por conta própria é associado, em muitas abordagens, com o tema do empreendedorismo. $\mathrm{O}$ trabalhador por conta própria e o proprietário de um negócio são frequentemente utilizados como proxy para o 
empreendedor, devido ao risco envolvido nessa atividade econômica ${ }^{10}$ (PARKER, 2009). Nessa perspectiva, o empreendedorismo sênior é visto como uma forma de gerar oportunidades econômicas às pessoas mais velhas e de mantê-las ativas no mercado de trabalho (CLEGG; FIFER, 2014; MOULTON; SCOTT, 2014).

O objetivo desse capítulo é investigar os determinantes da transição do trabalho assalariado para o trabalho por conta própria no final da carreira laboral no Brasil metropolitano. Em especial, pretende-se analisar o papel da aposentadoria nessa transição ocupacional. Três motivos justificam esse recorte: em primeiro lugar, como a aposentadoria é um evento importante na vida das pessoas e representa um custo para a previdência social, é preciso saber se essa fonte de renda representa um fator de atração ao trabalho autônomo ou se, ao contrário, desestimula essa decisão devido aos riscos envolvidos nessa escolha ocupacional. Caso a aposentadoria desestimule a transição para o trabalho por conta própria, as pessoas tenderiam a preservar essa fonte de renda e retirar-se precocemente do mercado de trabalho, fato que pode ter repercussões sobre as contas públicas. Em segundo lugar, como destacado anteriormente, a transição para o trabalho por conta própria no final da carreira laboral pode ter repercussões sobre o bem estar individual, relacionadas às incertezas dos rendimentos e a possibilidade de maior autonomia e flexibilidade no trabalho. Por último, e de forma mais geral, como a preponderância do trabalho autônomo aumenta com a idade, a investigação da inserção laboral das pessoas mais velhas no Brasil passa, necessariamente, pelo estudo do trabalho por conta própria.

Esse capítulo utilizou a Pesquisa Mensal de Emprego (PME), entre os anos de 2002 e 2007, e estudou o comportamento laboral das pessoas entre 50 e 69 anos de idade. A transição para o trabalho por conta própria foi analisada com a metodologia de pseudo-painel, construída com base na geração de nascimento, gênero, cor e nível de educação dos indivíduos. Essa metodologia permitiu o tratamento da possível endogeneidade da decisão de trabalhar, além de possibilitar o uso de técnicas de dados em painel, que são importantes para a investigação de problemas dinâmicos. Esse capítulo está dividido em sete partes, contando com essa introdução. A seção 2 faz uma revisão da literatura, destacando os principais trabalhos teóricos e empíricos que investigaram a transição para o trabalho por conta própria. As seções 3 e 4 apresentam o referencial teórico e a metodologia econométrica utilizada, respectivamente. Em seguida, a seção 5 explica a preparação da base de dados e apresenta as

\footnotetext{
${ }^{10}$ De acordo com Parker (2009, p. 10), a racionalidade em utilizar o trabalhador por conta própria ou o proprietário de um empreendimento como proxy do empreendedorismo baseia-se no risco que caracteriza esta atividade econômica, além do fato de que o empreendedor não trabalha por salário.
} 
estatísticas descritivas do problema em questão. A seção 6 discute os resultados econométricos e a seção 7 apresenta as considerações finais.

\subsection{Revisão da literatura}

A literatura em Economia costuma conceber a decisão de empreender como um problema de escolha ocupacional. Os indivíduos precisam decidir entre trabalhar por salário ou de forma autônoma, e escolhem a ocupação que oferecer a maior utilidade esperada ${ }^{11}$. Esse problema de escolha envolve risco, pois as pessoas que exploram seu próprio empreendimento enfrentam incertezas quanto à demanda pelos seus bens, aos custos de produção etc., que elevam a instabilidade dos seus rendimentos (PARKER, 2009). Dessa forma, a decisão de empreender depende de um amplo conjunto de fatores, que abrangem desde características individuais e demográficas, até as condições gerais da economia e do mercado de trabalho (BLANCHFLOWER, 2000).

Do ponto de vista das características individuais, dois aspectos são destacados com frequência nos estudos teóricos e empíricos: restrição de liquidez e aversão ao risco. A restrição de liquidez está relacionada à importância dos recursos próprios e da obtenção de empréstimos para a abertura de um negócio. Em um dos estudos seminais sobre o tema, Evans e Jovanovic (1989) estimou um modelo de transição do trabalho assalariado para o conta própria e encontrou que os ativos familiares impactam positivamente a probabilidade de transição. O papel da restrição de liquidez na decisão de empreender foi confirmado por outros trabalhos empíricos (DUNN; HOLTZ-EAKIN, 2000; JOHANSSON, 2000). Um conjunto de estudos corroborou o papel da restrição de liquidez, mas levando em consideração a possível endogeneidade da riqueza na decisão de trabalhar por conta própria. $\mathrm{O}$ argumento utilizado é que os ativos, individuais e familiares, podem estar correlacionados com variáveis não observáveis e que são importantes para explicar a decisão de abrir um negócio, como a existência de outros empreendedores na família e a aversão ao risco do indivíduo. Nesse sentido, alguns trabalhos têm utilizado choques exógenos como instrumento para a riqueza, como o recebimento de herança ou presente (BLANCHFLOWER; OSWALD, 1998; HOLTZ-EAKIN et al, 1994).

A atitude das pessoas em relação ao risco pode impactar a transição para o empreendedorismo, pois a renda esperada com o negócio próprio deve compensar os riscos envolvidos nessa atividade econômica, expressos na maior variância dos rendimentos

\footnotetext{
${ }^{11}$ Para um panorama histórico do debate sobre empreendedorismo em Economia e suas principais vertentes, ver Parker (2009, p.31-85).
} 
(SIMOES et al, 2013, p.12). Nesse sentido, a literatura tem sugerido que os trabalhadores por conta própria são mais tolerantes ao risco do que aqueles que trabalham por salário, embora esse resultado não seja consensual nos estudos empíricos (KIHLSTROM; LAFFONT, 1979). Outras características individuais são destacadas pela literatura, em especial, gênero, educação, idade, e estado civil. As mulheres possuem menor probabilidade de trabalhar por conta própria do que os homens e, quando inseridas nesse tipo de ocupação, tendem a utilizar mais recursos próprios, ou seja, menos financiamento externo, e a conduzir empreendimentos menores (BLANCHFLOWER, 2000; SIMOES et al, 2013). O efeito da educação formal na escolha pelo trabalho autônomo é controverso, mas a maior parte dos estudos empíricos têm encontrado efeitos positivos com relação a decisão de empreender ${ }^{12}$. O estado civil tem efeitos sobre os resultados alcançados no mercado de trabalho e, no caso do trabalho autônomo, há evidências de que as pessoas casadas têm maior probabilidade de transição de que os não casados (PARKER, 2009).

A idade impacta positivamente a probabilidade do indivíduo tornar-se conta própria. Do ponto de vista teórico, é possível levantar algumas hipóteses explicativas: pessoas mais velhas conseguem acumular capital financeiro, humano e social que, geralmente, não estão disponíveis aos mais novos. Além disso, o avanço da idade possibilita o aprendizado do ambiente de negócios, que favorece a identificação de oportunidades de empreender (PARKER, 2009). No entanto, há fatores que podem desestimular essa transição entre os indivíduos mais velhos, como o aumento da aversão ao risco, além do menor tempo de vida para aproveitar as altas taxas de retorno dos empreendimentos que têm maior custo de entrada (PARKER, 2009). Nesse sentido, há evidências de que a relação entre idade e entrada no trabalho autônomo seja quadrática (BLANCHFLOWER, 2000).

Uma das vertentes da literatura tem investigado fatores atratores e repulsores ao trabalho autônomo e há duas hipóteses interpretativas que organizam essa questão. A primeira sugere que os indivíduos são atraídos para o trabalho autônomo devido aos benefícios de se tornar um empreendedor; já a segunda acredita que essa escolha ocorre pelas condições ruins oferecidas pelo trabalho assalariado. Em suporte à primeira interpretação, há indicações de que os trabalhadores por conta própria relatam maior satisfação no trabalho do que os

\footnotetext{
12 A justificativa é que a escolaridade pode compor um conjunto de conhecimentos desejáveis aos empreendedores, denominados de habilidades empresariais, que são importantes para essa escolha ocupacional. A escolaridade possibilita a acumulação de conhecimentos específicos, que ajudam a formar as habilidades empresariais do indivíduo. No entanto, alguns artigos identificaram que os menos escolarizados têm maior propensão de trabalhar por conta própria, o que pode indicar uma relação em forma de $U$ entre escolaridade e escolha pelo trabalho autônomo (BLANCHFLOWER, 2000).
} 
assalariados (BLANCHFLOWER; OSWALD, 1998; BLANCHFLOWER, 2000). Além disso, há evidências de que os trabalhadores por conta própria valorizam questões como autonomia e flexibilidade no trabalho, especialmente as mulheres (LOMBARD, 2001). Já em suporte à segunda hipótese, Moore e Mueller (2002) encontraram que a mobilidade para o trabalho autônomo é impactada positivamente pela duração do desemprego.

Apesar da proporção de trabalhadores por conta própria aumentar com a idade, há relativamente poucos estudos que analisam os determinantes dessa escolha ocupacional exclusivamente entre indivíduos mais velhos (ZISSIMOPOULOS; KAROLY, 2007) A maior parte das pesquisas investiga essa questão a partir de amostras da população como um todo, ou apenas entre os mais jovens ${ }^{13}$. Há, no entanto, uma vertente crescente de artigos que estuda a decisão de empreender exclusivamente entre pessoas com 50 anos ou mais de idade, a partir de bases de dados específicas, que incluem informações sobre as condições de saúde, bemestar e histórico laboral dos indivíduos. Essas bases de dados possibilitam uma melhor compreensão da oferta de trabalho e da escolha pelo trabalho autônomo entre os indivíduos nessa faixa etária ${ }^{14}$.

Em um artigo seminal dessa vertente, Fuchs (1981) utilizou o Retirement History Survey para investigar os determinantes da transição do trabalho assalariado para a ocupação por conta própria entre homens brancos na faixa de 58 a 65 anos de idade nos Estados Unidos, entre 1969 e 1973. O autor estimou um modelo logit e encontrou que possuir experiência prévia como conta própria, ter jornada semanal de trabalho inferior a 35 horas ou superior a 50 horas, e estar ocupado em atividades gerenciais, profissionais ou de vendas aumenta a probabilidade de transição. A interpretação de Fuchs (1981) é que essas ocupações possuem características similares ao trabalho autônomo, como flexibilidade de horário, remuneração vinculada ao desempenho e jornadas de trabalho muito longas ou muito curtas. O autor mostrou também que os trabalhadores que esperam aposentadoria no trabalho atual, ou que estão sujeitos a aposentadoria compulsória em um período superior a dois anos da pesquisa tem menor probabilidade de transição para o trabalho autônomo.

\footnotetext{
${ }^{13}$ Por exemplo, os trabalhos de Evans e Jovanovic (1989a) e Evans e Jovanovic (1989b) utilizaram a National Longitudinal Survey of Young Men com informações de homens entre 14 e 24 anos de idade em 1966.

${ }^{14}$ Duas bases de dados internacionais específicas com pessoas de 50 anos ou mais são extensamente usadas em pesquisas acadêmicas. A Health and Retirement Study (HRS) é uma base bienal nos Estado Unidos, cuja primeira onda é de 1992. Na Europa, a Survey of Health, Ageing and Retirement in Europe (SHARE), também é uma base de dados bienal, que acompanha pessoas acima de 50 anos, desde 2005. No Brasil, não existe uma base nacional específica com indivíduos de meia idade e idosos. No entanto, há iniciativas locais, como a Saúde, Bem-Estar e Envelhecimento (SABE), específica para o município de São Paulo, e possui três ondas, 2000, 2006 e 2010.
} 
Bruce et al (2000) analisou as transições ocupacionais realizadas por indivíduos entre 51 a 61 anos de idade nos Estados Unidos com os dados da Health and Retirement Study (HRS) entre 1992 e 1996. Os autores estimaram um modelo logit multinomial e encontraram que a riqueza individual aumenta a probabilidade de transição do trabalho assalariado para o trabalho autônomo, relativamente a transição para a inatividade. Segundo os autores, esse resultado corrobora a importância da restrição de liquidez para a decisão de empreender entre as pessoas mais velhas, uma vez que o efeito renda poderia levar os indivíduos a parar de trabalhar.

Já Zissimipoulos e Karoly (2007) investigou a transição do assalariamento para o trabalho autônomo nos Estados Unidos utilizando a RHS entre 1992 e 2000, com pessoas na faixa de 51 a 69 anos de idade. Foi analisada a decisão de mobilidade dos assalariados full time para o trabalho por conta própria, por meio da estimação de um modelo logit multinomial, separadamente para homens e mulheres. O estudo corroborou a importância da riqueza familiar e das características da ocupação corrente para a decisão de empreender dois anos após a pesquisa. Alguns elementos que definem um trabalho de qualidade também mostraram-se significativos para a transição de interesse. Os trabalhadores que possuem algum plano de aposentadoria no trabalho atual ou que têm acesso a seguro saúde por parte do empregador têm menor probabilidade de transição. Já as pessoas que relataram que a saúde limita o seu trabalho têm maior probabilidade de mobilidade para o trabalho por conta própria, resultado distinto do sugerido por Fuchs (1981). Já a renda de aposentadoria, calculada a valor presente, não se mostrou significativa para transição para o trabalho por conta própria dois anos após a pesquisa.

Zissimipoulos et al (2009) analisou a transição para o trabalho por conta própria entre pessoas com 51 anos ou mais de idade nos Estados Unidos, utilizando os dados da HRS entre 1992 e 2004. Foram estimados três modelos probit, a partir das seguintes situações iniciais: desemprego, inatividade e emprego assalariado. Entre os assalariados, a riqueza individual é positiva e significativa para a decisão de empreender. Além disso, aqueles que já receberam renda de aposentadoria ou herança tem maior probabilidade de mudar para o trabalho por conta própria do que os que nunca receberam. O estudo utilizou uma medida de aversão ao risco e encontrou que os indivíduos menos avessos ao risco têm maior propensão de mudar para o trabalho autônomo. Com relação às características da ocupação atual, os assalariados que trabalham em firmas menores (até 5 funcionários), com maior salário hora, ou que não tem plano de previdência no emprego corrente, têm maior probabilidade de transição. 
Outra vertente da literatura interpreta a mobilidade para o trabalho autônomo, no final da carreira laboral, como uma forma de transição para a aposentadoria. Um conjunto de trabalhos têm mostrado, em especial nos Estados Unidos, que a aposentadoria, entendida como a saída definitiva do mercado de trabalho, não é um evento isolado e permanente para muitos trabalhadores. Ao contrário, a maioria dos trabalhadores fazem pelo menos uma transição ocupacional entre o emprego de carreira full time e a saída do mercado de trabalho (QUINN, 1980; CAHILL et al, 2006). Essa mudança ocupacional é conhecida na literatura como bridge jobs e tem na mobilidade para o trabalho autônomo uma de suas variantes. Giandrea et al (2008) investigou a transição dos trabalhadores assalariados de carreira full time para o trabalho por conta própria, utilizando a HRS de 1992 a 2004, com indivíduos na faixa de 51 a 61 anos de idade. Os autores estimaram um modelo logit multinomial e encontraram que, para os homens, possuir plano de saúde no trabalho atual e estar ocupado como blue collar diminui a probabilidade de utilizar o trabalho autônomo como emprego ponte. Já entre as mulheres, aqueles que não tem plano de saúde tem maior propensão de realizar essa mobilidade.

A literatura discutida anteriormente enfatiza a escolha pelo trabalho autônomo nos países desenvolvidos. No entanto, o trabalho por conta própria possui uma natureza distinta nos países em desenvolvimento, ou seja, os fatores que distinguem os trabalhadores autônomos dos empregados são diferentes nos dois grupos de países. Mel et al. (2008) destaca que, nos países em desenvolvimento, o risco assume um papel de maior relevância, devido às maiores incertezas econômicas e políticas envolvidas. Os empreendedores nos países em desenvolvimento dependem mais da própria habilidade empresarial e da capacidade de realizar diferentes tarefas, devido às fragilidades jurídicas e institucionais existentes. Por último, o papel da inovação no empreendedorismo tem um caráter mais restrito, pois poucas firmas atuam na fronteira tecnológica, e os empreendedores têm um menor nível médio de educação.

\subsection{Modelo Teórico}

O quadro teórico que fundamenta os possíveis impactos da aposentadoria na transição do trabalho assalariado para o trabalho por conta própria baseia-se nos seguintes pressupostos: (i) Os indivíduos são heterogêneos com relação a habilidade empresarial $\theta$ e conhecem a sua própria habilidade antes da decisão de empreender. Essa hipótese segue Lucas (1978) e Evans e Jovanovic (1989a) e parte de evidências de que os trabalhadores mais velhos 
acumularam educação formal, experiência no mercado de trabalho e capital social que lhes permitiu desenvolver e conhecer seus talentos empresariais.

(ii) Os indivíduos são avessos ao risco. Essa hipótese baseia-se em Cressy (2000) e em evidências de que os trabalhadores assalariados mais velhos tendem a preservar o seu patamar de renda, ou seja, são mais avessos ao risco (ZISSIMOPOULOS et al, 2009).

(iii) A utilidade das pessoas depende da renda recebida, $y_{i}$, e de características individuais, $z_{i}$, como educação, gênero, cor e estado civil, ou seja, $U_{i}=U\left(y_{i}, z_{i}\right)$, conforme Dunn e HoltzHeakin (2000).

Considera-se um modelo definido em dois períodos, em que todas as pessoas trabalham por salário no período inicial e continuam ocupadas no momento final, ou seja, nenhum indivíduo torna-se desempregado ou inativo. Os indivíduos precisam escolher se continuam trabalhando por salário no período final ou se mudam para o trabalho por conta própria. Considera-se que, no momento da primeira entrevista, todas as pessoas recebem um salário, $w_{i}$, e possuem uma dotação inicial de ativos, $A_{i}$, que envolve juros, aluguel e outras rendas e que, além disso, podem receber renda de aposentadoria ou pensão, $\operatorname{apos}_{i}$, ou seja, $\operatorname{apos}_{i} \geq 0$. Assim, a renda dos indivíduos no setor de salários é $y_{w}=w_{i}+r A_{i}+\operatorname{apos}_{i}$, onde $r$ é a taxa de retorno líquida da economia.

Para a abertura do empreendimento é necessário um custo de capital, $k_{i}$, que produz um rendimento bruto de $\theta_{i} f\left(k_{i}\right) \varepsilon$, onde $f($.) é uma função de produção e $\varepsilon$ é um termo de erro aleatório. Dessa forma, a renda total do trabalho autônomo é $y_{c p}=\theta_{i} f\left(k_{i}\right) \varepsilon+r\left(A_{i}-k_{i}\right)+$ $\operatorname{apos}_{i}$ em que a diferença $A_{i}+\operatorname{apos}_{i}-k_{i}$ é o capital restante do indivíduo após o investimento inicial. Se $\left(A_{i}+\operatorname{apos}_{i}-k_{i}\right)<0$ então a pessoa financiou o investimento, considerado que o montante investido é função dos ativos possuídos pelo indivíduo, ou seja, $k_{i} \leq f_{k}\left(A_{i}+\operatorname{apos}_{i}\right)$.

Como o rendimento do trabalho autônomo é incerto, existe uma probabilidade $\pi$ do empreendimento ser bem sucedido e gerar uma renda $y_{1 c p}$, e uma probabilidade $1-\pi$ do negócio fracassar e gerar uma renda menor, $y_{2 c p}$. O indivíduo optará pela mobilidade ocupacional se a utilidade esperada com o trabalho autônomo for superior à utilidade esperada com o trabalho assalariado. As utilidades de ambas as ocupações podem ser escritas como:

$$
\begin{gathered}
U\left(y_{w} ; Z_{i}\right)=U\left(w_{i}+r A_{i}+\operatorname{apos}_{i} ; Z_{i}\right) \\
E\left[U\left(y_{c p} ; Z_{i}\right)\right]=\pi U\left(y_{1 c p} ; Z_{i}\right)+(1-\pi) U\left(y_{2 c p} ; Z_{i}\right)
\end{gathered}
$$


Em que (5) representa a utilidade com o trabalho assalariado e (6) é a utilidade esperada com o trabalho por conta própria. As utilidades dependem dos rendimentos de cada ocupação, da riqueza individual, da renda de aposentadoria e do vetor de características individuais. Dessa forma, o indivíduo mudará para a ocupação por conta própria se

$$
E\left[U\left(y_{c p} ; Z_{i}\right)\right] \geq U\left(y_{w} ; Z_{i}\right)
$$

Essa análise da mobilidade ocupacional permite identificar o impacto da aposentadoria na transição para o trabalho por conta própria. Dois efeitos podem ser constatados: renda e precaução:

a) efeito renda

Considerando que o indivíduo possui restrição de liquidez, ou seja, $\frac{\partial k}{\partial A}>0$, então a maximização da utilidade esperada determina o capital investido ótimo $k^{*}=g\left(A_{i}\right.$, apos $\left.i\right)$. Uma análise de estática comparativa revela a existência de um efeito renda (ER) positivo da aposentadoria no montante do capital investido. Formalmente:

$$
E R=\frac{\partial k}{\partial a p o s}>0
$$

Nesse contexto, o impacto da aposentadoria pode ser interpretado não somente pelo seu papel de elevação de renda, mas também pela maior facilidade de acesso ao crédito, formal e informal, por se tratar de uma fonte de renda estável e vitalícia. Nesse sentido, esse resultado está em linha com as predições da literatura, de que o acesso a recursos financeiro tem efeitos sobre a decisão de empreender.

b) efeito precaução

A aposentadoria pode ter outro efeito sobre a decisão de empreender, relacionado às incertezas envolvidas no trabalho autônomo. De um lado, a aposentadoria pode diminuir os riscos envolvidos nessa decisão de mobilidade, porque funciona como um seguro contra a probabilidade de fracasso do negócio. Nesse sentido, o impacto seria similar ao efeito renda. De outro lado, a aposentadoria funciona como um seguro para as pessoas mais velhas, devido a imprevistos com relação a saúde e elevações no custo de vida. Neste caso, a renda de aposentadoria impactaria negativamente a transição para o trabalho autônomo, pois os indivíduos, especialmente os mais avessos ao risco, tenderiam a preservar essa fonte de renda e não comprometê-la em um negócio incerto. 


\subsection{Metodologia empírica}

Com base em Moscarini e Vella (2008), o problema da mobilidade ocupacional pode ser especificado econometricamente como uma variável latente. Considere $t=1,2, \ldots, T$ cross sections e $i=1,2, \ldots, N_{t}$ indivíduos em cada período. Para cada indivíduo $i$ na cross section $t$, a mobilidade ocupacional é definida como:

$$
m o b_{i t}^{*}=\beta_{1} a_{p o s}+\beta_{2} x_{i t}+u_{i t}
$$

Onde $m o b_{i t}^{*}$ é uma variável latente que captura a propensão do indivíduo $i$ mudar para o trabalho por conta própria entre $t$ e $t+1, a p o s_{i t}$ indica o status de aposentadoria do indivíduo $i$ na cross section $t$, $x_{i t}$ é um vetor de variáveis de controle individuais, $\beta_{1}$ e $\beta_{2}$ são os parâmetros de interesse, e $u_{i t}$ é o termo de erro aleatório. A variável $m o b_{i t}^{*}$ é não observável, mas considera-se que transição ocupacional de interesse ocorre somente se $m o b_{i t}^{*}$ for superior a um determinado patamar mínimo. Dessa forma, a análise empírica é conduzida com a variável observável $m o b_{i t+1}$, que assume o valor 1 se o indivíduo mudou para a ocupação por conta própria entre $t$ e $t+1$, e 0 caso contrário.

A investigação é restrita aos indivíduos ocupados nos dois períodos, de modo que os desempregados e inativos não serão incluídos na análise. Essa delimitação permite investigar de forma mais precisa os determinantes da transição para o trabalho por conta própria entre os assalariados, formais e informais, que estão no final da carreira laboral, mas que mantiveramse ocupados em $t$ e $t+1$. Essa escolha metodológica possibilita avaliar, além das características individuais e domiciliares, os atributos da ocupação prévia que dirigem essa decisão de mobilidade. Além disso, torna o subconjunto amostral mais homogêneo, uma vez que a decisão de inatividade está correlacionada com variáveis não observáveis, em especial, com o estado de saúde da pessoa, informação não disponível na base de dados utilizada.

Moscarini e Vella (2008) argumentam que restringir a observação da mobilidade ocupacional aos ocupados pode inserir um viés de seleção na amostra, fazendo com que os parâmetros estimados da equação (1) sejam consistentes somente para esses indivíduos e não para conjunto da população. Isso ocorrerá se a decisão de participação no mercado de trabalho for endógena à de mobilidade, ou seja, se as variáveis não observáveis que impactam a decisão de mobilidade forem correlacionadas com a decisão de trabalhar do indivíduo. Formalmente, e equação de participação pode ser escrita como:

$$
\operatorname{trab}_{i t}^{*}=\alpha_{1} \operatorname{apos}_{i t}+\alpha_{2} x_{i t}+\varepsilon_{i t}
$$

Onde $t r a b_{i t}^{*}$ é uma variável latente que captura a propensão do indivíduo $i$ trabalhar nos períodos $t$ e $t+1, \alpha_{1}$ e $\alpha_{2}$ são parâmetros populacionais, e $\varepsilon_{i t}$ é o termo de erro aleatório. 
A variável $\operatorname{tra} b_{i t}^{*}$ é capturada por meio da medida observável trab $b_{i, t+1}$, que assume o valor 1 se a pessoa manteve-se ocupada em $t$ e $t+1$, e 0 caso contrário. Para acomodar a possível endogeneidade da decisão de trabalhar na equação (1), assume-se que os termos de erro $u_{i t}$ e $\varepsilon_{i t}$ são correlacionados para cada indivíduo.

A estratégia de identificação proposta para lidar com a endogeneidade se apoia no trabalho de Moscarini e Vella (2008), e é baseada na agregação dos indivíduos a partir de características comuns e invariantes no tempo: geração de nascimento, cor, gênero e escolaridade. Para cada grupo homogêneo de indivíduos, chamado de coorte (ou célula), as variáveis que compõe os modelos (1) e (2) são determinadas a partir do cálculo da média entre os indivíduos que compõe cada célula. Assim, as equações de mobilidade e participação podem ser reescritas da seguinte forma:

$$
\begin{aligned}
& \overline{\operatorname{mob}}_{c, t+1}=\gamma_{1} \overline{\operatorname{apos}}_{c, t}+\gamma_{2} \bar{x}_{c t}+\bar{u}_{c t} \\
& \overline{\operatorname{trab}}_{c, t+1}=\delta_{1} \overline{\operatorname{apos}}_{c, t}+\delta_{2} \bar{x}_{c t}+\bar{\varepsilon}_{c t}
\end{aligned}
$$

Onde $\overline{m o b}_{c, t+1}$ representa a proporção de pessoas que mudaram para o trabalho por conta própria entre $t$ e $t+1$ na coorte $c$, e $\overline{t r a b}_{c, t+1}$ denota proporção dos indivíduos que se mantiveram ocupados em $t$ e $t+1$ na coorte $c$. As variáveis $\overline{\operatorname{apos}}_{c, t+1}$ e $\bar{x}_{c t}$, indicam a proporção de aposentados e a média das variáveis explicativas, todos avaliados na coorte $c$ e no período $t$. Já as variáveis $\bar{u}_{c t}$ e $\bar{\varepsilon}_{c t}$ representam a média dos termos de erro entre os indivíduos que compõe a coorte $c$ no período $t$, relacionados às decisões de mobilidade $\mathrm{e}$ trabalho, respectivamente.

Para levar em conta a endogeneidade da decisão de trabalhar, permite-se que os erros $\bar{u}_{c t}$ e $\bar{\varepsilon}_{c t}$ sejam correlacionados, ou seja, que o componente não observável $\bar{\varepsilon}_{c t}$ impacte simultaneamente a participação no mercado de trabalho e a mobilidade ocupacional. Cada erro idiossincrático pode ser decomposto, sem perda de generalidade, como a soma de um termo comum a ambos e um componente ortogonal (MOSCARINI; VELLLA, 2008, p. 13). A hipótese de identificação dessa investigação é que, em cada coorte, as características não observáveis que impactam ambas as decisões são invariantes no tempo. Ou seja,

$$
\begin{aligned}
& \bar{u}_{c t}=\eta_{c}+\bar{v}_{c t} \\
& \bar{\varepsilon}_{c t}=\eta_{c}+\bar{e}_{c t}
\end{aligned}
$$

Onde $\operatorname{cov}\left(\bar{v}_{c t}, \bar{e}_{c t}\right)=0$ e $\operatorname{cov}\left(\overline{u_{c t}}, \overline{\varepsilon_{c t}}\right) \neq 0$ devido a $\operatorname{cov}\left(\eta_{c}, \eta_{c}\right)=\operatorname{var}\left(\eta_{c}\right) \neq 0$. 
Substituindo a decomposição termo de erro (5) na equação (3), temos:

$$
\overline{m o b}_{c, t+1}=\gamma_{1} \overline{a p o s}_{c, t}+\gamma_{2} \bar{x}_{c t}+\eta_{c}+\bar{v}_{c t}
$$

Dessa forma, utilizando a hipótese de que a seleção amostral ocorre sobre os componentes invariantes no tempo, uma metodologia de estimação que controla os efeitos fixos de coorte, $\eta_{c}$, possibilita estimar os parâmetros da equação (7) de forma consistente. A metodologia utilizada é a de pseudo-painel, que permite o controle de efeitos fixos de coorte, e será detalhada na seção 5 .

A estratégia de identificação baseada na agregação de indivíduos com características similares apoia-se em evidências sobre a natureza do envelhecimento populacional e do mercado de trabalho no Brasil. Em uma primeira aproximação, é possível afirmar que pessoas que nasceram no mesmo ano, ou que são da mesma geração, foram expostas às mesmas mudanças institucionais com relação às regras de aposentadoria e pensão e, nesse sentido, possuem efeitos fixos similares. No entanto, a diferenciação pelo ano de nascimento não é suficiente para construir coortes homogêneas no Brasil, pois a inserção laboral das coortes mais velhas depende da interação entre pelo menos três variáveis: escolaridade, gênero e cor. Nesse sentido, considera-se que pessoas que nasceram na mesma geração, são do mesmo gênero e cor e com escolaridade similar, têm efeitos fixos análogos.

\subsection{Preparação da base de dados}

A base de dados utilizada nesse capítulo é a Pesquisa Mensal de Emprego (PME), realizada pelo Instituto Brasileiro de Geografia e Estatística (IBGE) em seis regiões metropolitanas: São Paulo, Rio de Janeiro, Belo Horizonte, Recife, Salvador e Porto Alegre. A PME é uma pesquisa domiciliar de periodicidade mensal, que aborda questões específicas do mercado de trabalho e algumas informações educacionais e demográficas, que possibilitam uma melhor compreensão da inserção laboral das pessoas. A PME possui características longitudinais que a tornam adequada para esse tipo de investigação. $\mathrm{O}$ seu painel permite acompanhar os domicílios por um período de 16 meses, em um esquema de rotação 4-8-4, ou seja, cada domicílio é entrevistado por 4 meses consecutivos, sai da amostra por 8 meses, e retorna por mais 4 meses até sair completamente da amostra (IBGE, 2002).

A análise das transições ocupacionais é referente ao período de 2002 a 2007. Essa delimitação apoia-se no referencial teórico utilizado, de que a escolha pelo trabalho por conta própria depende da percepção de risco dos indivíduos. Nesse sentido, procurou-se isolar a investigação dos efeitos da crise econômica de 2008, que possivelmente elevou as incertezas sobre o desempenho da economia. Em um contexto de elevação de incertezas, o papel da 
aposentadoria na escolha ocupacional pode mudar, em especial para os indivíduos mais avessos ao risco, que tenderiam a preservar essa renda garantida. Destaca-se ainda que a PME mudou a sua metodologia a partir de março de 2002, motivo pelo qual a investigação não envolveu os anos anteriores da pesquisa. O estudo é restrito aos indivíduos entre 50 e 69 anos de idade, ou seja, a amostra incluiu as pessoas que nasceram entre 1934 (que completaram 68 anos em 2002) e 1956 (que completaram 50 anos em 2006). Além disso, fazem parte da amostra somente as pessoas que estavam ocupadas na semana de referência da pesquisa, com exceção dos funcionários públicos (que têm regras específicas de elegibilidade) e daqueles que trabalhavam sem remuneração ${ }^{15}$.

Apesar da sua natureza longitudinal e de possuir um amplo conjunto de informações sobre o mercado de trabalho, a PME apresenta algumas limitações para esse estudo. Em primeiro lugar, Ribas e Soares (2008) mostraram que o painel da PME possui uma alta taxa de atrito de indivíduos e que essa taxa pode ser maior entre as pessoas mais velhas. Segundo os autores, um dos motivos dessa perda decorre da PME não utilizar um código que permita identificar cada entrevistado em diferentes períodos. A estratégia convencional utilizada é emparelhar os indivíduos utilizando as informações reportadas da data de nascimento (dia, mês e ano) e sexo. No entanto, o emparelhamento pode não ocorrer se houver inconsistência nessas informações nos meses subsequentes. Para lidar com essa limitação, foi utilizado o algoritmo proposto por Ribas e Soares (2008) que cria um identificador para cada entrevistado levando em consideração possíveis erros nas informações utilizadas para a reconstituição do painel ${ }^{16}$.

Outra limitação da PME para esse estudo diz respeito ao seu questionário incluir somente a renda do trabalho, não constando outras modalidades de rendimento como aposentadoria, pensões e transferências governamentais, o que poderia inviabilizar a investigação proposta. Para superar essa limitação, a renda do não trabalho foi imputada a partir da PNAD, utilizando o algoritmo desenvolvido por Ribas e Machado (2009). A ideia dessa metodologia é estimar as variáveis de interesse com base em covariadas comuns em ambas as bases de dados, procedimento simplificado devido às semelhanças existentes entre a PME e a PNAD. O algoritmo utiliza o modelo de dois estágios de Heckman e possibilitou a

\footnotetext{
${ }^{15}$ A opção metodológica de incluir os trabalhadores a partir dos 50 anos de idade baseia-se no fato de que no Brasil não existe idade mínima de aposentadoria para os trabalhadores do setor privado. Já o limite superior de 69 anos justifica-se por abranger a faixa de 65 anos, que define o critério de elegibilidade de aposentadoria por idade para os homens do setor privado e, ao mesmo tempo, procura não incluir o grupo dos indivíduos mais idosos, que possuem um estado de saúde mais frágil.

${ }^{16}$ Ribas e Soares (2008) mostraram que a taxa de atrito de indivíduos no painel da PME, com o amparelhamento convencional, supera $50 \%$ após nove meses na pesquisa. Com a utilização do algoritmo proposto, os autores recuperaram entre 15 p.p. e 25 p.p. da amostra.
} 
imputação de três rendas não trabalho na PME: aposentadoria, pensão e outras rendas (juros, aluguéis, transferências etc.) $)^{17}$.

Por último, o esquema de rotação da PME limita o uso de modelos com dados em painel, pois permite o registro de apenas uma transição ocupacional por ano para cada indivíduo. Para superar essa limitação, foi utilizada a metodologia de pseudo-painel, que visa aumentar a variabilidade temporal da amostra e permitir o uso de modelos com dados em painel, que são os mais adequados para problemas dinâmicos (OLIVERIA; MACHADO, 2013). Essa abordagem aumenta a variabilidade temporal da base e permite a estimação consistente de modelos com dados em painel. Com base em Machado e Oliveira (2013), o pseudo-painel foi construído a partir da PME. Os seguintes passos foram seguidos:

a) Selecionar os meses de março, julho e novembro de cada ano para compor a base. Esse procedimento tem dois objetivos: garante que cada indivíduo seja entrevistado somente uma vez ao ano, no intuito de garantir que os cortes transversais sejam independentes, além de controlar a sazonalidade da pesquisa.

b) As pessoas foram acompanhadas com relação a sua posição na ocupação nos anos 20022003, 2003-2004, 2005-2006 e 2006-2007 de modo a permitir a construção da variável binária que indica se o indivíduo fez a transição para o trabalho por conta própria ou não. Conforme discutido, foram incluídos na amostra somente as pessoas que eram trabalhadores formais ou informais no ano inicial, e que mantiveram-se ocupados no período final, totalizando 13437 observações.

c) Após o registro da variável binária, os indivíduos foram agrupados em células homogêneas, que foram construídas com base em quatro características invariantes no tempo: geração de nascimento (4 faixas), gênero (2 faixas), cor (2 faixas) e educação (4 faixas), totalizando de 64 células diferentes ${ }^{18}$. As gerações de nascimento foram definidas em períodos de 5 anos, com exceção da geração mais antiga: 1934-1941, 1942-1946, 19471951, 1952-1956. A educação foi dividida em 0 a 3, 4 a 7, 8 a 10 e 11 ou mais anos de

\footnotetext{
${ }^{17} \mathrm{O}$ procedimento permite imputar quatro rendimentos na PME: aposentadoria, pensão, outras rendas (juros, aluguéis, transferências etc.) dos mais pobres e outras rendas dos mais ricos. Cada modelo de rendimento foi estimado na PNAD com o método de dois estágios de Heckman. No primeiro estágio foi estimada a probabilidade de cada domicílio ou indivíduo receber determinada renda, com base em características observáveis em ambas as bases de dados. Essa etapa permitiu identificar na PME as pessoas e residências que terão renda imputada. No segundo estágio, o valor da renda foi estimado na PNAD e imputado na PME.

18 A construção das coortes, segundo proposto por Deaton (1985), deve basear-se em características individuais que são invariantes no tempo, pois cada indivíduo deve pertencer a uma única célula. A educação, embora mude ao logo do ciclo de vida da pessoa, foi considerada invariante na faixa etária em questão.
} 
estudo, a cor foi definida em brancos (incluindo amarelos) e negros (incluindo pardos e indígenas), e o gênero, em masculino e feminino.

A estimação consistente da equação (7) depende do número de observações por coorte, embora não exista um critério objetivo para definir essa ordem de grandeza (VERBEEK, 2007). O

Gráfico 9 mostra o número de observações por coorte, cujo tamanho médio é de aproximadamente 70 indivíduos. Percebe-se que as coortes mais antigas têm tamanho médio menor. Esse fato reflete a menor proporção de trabalhadores mais velhos no mercado de trabalho e, de modo a levar isso em consideração, foram utilizados os pesos na estimação da equação (7), de modo a refletir a menor representatividade das coortes mais velhas na população economicamente ativa.

\section{Gráfico 9. Número de observações por coorte}

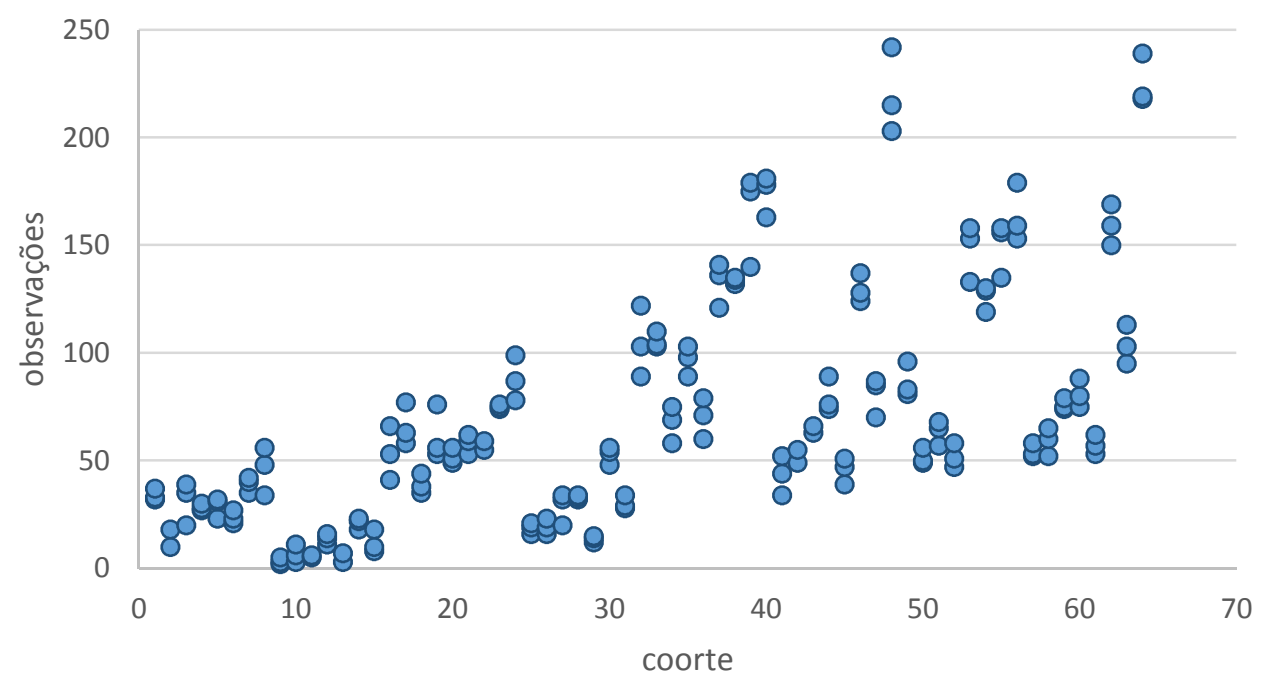

Fonte: IBGE (2014b). Elaborado pelo autor com base na PME (2002 a 2007)

\subsubsection{Estatísticas descritivas}

Nesse estudo uma pessoa é considerada aposentada se ela recebe renda de aposentadoria ou pensão na semana referência. Na perspectiva dessa investigação, a renda de pensão tem um papel similar ao da aposentadoria, pois trata-se de uma renda de caráter não transitório, que pode ter impacto sobre as decisões ocupacionais dos trabalhadores mais velhos. Além disso, há evidências de erro de medida na declaração de aposentadoria nas pesquisas domiciliares, uma vez que as pessoas podem reportar-se como aposentadas quando recebem renda de pensão (RIBAS; MACHADO, 2009). 
Tabela 6. Estatísticas descritivas

\begin{tabular}{|c|c|c|c|}
\hline Variáveis & Descrição das variáveis & Média & $\begin{array}{l}\text { Desvio } \\
\text { Padrão }\end{array}$ \\
\hline Mobilidade $(m o b)$ & Mudou para conta própria (dummy) & 0.11 & 0.31 \\
\hline Aposentadoria & Recebe aposentadoria (dummy) & 0.22 & 0.42 \\
\hline Aposentadoria 1 & Renda de aposentadoria - $1^{\circ}$ quartil (dummy) & 377 & 112 \\
\hline Aposentadoria 2 & Renda de aposentadoria - $2^{\circ}$ quartil (dummy) & 735 & 116 \\
\hline Aposentadoria 3 & Renda de aposentadoria - $3^{\circ}$ quartil (dummy) & 1312 & 257 \\
\hline Aposentadoria 4 & Renda de aposentadoria - $4^{\circ}$ quartil (dummy) & 4482 & 4008 \\
\hline Salário 1 & Salário - $1^{\circ}$ quartil (dummy) & 410 & 118 \\
\hline Salário 2 & Salário - $2^{\circ}$ quartil (dummy) & 700 & 87 \\
\hline Salário 3 & Salário - $3^{\circ}$ quartil (dummy) & 1143 & 205 \\
\hline Salário 4 & Salário -o $4^{\circ}$ quartil (dummy) & 4470 & 4353 \\
\hline Outras rendas 1 & $\begin{array}{l}\text { Aluguel, juros, transferências - } 1^{\circ} \text { quartil } \\
(\text { dummy })\end{array}$ & 42 & 24 \\
\hline Outras rendas2 & $\begin{array}{l}\text { Aluguel, juros, transferências }-2^{\circ} \text { quartil } \\
(\text { dummy })\end{array}$ & 172 & 51 \\
\hline Outras rendas3 & $\begin{array}{l}\text { Aluguel, juros, transferências - } 3^{\circ} \text { quartil } \\
(\text { dummy })\end{array}$ & 484 & 152 \\
\hline Outras rendas 4 & $\begin{array}{l}\text { Aluguel, juros, transferências - } 4^{\circ} \text { quartil } \\
(\text { dummy })\end{array}$ & 7551 & 70564 \\
\hline Jornada $(0-39 h)$ & Jornada até 39h (dummy) & 0.15 & 0.37 \\
\hline Jornada (40-44h) & Jornada de $40 \mathrm{~h}$ a $44 \mathrm{~h}$ (dummy) & 0.50 & 0.50 \\
\hline Jornada ( $45 \mathrm{~h}$ ou mais) & Jornada de $45 \mathrm{~h}$ ou mais (dummy) & 0.35 & 0.47 \\
\hline Formal & Trabalho formal (dummy) & 0.65 & 0.48 \\
\hline Tamanho da firma & Firma de 2 a 5 funcionários & 0.10 & 0.31 \\
\hline $\begin{array}{l}\text { Duração do emprego (0-2 } \\
\text { anos) }\end{array}$ & Tempo de duração do trabalho & 0.39 & 0.07 \\
\hline Gerência & Dirigentes de produção e operações & 0.07 & 0.26 \\
\hline Profissionais & Profissionais de nível superior & 0.07 & 0.25 \\
\hline Técnicos & Técnicos de nível médio & 0.08 & 0.27 \\
\hline Serviços administrativos & Trabalhadores de serviços administrativos & 0.09 & 0.28 \\
\hline Serviço e comércio & Trabalhadores dos serviços/comércio & 0.42 & 0.49 \\
\hline Manual & $\begin{array}{l}\text { Trabalhadores de } \\
\text { reparação/manutenção/instalação }\end{array}$ & 0.28 & 0.45 \\
\hline Anos de estudo & Anos de escolaridade & 6.86 & 4.43 \\
\hline Chefe & Chefe da família (dummy) & 0.71 & 0.45 \\
\hline Casado & Pessoa é casada (dummy) & 0.71 & 0.46 \\
\hline Idade & Idade da pessoa & 55.6 & 4.49 \\
\hline
\end{tabular}

Fonte: IBGE (2014b). Elaborado pelo autor com base na PME (2002 a 2007) 
A partir da especificação econométrica discutida anteriormente, as variáveis utilizadas na equação (7) estão descritas na Tabela 6, que apresenta a média e o desvio padrão das variáveis no momento da primeira entrevista, ou seja, contém as informações dos trabalhadores formais e informais em $t$, e que continuaram trabalhando em $t+1$. A variável dependente mobilidade mostra que $11 \%$ dos trabalhadores assalariados em $t$ mudaram para o trabalho por conta própria em $t+1$. Além disso, $22 \%$ da amostra recebia renda de aposentadoria ou pensão no momento da primeira entrevista. Para incorporar possíveis não linearidades, os valores monetários da renda de aposentadoria, dos salários e das outras rendas são representados em quartis, de modo que cada quartil contém $25 \%$ da amostra ${ }^{19}$. Percebe-se que há grande diferença nos quartis entre todas as fontes de renda, assim como elevado desvio padrão nos quartis superiores, sugerindo a existência de grandes desigualdades de renda. Com relação à jornada de trabalho, enquanto $15 \%$ da amostra trabalhava menos do que 39 horas semanais, $51 \%$ trabalhava entre $40 \mathrm{~h}$ e $44 \mathrm{~h}$ e $35 \%$ tinha jornada superior a $44 \mathrm{~h}$ semanais, evidenciando a elevada carga de trabalho nessa faixa etária. Com relação ao grau de formalização, $65 \%$ dos trabalhadores tinham carteira de trabalho, enquanto $35 \%$ eram informais. Já a ocupação dos trabalhadores, baseada na Classificação Brasileira de Ocupações (CBO) mostra uma preponderância das ocupações em serviços/comércio e de trabalhos que exigem habilidades manuais. A escolaridade média da amostra é de aproximadamente 6,8 anos, e a idade média é cerca de 55 anos. Por último, há grande preponderância de indivíduos casados e de chefes de família.

\subsubsection{Transições Ocupacionais}

O padrão de transição ocupacional dos trabalhadores acima de 50 anos de idade é analisado na Tabela 7, seguindo a decomposição proposta por Zissimipoulos e Karoly (2007). Para cada estado inicial, formal e informal, foi determinada a proporção de trabalhadores que se mantiveram na mesma posição entre $t$ e $t+1$, assim como a fração de trabalhadores que migraram para outra posição na ocupação. A análise foi conduzida em diferentes faixas etárias, separadamente para homens e mulheres.

Observa-se que a taxa de continuidade no trabalho formal é superior ao informal para ambos os gêneros. Mais especificamente, $88,5 \%$ dos homens e $87,1 \%$ das mulheres que eram formais em $t$ continuaram formais em $t+1$. Já entre os informais, $51,8 \%$ dos homens e $71.5 \%$ das mulheres mantiveram-se na mesma posição em $t+1$. O emprego com carteira de assinada

\footnotetext{
${ }^{19}$ Os valores monetários foram deflacionados a preços de junho de 2014 utilizando o INPC.
} 
proporciona uma serie de benefícios aos trabalhadores, e pode indicar que a qualidade da ocupação diminui a taxa de saída do trabalho formal, relativamente ao informal.

As demais transições revelam diferenças de mobilidade entre os gêneros. A análise a partir dos trabalhadores formais em $t$ mostra que os homens possuem taxas de transição similares para o trabalho por conta própria e o trabalho informal, 5,6\% e 5,9\%, respectivamente. Já entre as mulheres formais em $t$, apenas 3,6\% migraram para o trabalho por conta própria em $t+1$, contra $9,4 \%$ para a informalidade. Quando analisadas as transições a partir do trabalho informal em $t$, observa-se que $28,2 \%$ dos homens tornou-se conta própria e $20 \%$ migrou para o trabalho formal em $t+1$. Entre as mulheres, é interessante destacar que uma proporção similar das trabalhadoras informais optou pelo trabalho por conta própria e pela formalidade em $t+1$, em torno de $14 \%$.

A análise descritiva mostra que a taxa de transição para o trabalho por conta própria é maior entre os homens do que entre as mulheres, em todas as transições ocupacionais. Dessa forma, as estatísticas sugerem que a propensão de tornar-se conta própria é maior entre os homens, resultado destacado com frequência na literatura empírica. Além disso, os dados mostram que a taxa de transição para o trabalho por conta própria é relativamente estável com o avanço da idade, tanto para os homens quanto para as mulheres. Esse resultado fica mais pronunciado quando comparado com a transição para o trabalho informal. Por exemplo, entre as mulheres que saíram do trabalho formal em $t$, a taxa de transição para o trabalho informal passou de 8,5\%, na faixa de 50 a 54 anos, para $21,2 \%$, na faixa de 65 a 69 anos. Já a taxa de transição para o trabalho por conta própria passou de 3,1\% para 2,6\%, nos mesmos intervalos etários. Por último, a Tabela 7 sugere que a propensão de mudar para o trabalho por conta própria entre $t$ e $t+1$ é maior entre os trabalhadores sem carteira assinada, tanto para os homens quanto para as mulheres. Esse resultado pode indicar que a escolha pelo trabalho autônomo no Brasil metropolitano é dirigida mais pelas condições desfavoráveis do trabalho assalariado do que pelas vantagens oferecidas pelo trabalho por conta própria.

Tabela 7 Transição ocupacional dos trabalhadores formais e informais entre $t$ e $t+1$ 


\begin{tabular}{|c|c|c|c|c|c|}
\hline \multirow[b]{2}{*}{ Posição em t } & \multicolumn{5}{|c|}{ Posição em $t+1$} \\
\hline & Formal (\%) & Informal (\%) & Conta própria (\%) & Total (\%) & Total (amostra) \\
\hline \multicolumn{6}{|l|}{ a) Homens } \\
\hline \multicolumn{6}{|l|}{ Formal } \\
\hline Total & 88.5 & 5.9 & 5.6 & 100 & 5688 \\
\hline \multicolumn{6}{|l|}{ Por idade } \\
\hline $50-54$ & 89.4 & 5.4 & 5.2 & 100 & 3229 \\
\hline $55-59$ & 87.8 & 5.9 & 6.3 & 100 & 1543 \\
\hline $60-64$ & 86.5 & 7.4 & 6.1 & 100 & 689 \\
\hline $65-69$ & 85.0 & 9.2 & 5.8 & 100 & 227 \\
\hline \multicolumn{6}{|l|}{ Informal } \\
\hline Total & 20.0 & 51.8 & 28.2 & 100 & 2013 \\
\hline \multicolumn{6}{|l|}{ Por idade } \\
\hline $50-54$ & 22.1 & 46.1 & 31.8 & 100 & 902 \\
\hline $55-59$ & 17.3 & 56.3 & 26.4 & 100 & 601 \\
\hline $60-64$ & 22.8 & 52.4 & 24.8 & 100 & 357 \\
\hline $65-69$ & 12.5 & 64.3 & 23.2 & 100 & 153 \\
\hline \multicolumn{6}{|l|}{ b) Mulheres } \\
\hline \multicolumn{6}{|l|}{ Formal } \\
\hline Total & 87.1 & 9.4 & 3.6 & 100 & 3196 \\
\hline \multicolumn{6}{|l|}{ Por idade } \\
\hline $50-54$ & 88.4 & 8.5 & 3.1 & 100 & 1845 \\
\hline $55-59$ & 86.6 & 9.1 & 4.3 & 100 & 944 \\
\hline $60-64$ & 84.8 & 11.2 & 4.0 & 100 & 308 \\
\hline $65-69$ & 76.3 & 21.2 & 2.6 & 100 & 99 \\
\hline \multicolumn{6}{|l|}{ Informal } \\
\hline Total & 14.5 & 71.5 & 14.1 & 100 & 3409 \\
\hline \multicolumn{6}{|l|}{ Por idade } \\
\hline $50-54$ & 15.5 & 71.4 & 13.0 & 100 & 1337 \\
\hline $55-59$ & 13.7 & 71.0 & 15.4 & 100 & 695 \\
\hline $60-64$ & 13.1 & 74.0 & 12.8 & 100 & 367 \\
\hline $65-69$ & 12.0 & 67.8 & 20.0 & 100 & 141 \\
\hline
\end{tabular}

Fonte: IBGE (2014b). Elaborado pelo autor com base na PME (2002 a 2007)

\subsection{Resultados econométricos}

A Tabela 8 Esse resultado está parcialmente em linha com Zissimipoulos et al (2009), que mostraram que a renda de aposentadoria (dummy) impacta positivamente a probabilidade de transição para o trabalho por conta própria. 
Tabela 8apresenta a estimação da equação (7), que avalia os determinantes da transição do trabalho assalariado para o trabalho por conta própria, a partir dos modelos de efeito fixo (EF) e de mínimos quadrados ordinários agrupado (MQO), separadamente para homens e mulheres. As colunas 1 e 3 apresentam os resultados do modelo de mínimo quadrados ordinários, enquanto as colunas 2 e 4 mostram as estimativas do modelo de efeito fixo, para homens e mulheres, respectivamente. As variáveis são definidas como valores médios ou proporções. Assim, os coeficientes das regressões indicam a variação na taxa de entrada no trabalho por conta própria como resposta a uma mudança de $1 \%$, no caso das proporções, ou de 1 unidade, no caso dos valores médios.

Os resultados indicam que receber renda de aposentadoria (dummy) em $t$ não é significativo para a transição para o trabalho por conta própria em $t+1$, para ambos os gêneros. No entanto, há uma indicação de que o sentido do impacto é distinto, com impacto negativo para os homens e positivo para as mulheres. Já as faixas de renda de aposentadoria mostraram-se significativas, especialmente para os homens. A partir dos resultados do modelo de efeito fixo, se a proporção de homens no primeiro quartil de aposentadoria aumentar em $1 \%$, a proporção de aposentados se elevará em $0.13 \%$, em relação aos homens que estão no quartil superior de renda de aposentadoria. Os homens que estão no segundo e terceiro quartis também têm um impacto positivo e significativo sobre a transição de interesse. Já para as mulheres, somente o quartil inferior de renda de aposentadoria mostrou-se significativo. Mais especificamente, se a proporção de mulheres no primeiro quartil de aposentadoria aumentar em $1 \%$, a proporção de aposentadas se elevará em $0.10 \%$, em relação aos homens que estão no quartil superior de renda de aposentadoria. Esse resultado está parcialmente em linha com Zissimipoulos et al (2009), que mostraram que a renda de aposentadoria (dummy) impacta positivamente a probabilidade de transição para o trabalho por conta própria. ${ }^{20}$

Tabela 8. Determinantes da transição para o trabalho por conta própria entre homens e mulheres.

\begin{tabular}{|c|c|c|c|c|}
\hline \multirow{3}{*}{$\begin{array}{l}\text { Variável dependente } \\
\text { Transição para conta própria }\end{array}$} & \multicolumn{2}{|c|}{ Homens } & \multicolumn{2}{|c|}{ Mulheres } \\
\hline & MQO & $\mathbf{E F}$ & MQO & EF \\
\hline & (1) & (2) & (3) & (4) \\
\hline \multirow[t]{2}{*}{ Aposentadoria } & -0.072 & -0.118 & 0.119 & 0.101 \\
\hline & $(0.065)$ & $(0.071)$ & $(0.077)$ & $(0.065)$ \\
\hline Renda de aposentadoria1 & $0.099 *$ & $0.132 * *$ & $0.099 * *$ & $0.101 * *$ \\
\hline
\end{tabular}

\footnotetext{
${ }^{20}$ Zissimopoulos et al (2009) avaliou somente a dummy de aposentadoria (estar ou não aposentado) e não o valor da renda de aposentadoria em si.
} 


\begin{tabular}{|c|c|c|c|c|}
\hline \multirow{3}{*}{$\begin{array}{l}\text { Variável dependente } \\
\text { Transição para conta própria }\end{array}$} & \multicolumn{2}{|c|}{ Homens } & \multicolumn{2}{|c|}{ Mulheres } \\
\hline & \multirow{2}{*}{$\begin{array}{c}\text { MQO } \\
\text { (1) }\end{array}$} & \multirow{2}{*}{$\begin{array}{l}\text { EF } \\
(2)\end{array}$} & \multirow{2}{*}{$\begin{array}{c}\text { MQO } \\
\text { (3) }\end{array}$} & \multirow{2}{*}{$\begin{array}{l}\text { EF } \\
(4)\end{array}$} \\
\hline & & & & \\
\hline & $(0.050)$ & $(0.057)$ & $(0.048)$ & $(0.041)$ \\
\hline \multirow[t]{2}{*}{ Renda de aposentadoria2 } & $0.107 * *$ & $0.094 * *$ & 0.050 & 0.113 \\
\hline & $(0.046)$ & $(0.042)$ & $(0.052)$ & $(0.073)$ \\
\hline \multirow[t]{2}{*}{ Renda de aposentadoria3 } & $0.072 *$ & $0.103 * *$ & 0.007 & 0.006 \\
\hline & $(0.037)$ & $(0.041)$ & $(0.044)$ & $(0.048)$ \\
\hline \multirow[t]{2}{*}{ Salário1 } & 0.026 & -0.083 & 0.148 & -0.102 \\
\hline & $(0.117)$ & $(0.096)$ & $(0.105)$ & $(0.101)$ \\
\hline \multirow[t]{2}{*}{ Salário2 } & $0.239 * *$ & $0.183 * *$ & 0.020 & -0.129 \\
\hline & $(0.108)$ & $(0.082)$ & $(0.083)$ & $(0.093)$ \\
\hline \multirow[t]{2}{*}{ Salário3 } & 0.017 & 0.047 & 0.019 & $-0.175^{*}$ \\
\hline & $(0.076)$ & $(0.067)$ & $(0.095)$ & $(0.101)$ \\
\hline \multirow[t]{2}{*}{ Outras rendas 1} & 0.038 & 0.039 & 0.021 & $0.036^{*}$ \\
\hline & $(0.023)$ & $(0.028)$ & $(0.023)$ & $(0.020)$ \\
\hline \multirow[t]{2}{*}{ Outras rendas 2} & 0.026 & 0.036 & 0.017 & -0.015 \\
\hline & $(0.027)$ & $(0.026)$ & $(0.026)$ & $(0.026)$ \\
\hline \multirow[t]{2}{*}{ Outras rendas3 } & -0.009 & -0.004 & $0.066^{* *}$ & $0.068 * *$ \\
\hline & $(0.022)$ & $(0.020)$ & $(0.030)$ & $(0.026)$ \\
\hline \multicolumn{5}{|l|}{ Referência - Jornada ( 45 h ou mais) } \\
\hline \multirow[t]{2}{*}{ Jornada $(0-39 h)$} & $0.257 * *$ & 0.069 & -0.153 & $-0.340 * * *$ \\
\hline & $(0.121)$ & $(0.099)$ & $(0.098)$ & $(0.114)$ \\
\hline \multirow[t]{2}{*}{ Jornada (40h a 44h) } & 0.053 & -0.050 & -0.101 & $-0.165 * *$ \\
\hline & $(0.047)$ & $(0.062)$ & $(0.079)$ & $(0.076)$ \\
\hline \multirow[t]{2}{*}{ Formal } & $-0.111^{*}$ & -0.062 & -0.071 & -0.078 \\
\hline & $(0.062)$ & $(0.059)$ & $(0.061)$ & $(0.069)$ \\
\hline \multirow[t]{2}{*}{ Tamanho da firma (2 a 5 funcionários) } & 0.098 & 0.193 & 0.102 & $0.188 * * *$ \\
\hline & $(0.074)$ & $(0.115)$ & $(0.061)$ & $(0.048)$ \\
\hline \multirow[t]{2}{*}{ Duração do emprego (0 a 2 anos) } & $0.150 * *$ & $0.215^{* * *}$ & -0.036 & -0.042 \\
\hline & $(0.064)$ & $(0.051)$ & $(0.074)$ & $(0.112)$ \\
\hline \multirow[t]{2}{*}{ Anos de estudo } & $0.012 * *$ & 0.023 & $0.011 * * *$ & 0.019 \\
\hline & $(0.005)$ & $(0.029)$ & $(0.004)$ & $(0.040)$ \\
\hline \multirow[t]{2}{*}{ Chefe } & $-0.318^{* * *}$ & $-0.391 * * *$ & 0.071 & 0.117 \\
\hline & $(0.094)$ & $(0.092)$ & $(0.079)$ & $(0.095)$ \\
\hline \multirow[t]{2}{*}{ Casado } & -0.078 & 0.026 & $0.137^{*}$ & $0.193 * *$ \\
\hline & $(0.087)$ & $(0.079)$ & $(0.080)$ & $(0.073)$ \\
\hline \multicolumn{5}{|l|}{ Referência - Profissionais } \\
\hline Gerente de empresas & 0.215 & -0.165 & 0.164 & 0.199 \\
\hline
\end{tabular}




\begin{tabular}{|c|c|c|c|c|}
\hline \multirow{3}{*}{$\begin{array}{l}\text { Variável dependente } \\
\text { Transição para conta própria }\end{array}$} & \multicolumn{2}{|c|}{ Homens } & \multicolumn{2}{|c|}{ Mulheres } \\
\hline & \multirow{2}{*}{$\begin{array}{c}\text { MQO } \\
\text { (1) }\end{array}$} & \multirow{2}{*}{$\begin{array}{l}\mathbf{E F} \\
(2)\end{array}$} & \multirow{2}{*}{$\begin{array}{c}\text { MQO } \\
\text { (3) }\end{array}$} & \multirow{2}{*}{$\begin{array}{l}\text { EF } \\
(4)\end{array}$} \\
\hline & & & & \\
\hline & $\begin{array}{l}(0.158) \\
\end{array}$ & $(0.220)$ & $\begin{array}{l}(0.177) \\
\end{array}$ & $(0.207)$ \\
\hline \multirow{2}{*}{ Técnicos } & 0.085 & -0.149 & 0.142 & 0.110 \\
\hline & $(0.133)$ & $(0.231)$ & $(0.171)$ & $(0.200)$ \\
\hline \multirow[t]{2}{*}{ Serviços administrativos } & 0.011 & -0.352 & 0.048 & -0.298 \\
\hline & $(0.135)$ & $(0.221)$ & $(0.162)$ & $(0.251)$ \\
\hline \multirow[t]{2}{*}{ Serviços e comércio } & -0.079 & -0.255 & -0.016 & -0.070 \\
\hline & $(0.113)$ & $(0.205)$ & $(0.130)$ & $(0.183)$ \\
\hline \multirow[t]{2}{*}{ Manual } & 0.119 & -0.276 & 0.064 & 0.056 \\
\hline & $(0.114)$ & $(0.231)$ & $(0.121)$ & $(0.167)$ \\
\hline \multirow[t]{2}{*}{ Idade } & 0.040 & -0.236 & 0.027 & -0.215 \\
\hline & $(0.028)$ & $(0.161)$ & $(0.040)$ & $(0.280)$ \\
\hline \multirow[t]{2}{*}{ Idade ao quadrado } & -0.000 & 0.002 & -0.000 & 0.002 \\
\hline & $(0.000)$ & $(0.001)$ & $(0.000)$ & $(0.003)$ \\
\hline Dummy de ano & Sim & Sim & Sim & Sim \\
\hline Dummy de Região Metropolitana & Sim & Não & Sim & Não \\
\hline
\end{tabular}

Fonte: Elaborado pelos autores com base na PME/IBGE

Nota: * Estatisticamente significativo a $10 \%$, ** Estatisticamente significativo a 5\%, *** Estatisticamente significativo a $1 \%$. Desvio padrão em parênteses

Os quartis de salário e a jornada de trabalho mostram que o padrão de transição para o trabalho por conta própria em é distinto entre os gêneros. Para os homens, estar no segundo quartil de salário em $t$ impacta positivamente a transição para o trabalho autônomo em $t+1$, mas a jornada semanal não é significativa para explicar a decisão de trabalhar por conta própria um ano após a primeira entrevista. Já entre as mulheres, a jornada de trabalho é significativa para a explicar a transição de interesse, com maior preponderância para aquelas que possuem longas jornadas. O terceiro quartil de salário é negativo e marginalmente significativo para a transição de interesse. Esses resultados podem indicar que a mobilidade para o trabalho autônomo representa uma opção de flexibilidade de horário para as mulheres, enquanto para os homens representa uma oportunidade de ganhos ou complemento de renda. Esta indicação corrobora alguns achados na literatura internacional, de que as motivações para o trabalho autônomo são distintas entre homens e mulheres (LOMBARD, 2001).

Já as outras rendas, que contém as rendas de aluguel, juros e transferências, são significativas somente para as mulheres. Essa fonte de renda pode ser compreendida como uma proxy para a riqueza familiar, variável não disponível na PME, e corrobora a hipótese de 
restrição de liquidez para a decisão de empreender para as mulheres mais velhas (BRUCE et al, 2000; ZISSIMOPOULOS; KAROLY, 2007).

Ao contrário do sugerido pelas estatísticas descritivas, a posição na ocupação em $t$, formal ou informal, não se mostrou significativa para a transição para o trabalho autônomo em $t+1$. O tamanho da firma é significativo para explicar a transição das mulheres, com maior preponderância para aquelas que trabalham em firmas pequenas. Já a duração do emprego atual é importante para explicar a decisão de mobilidade dos homens; se aumentar em $1 \%$ o número de homens que estão no mesmo emprego há no máximo dois anos, a taxa de transição para o trabalho por conta própria aumenta em cerca de $0.2 \%$, relativamente aos trabalhadores que estão no mesmo emprego a mais tempo. O tempo de permanência na mesma ocupação é uma característica de um emprego de qualidade (GONZAGA, 1998), que pode sugerir que os homens mais velhos que estão em ocupações com maior rotatividade, e portanto, de pior qualidade, têm maior propensão de trabalhar por conta própria.

Com relação às variáveis sociodemográficas, ser chefe de família em $t$ é negativo e significativo para a decisão de mobilidade dos homens. Esse resultado ponde indicar que os homens que possuem essa condição na família tendem a evitar a transição para o trabalho por conta própria devido a maior instabilidade dos rendimentos do trabalho autônomo, que poderia comprometer os rendimentos de toda a família. Ser casado é positivo e significativo para as mulheres, resultado em linha com outros estudos empíricos discutidos anteriormente. Por último, a educação, a idade e a ocupação do trabalho não se mostraram significativos para a transição de interesse.

\subsection{Considerações finais}

Esse capítulo investigou os determinantes da transição do trabalho assalariado, formal e informal, para o trabalho por conta própria no Brasil metropolitano, com indivíduos na faixa de 50 a 69 anos de idade, utilizando os dados da PME entre os anos de 2002 e 2007. Especificamente, procurou-se analisar o papel da aposentadoria nesse processo, ou seja, se a renda de aposentadoria favorece a decisão de trabalhar por conta própria. Esse é um tema relevante na medida em que a proporção de trabalhadores por conta própria aumenta significativamente com a idade. Além disso, essa transição pode trazer ter implicações sobre o bem-estar das pessoas mais velhas, relacionadas a maior instabilidade dos rendimentos e flexibilidade no trabalho. A maior parte dos trabalhos dessa vertente de pesquisa reside nos países desenvolvidos, devido ao estágio mais avançado do envelhecimento populacional, além de possuírem bases de dados detalhadas sobre o histórico laboral e as condições de saúde das 
pessoas com 50 anos ou mais de idade. Nesse sentido, esse trabalho pretende contribuir com uma linha de pesquisa ainda pouco explorada nos países em desenvolvimento. Para tanto, foi necessário realizar a imputação da renda do não trabalho a partir da PNAD, pois a PME não possui essa informação. Além disso, como o esquema de rotação da PME permite o registro de apenas uma transição ocupacional por ano para cada indivíduo, foi utilizada a metodologia de pseudo-painel, que gera maior variabilidade temporal, e permite o uso de técnica de dados em painel. Em particular, a construção do pseudo-painel permitiu o uso de modelos que controlam a heterogeneidade individual, levando em conta a possível endogeneidade da decisão de trabalhar. Os resultados mostraram que a renda de aposentadoria é uma variável importante para explicar a transição para o trabalho por conta própria entre os trabalhadores mais velhos, especialmente entre os homens, e nos menores quartis de aposentadoria. Já a dummy de aposentadoria não se revelou significativa para essa transição ocupacional. Os demais determinantes sugerem que a natureza dessa decisão mobilidade é distinta entre homens e mulheres. Entre as mulheres, a escolha pelo trabalho autônomo parece vinculada à maior flexibilidade de horário e ao trabalho em firmas pequenas. Já entre os homens, o salário mostrou-se positivo e significativo para a escolha ocupacional de interesse. Além disso, os resultados sugerem que os homens que são chefe de família têm menor propensão de mudar para o trabalho por conta própria, possivelmente devido à incerteza que acompanha a renda do trabalho autônomo, que pode comprometer os rendimentos de toda a família. Para as mulheres, estar casada tem impacto positivo e significativo para a transição para o trabalho autônomo. Colocando os resultados em perspectiva, a transição para o trabalho por conta própria no final da carreira laboral no Brasil metropolitano parece estar vinculada, pelo menos parcialmente, às condições desfavoráveis do assalariamento. Os resultados sugerem que os homens que estão em empregos com alta rotatividade têm maior propensão de trabalhar de forma autônoma, assim como as mulheres que trabalham em firmas pequenas. Esse fato pode sugerir que o mercado de trabalho precisa se adaptar às necessidades de um país que envelhece em um ritmo acelerado. Nesse sentido, é importante que essa pesquisa seja estendida e aprofundada em outras direções, como no papel da escolaridade requerida pela ocupação na decisão de mobilidade das pessoas mais velhas, bem como no estudo da possível discriminação etária no mercado de trabalho. 


\section{OS EFEITOS DA APOSENTADORIA NA SAÚDE DOS IDOSOS NA CIDADE DE SÃO PAULO}

\subsection{Introdução}

Três tendências sociodemográficas se consolidaram nas últimas décadas, em especial nos países desenvolvidos, e organizaram parte da agenda de pesquisa e das preocupações com os rumos da aposentadoria: envelhecimento populacional, aumento da expectativa de vida e queda na taxa de participação dos idosos no mercado de trabalho (GRUBER; WISE, 1998).

O envelhecimento populacional é uma tendência consolidada em quase todas as regiões do mundo. Esse fenômeno encontra-se mais aprofundado nos países desenvolvidos, embora a maioria dos idosos do mundo residam nos países em desenvolvimento desde a década de $1950^{21}$ (UNITED NATIONS, 2013, p. 9). A Tabela 9Erro! Fonte de referência não encontrada. mostra a evolução de três indicadores de envelhecimento populacional: a proporção de indivíduos com 60 anos de idade ou mais na população, a idade mediana, e a razão de dependência, definida como a razão entre adultos (15 a 64 anos) e adultos idosos (65 anos ou mais).

Tabela 9. Indicadores de envelhecimento populacional, por grupo de países

\begin{tabular}{|c|c|c|c|c|c|c|c|c|c|}
\hline \multirow[b]{2}{*}{ Países } & \multicolumn{3}{|c|}{ Proporção de idosos (\%) } & \multicolumn{3}{|c|}{ Idade mediana } & \multicolumn{3}{|c|}{ Razão de dependência } \\
\hline & 1950 & 2013 & 2050 & 1950 & 2013 & 1950 & 1950 & 2013 & 2050 \\
\hline Desenvolvidos & 12 & 23 & 32 & 28 & 40 & 44 & 8 & 4 & 2 \\
\hline Em desenvolvimento & 6 & 9 & 19 & 21 & 26 & 35 & 15 & 11 & 5 \\
\hline
\end{tabular}

Fonte: UNITED NATIONS (2015)

A evolução da proporção de idosos e da idade mediana confirma que as sociedades estão envelhecendo e que esse processo está mais estabelecido nos países desenvolvidos. Nos países em desenvolvimento, o aumento na proporção de idosos foi menor entre 1950 e 2013, mas a projeção é de aceleração nas próximas décadas, alcançando 19\% em 2050. Já a razão de dependência, que é uma medida simples da capacidade de transferência intergeracional, mostrou forte redução entre 1950 e 2013 nos países desenvolvidos, e as perspectivas são de queda para ambos os grupos de países em 2050, sugerindo dificuldades crescentes para a realização de transferências aos indivíduos mais velhos.

Associado ao envelhecimento populacional, o aumento da expectativa de vida ao nascer é uma tendência difundida em todas as regiões do mundo. Nos países desenvolvidos, a

\footnotetext{
${ }^{21}$ No contexto das estatísticas demográficas, os países desenvolvidos referem-se a Europa, América do Norte, Japão, Austrália e Nova Zelândia. Os países em desenvolvimentos incluem um conjunto de países da África, Ásia, América Latina e Caribe e Oceania. Não foram incluídas as estatísticas dos países menos desenvolvidos, que envolve uma lista de 49 países com os piores indicadores sociodemográficos. (UNITED NATIONS, 2013)
} 
esperança de vida era de 65 anos em 1950 e alcançou 78 anos em 2010-2015, em valores estimados. Embora as pessoas vivam mais, em média, nos países desenvolvidos, a diferença em relação às regiões menos desenvolvidas vem caindo, de 23 anos para 10 anos, no mesmo período. A expectativa de vida aos 60 anos também possui uma tendência de aumento, de 23 anos em 2010-2015 para 26 anos em 2045-2050, nos países desenvolvidos, e de 19 anos para 21 anos, nas regiões em desenvolvimento, no mesmo período analisado (UNITED NATIONS, 2013, p. 6-7).

Essas mudanças demográficas têm pressionado os sistemas previdenciários de um amplo conjunto de países, pois caminham no sentido de elevar o tempo de recebimento dos benefícios e diminuir a relação contribuinte/beneficiário. Além disso, essas tendências demográficas foram acompanhadas por um movimento de queda na taxa de participação de indivíduos mais velhos no mercado de trabalho, em especial nos países desenvolvidos. Enquanto em 1960, o nível de atividade dos homens entre 60 e 64 anos era superior a 70\% em muitos desses países, no final da década de 1990 essa taxa caiu para menos 40\% e, em alguns casos, para menos de $20 \%{ }^{22}$ (GRUBER; WISE, 1998). A taxa de participação dos indivíduos mais velhos é mais elevada nos países em desenvolvimento, embora haja grande dispersão entre estes. Há uma tendência de queda nessa taxa, de 45\% em 1990 para 40\% em 2020 (UNITED NATIONS, 2013, p. 49-53).

A combinação do aumento da expectativa de vida e da queda na taxa de participação de idosos no mercado de trabalho representa uma elevação da proporção da vida das pessoas passada na aposentadoria. Uma questão que se coloca a partir dessa constatação é se a aposentadoria estendida tem efeitos sobre a saúde física e mental dos indivíduos (BONSANG et al, 2012, p. 490). Nesse sentido, a avaliação das reformas previdenciárias que alteram a idade mínima de acesso aos benefícios precisa incluir esse efeito, pois podem ter um impacto direto sobre a saúde dos aposentados (DAVE et al, 2008, p. 498). A investigação dos efeitos da aposentadoria em saúde é relevante não somente ao nível do indivíduo, mas também com relação às políticas de saúde. A depender da natureza e da intensidade do impacto, as recomendações de políticas públicas podem ser diferentes, de modo que o debate em torno das reformas precisa incorporar esse aspecto (DAVE et al, 2008; NEUMAN, 2004). Se a aposentadoria tiver efeitos deletérios sobre a saúde das pessoas, elevar a idade mínima pode

\footnotetext{
${ }^{22}$ Em 1960, o nível de atividade dos homens entre 60 e 64 anos era superior a 70\% na França, Bélgica, Holanda, Alemanha, Espanha, Reino Unido, Suécia, Estados Unidos e Japão, e em torno de $60 \%$ na Itália; no final da década de 1990, essa taxa caiu para menos de $20 \%$ nos três primeiros países e na Itália, para $35 \%$ na Alemanha e $40 \%$ na Espanha. Essa queda no nível de atividade deve-se, entre outros motivos, aos incentivos criados pelos sistemas de aposentadoria, que desestimulam a participação laboral de indivíduos mais velhos após a idade legal de elegibilidade (GRUBER; WISE, 1998).
} 
reduzir a procura por serviços de saúde, diminuindo assim os seus custos. De outro lado, se o efeito esperado é positivo, a elevação na idade de elegibilidade pode impactar negativamente os gastos com saúde, em especial pela demanda dos indivíduos de menor renda, que tendem a apresentar saúde mais fragilizada. Neste caso, essa parcela da população seria afetada com maior intensidade, por não usufruir dos ganhos advindos da aposentadoria antecipada (NEUMAN, 2004, p. 7).

A agenda de pesquisa que investiga os efeitos causais da aposentadoria em saúde centra-se nos países desenvolvidos, com ênfase nos Estados Unidos e Europa. Isso pode ser explicado pelo processo de envelhecimento populacional se encontrar mais consolidado nesses países, além de possuírem bases de dados que possibilitam esse tipo de pesquisa. Nos países em desenvolvimento, há uma lacuna de pesquisas nessa temática, justificada, em parte, pela menor disponibilidade de dados. Pelo menos três argumentos justificam a realização de estudos nessa temática nas regiões em desenvolvimento. Em primeiro lugar, a maioria dos idosos do mundo reside nos países em desenvolvimento, ou seja, o estudo da saúde na velhice, em todos os seus aspectos, precisa incluir essas nações. Em segundo lugar, como o processo de envelhecimento populacional nos países em desenvolvimento ocorre em um ritmo acelerado, esses países precisam se preparar para as demandas de sociedades que envelhecem.

Por último, e de forma mais geral, é importante compreender quais efeitos da aposentadoria em saúde, identificados nos países desenvolvidos, podem ser generalizados e quais efeitos são específicos dos países em desenvolvimento. Isso porque, o envelhecimento populacional experimentado pelos países em desenvolvimento possui especificidades que podem ter implicações sobre a saúde dos indivíduos mais velhos. Nos países da América Latina e Caribe, por exemplo, as quedas bruscas na mortalidade e na fecundidade, que geraram uma elevada velocidade do envelhecimento, ocorreram em meio a contextos sociais e econômicos frágeis, sem que os países pudessem se preparar para as demandas do envelhecimento $^{23}$. Nos países desenvolvidos, ao contrário, a transição demográfica para sociedades mais velhas ocorreu de forma mais gradual, e posterior ao estabelecimento de padrões adequados de vida (PALLONI; PELÁEZ, 2003).

\footnotetext{
${ }^{23}$ Palloni e Peláez (2003, p.15-25) argumentam que o rápido declínio da mortalidade, iniciado na década de 1940, ocorreu especialmente na primeira infância, e foi fruto mais dos avanços da medicina do que propriamente de melhoras nas condições de vida. Nesse sentido, os autores sugerem que os indivíduos que completarem 60 anos entre 2000 e 2020 na região terão piores distribuições de saúde do que idosos de outras localidades, mesmo controlando para a condições socioeconômicas
} 


\subsection{Revisão da literatura}

A investigação dos efeitos da aposentadoria na saúde dos indivíduos constitui uma agenda de pesquisa que envolve distintos campos do conhecimento. Os primeiros estudos na área foram conduzidos por sociólogos nas décadas de 1960 e 1970 e previam uma deterioração do estado de saúde do aposentado, devido a separação de suas funções produtivas, da perda de status e identidade social e da quebra de redes de apoio. Relacionada à essa perspectiva, alguns autores concebiam a transição para a aposentadoria como um evento indutor de stress em si, baseado na hipótese de que essa transição envolve mudanças de grande escala na relação entre o indivíduo e seu ambiente ${ }^{24}$ (MINKLER, 1981, p.119-120).

Ainda entre os trabalhos seminais, Atchley (1976) propôs um modelo teórico em que a aposentadoria é compreendida como um processo, e não como um evento isolado no tempo. $\mathrm{O}$ autor tipificou sete fases da aposentadoria, com distintos efeitos no bem estar individual. Essas fases envolvem desde o período anterior à aposentadoria em si, marcada por uma fase de stress, passando por distintos estágios após a saída do mercado de trabalho. O trabalho de Atchey (1976) também se alinha às perspectivas dos trabalhos seminais, que previam uma deterioração das condições de saúde do aposentado. Uma questão importante no trabalho do autor foi ter chamado a atenção para o efeito cumulativo da aposentadoria na saúde e não apenas no efeito instantâneo.

Alguns trabalhos posteriores começaram a refutar a ideia anedótica de que a aposentadoria prejudica a saúde dos indivíduos mais velhos (BOSSE, 1991; EKERDT et al, 1983). Em particular, Bosse et al (1991), mostraram que 70\% dos recentes aposentados não consideravam a aposentadoria como um evento estressante, em comparação com outros acontecimentos, como divórcio, morte de um amigo e problemas

Conforme discutido acima, os trabalhos iniciais levantaram importantes aspectos da relação entre aposentadoria e saúde. No entanto, Coe e Zamarro (2011, p. 77) argumentam que esse debate inicial gerou poucas evidências empíricas conclusivas, pois muitos estudos não levaram em conta que a decisão de se aposentar depende do estado de saúde pregresso do indivíduo, ou seja, que a relação entre essas variáveis pode ser endógena. Segundo Coe e Zamarro (2011, p. 77), o não tratamento do problema da endogoneidade faz com que esses trabalhos possuam somente correlação, mas não causalidade.

\footnotetext{
${ }^{24}$ Esse impacto depende do grau de controle que o indivíduo tem sobre a aposentadoria (voluntária ou compulsória), do momento da ocorrência no ciclo de vida (precoce o normal) e do estágio da aposentadoria que está sendo examinado (MINKLER, 1981, p.119).
} 
Os estudos empíricos mais recentes, em especial no campo da Economia, têm destacado a relevância da possível endogeneidade entre saúde e aposentadoria para a identificação de relações causais ${ }^{25}$. A depender da dimensão da saúde que está sendo avaliada e das características dos dados disponíveis (longitudinais ou cross section), distintas estratégias de identificação têm sido propostas na literatura. As dimensões de saúde mais investigadas são: saúde autorreportada (indicador subjetivo da condição geral de saúde), capacidade funcional (mobilidade e atividades da vida diária) e saúde mental (sintomas de depressão e funcionamento cognitivo). Uma estratégia que vem se consolidando é tratar a endogeneidade da decisão de aposentadoria pelo método de variáveis instrumentais, utilizando as idades de aposentadoria, antecipada e plena, como instrumento.

Muitos estudos acadêmicos têm identificado a existência de efeitos causais da aposentadoria na saúde dos idosos, mas ainda não há um consenso sobre a natureza desse impacto e sobre os mecanismos da aposentadoria que produzem tais mudanças. Essa falta de consenso tem levado um conjunto de pesquisadores a trabalhar com distintas dimensões da saúde, envolvendo indicadores objetivos e subjetivos, com o intuito de compreender melhor esse efeito. Nessa perspectiva, destacam-se os trabalhos de Coe a Zamarro (2011), Insler (2014), Neuman (2008) e Dave et al (2008).

Coe e Zamarro (2011) investigaram os efeitos da aposentadoria na autopercepção de saúde, em sintomas de depressão e no funcionamento cognitivo de indivíduos mais velhos em 11 países europeus. Além disso, para minimizar o viés da saúde subjetiva, um indicador geral foi criado a partir da agregação de medidas objetivas de saúde. Os autores utilizaram dados em cross section da SHARE e as idades legais de aposentadoria, antecipada e plena, como instrumentos para a decisão de aposentadoria. Os resultados indicam que a aposentadoria melhora o indicador geral de saúde e diminui a probabilidade dos indivíduos reportarem uma saúde regular, ruim ou muito ruim.

Neuman (2008) estudou os impactos da aposentadoria na autopercepção de saúde e em indicadores de saúde física e mental dos indivíduos mais velhos nos Estados Unidos. O autor utilizou os dados longitudinais da RHS, com variáveis defasadas, e as idades legais de aposentadoria como instrumentos para a decisão de aposentadoria. Os resultados indicam que diminui a probabilidade do indivíduo reportar uma saúde ruim, ou seja, indicam que a saúde dos aposentados é preservada com a aposentadoria.

\footnotetext{
${ }^{25}$ A aposentadoria pode ser considerado um grande mecanismo de seleção, e tratar dessas questões constitui uma fronteira metodológica dessa linha de pesquisa (EKERDT, 2010, p. 72)
} 
Já Dave et al (2008) investigaram os efeitos da aposentadoria na autopercepção de saúde e em indicadores de saúde física e mental de indivíduos mais velhos nos Estados Unidos $^{26}$ com os dados longitudinais da HRS. Ao contrário dos artigos anteriores que utilizaram variáveis instrumentais, os autores trataram a endogeneidade por meio da estimação de um modelo de efeito fixo, focando nos indivíduos saudáveis antes da aposentadoria. Essa hipótese de identificação considerou que a exclusão dos indivíduos doentes antes da aposentadoria reduziria a possibilidade de simultaneidade entre saúde e a decisão de aposentadoria. Os resultados indicaram que a aposentadoria tem efeitos deletérios sobre mobilidade, atividades básicas da vida diária, número de doenças crônicas e sintomas de depressão.

Outro conjunto de artigos vem trabalhando em questões mais específicas, em especial, no impacto da aposentadoria em funcionamento cognitivo, sintomas de depressão e mortalidade. Bonsang et (2012) investigam o efeito da aposentadoria no funcionamento cognitivo (baseados em testes de memória episódica) de indivíduos entre 51 e 75 anos, residentes no EUA. Os autores utilizaram os dados longitudinais da HRS e levaram em conta a problema da endogeneidade com o modelo de efeito fixo, juntamente com a instrumentalização da decisão de aposentadoria. Os resultados indicaram uma piora nas funções cognitivas dos aposentados.

\subsection{Função de produção de saúde e a decisão de aposentadoria}

A investigação dos efeitos da decisão de aposentadoria na saúde das pessoas se baseará no modelo de demanda por saúde desenvolvido por Grossman (1972). De acordo com Dave et al (2008, p. 500-501), apesar desse modelo teórico não fornecer uma resposta inequívoca do sentido desse impacto, oferece um quadro analítico que permite estudar os resultados de saúde.

O modelo de Grossman (1972) entende que os consumidores demandam saúde por dois motivos. Em primeiro lugar, a saúde é um bem de consumo, com impacto direto sobre a utilidade do indivíduo (uma doença, por exemplo, é considerada uma desutilidade). Além disso, a saúde é um bem de investimento que determina o tempo disponível do indivíduo para o mercado de trabalho e outras atividades. O ponto de partida desse modelo é a maximização da utilidade intertemporal, que contém bens de saúde e outros bens de consumo:

\footnotetext{
${ }^{26}$ Os indicadores objetivos são dificuldade com mobilidade, atividades básicas da vida diária, diabetes, doença no coração, AVC, pressão alta, artrite, problemas psicológicos, sintomas de depressão e câncer.
} 


$$
U=U\left(\phi_{0} H_{0}, \ldots, \phi_{n} H_{n}, Z_{0}, \ldots, Z_{n}\right)
$$

Onde:

$\mathrm{i}=0, \ldots, \mathrm{n}$ período de tempo

$\mathrm{n}$ - tempo de vida do indivíduo

$\mathrm{H}_{0}$ - estoque inicial de saúde

$\phi_{i}$ - fluxo de serviço por unidade de estoque de saúde no período $i$

$\phi_{i} H_{i}$ - consumo total de serviços de saúde no período $i$

$\mathrm{Z}_{\mathrm{i}}$ - consumo de outros bens

Supõe-se que a variação líquida no estoque de saúde é dada pelo investimento em saúde menos a depreciação:

$$
H_{i+1}-H_{i}=I_{i}-\delta_{i} H_{i}
$$

Onde $I_{i}$ é o investimento bruto em saúde e $\delta_{i}$ é a taxa de depreciação no período $i$ assumida exógena, mas que pode variar com a idade. As funções de produção por investimento bruto em saúde, $I_{i}$, e de outros bens, $Z_{i}$, são definidas como:

$$
\begin{aligned}
& I_{i}=I_{i}\left(M_{i}, T H_{i}, E_{i}\right) \\
& Z_{i}=I_{i}\left(X_{i}, T_{i}, E_{i}\right)
\end{aligned}
$$

Onde $M_{i}$ são as despesas médicas, $X_{i}$ são os insumos para produzir o bem $Z_{i}, E_{i}$ é o estoque de capital humano, e $T H_{i}$ e $T_{i}$ são os insumos de tempo. As quantidades de equilíbrio de $H_{i}$ e $Z_{i}$ podem ser determinadas pela maximização da utilidade sujeita às equações (2) e (3) e pela renda máxima do indivíduo. A condição de primeira ordem é dada por:

$$
G_{t}\left(W_{t}+\frac{U_{h_{t}}}{\lambda}(1+r)^{t}\right)=C_{t-1}\left(r-\check{C}_{t-1}+\delta_{t}\right)
$$

A condição de primeira ordem iguala o benefício marginal ao custo marginal do capital saúde. Na equação (4), $G_{t}$ é o produto marginal do capital saúde, $W_{t}$ é a taxa salarial, $\frac{U_{h_{t}}}{\lambda}$ mede o valor monetário do aumento na utilidade devido à elevação de uma unidade no tempo com saúde, $C_{t-1}$ é o custo marginal do investimento bruto de saúde em t-1, $\check{C}_{t-1}$ é a mudança percentual no custo marginal entre t-1 e t, e $\delta_{t}$ é a taxa de depreciação do capital saúde.

De acordo com Dave et al (2006, p. 6-7), o valor do tempo do indivíduo é o máximo da taxa salarial ou do equivalente monetário da utilidade marginal do tempo. Se em algum momento do ciclo de vida a taxa salarial ficar abaixo do valor monetário do tempo, então o indivíduo escolhe se aposentar. Para um indivíduo aposentado, o salário não representa mais o valor do tempo e assim, na condição de primeira ordem, a taxa salarial é substituída pelo valor 
monetário da utilidade marginal do tempo $\frac{U_{h_{t}}}{\lambda}$ na aposentadoria. Segundo os autores, a forma como a aposentadoria impacta a saúde depende do benefício marginal e do custo marginal do capital saúde que, por sua vez, depende do comportamento do valor marginal do tempo, se é crescente ou decrescente, após a aposentadoria. Se o valor marginal do tempo crescente significa que a pessoa valoriza mais o seu tempo e espera-se que demanda por saúde aumente. De outro lado, se o valor marginal é decrescente após a aposentadoria, o indivíduo deve diminuir a demanda por saúde.

\subsection{Metodologia Empírica}

A identificação da relação causal entre a decisão de aposentadoria e a condição de saúde do indivíduo encontra uma serie de dificuldades empíricas. A questão central é que essa decisão pode ser endógena ao estado de saúde da pessoa, tornando inconsistente a estimação pelo método de mínimos quadrados ordinários. Com base em Dave et al (2008, p. 501-502), os mecanismos pelos quais a aposentadoria pode ser endógena ao estado de saúde do indivíduo podem ser analisados pelas especificações lineares dos seguintes modelos estruturais:

$$
\begin{aligned}
& \text { saúde }_{i t}=\alpha_{1} \operatorname{apos}_{i t}+\alpha_{2} I_{i t}+\alpha_{3} X_{i t}+\alpha_{4} \mu_{i}+\varepsilon_{i t} \\
& \operatorname{apos}_{i t}=\beta_{1} \text { saúde }_{i t}+\beta_{2} E_{i t}+\beta_{3} X_{i t}+\beta_{4} \mu_{i}+\eta_{i t}
\end{aligned}
$$

A equação (5) é a função de demanda para resultados negativos de saúde do indivíduo $i$ no tempo $t$ ( saúde $_{i t}$ ), que depende do status de aposentadoria $\left(\operatorname{apos}_{i t}\right)$, dos determinantes específicos de saúde $\left(I_{i t}\right)$, das variáveis sociodemográficas $\left(X_{i t}\right)$, das características individuais não observáveis e invariantes no tempo $\left(\mu_{i}\right)$, e do termo de erro $\left(\varepsilon_{i t}\right)$. A equação (6) é a função da oferta de trabalho, na forma de decisão de aposentadoria $\left(\operatorname{apos}_{i t}\right)$. A variável $E_{i t}$ indica os determinantes específicos dessa decisão e $\eta_{i t}$ é o erro idiossincrático.

O parâmetro de interesse $\alpha_{1}$, que representa a causalidade da decisão de aposentadoria nos resultados de saúde, pode ser inconsistente se a equação (5) for estimada diretamente por MQO. Duas fontes de endogeneidade podem ser identificadas: a primeira ocorre se $\alpha_{4} \neq$ 0 e $\beta_{4} \neq 0$, tornando o fixo individual $\mu_{i}$ correlacionado simultaneamente com a aposentadoria e o estado de saúde do indivíduo. A segunda possibilidade de endogeneidade ocorre se $\beta_{1} \neq 0$, ou seja, da existência de simultaneidade entre o estado de saúde e a decisão de aposentadoria, expressa na correlação de ambas com o termo de erro $\varepsilon_{i t}$. 
Com o objetivo de estimar o impacto da aposentadoria na saúde dos indivíduos, a estratégia de identificação proposta por esse estudo levará em conta as duas fontes de endogeneidade. Em primeiro lugar, a partir da disponibilidade de dados longitudinais, o parâmetro de interesse será estimado com o modelo de efeito fixo, que controla para as variáveis não observáveis e invariantes no tempo, $\mu_{i}$. Ou seja, fatores como background familiar, cuidados de saúde na primeira infância e histórico no mercado de trabalho, que são específicos do indivíduo e podem impactar o estado de saúde e a decisão de aposentadoria são levados em conta com essa estratégia de identificação.

Apesar de considerar a heterogeneidade individual, o modelo de efeito fixo não trata a simultaneidade entre saúde e aposentadoria quando esta é originada por choques aleatórios, $\varepsilon_{i t}$. Para levar em conta essa possível dimensão da endogeneidade, a estratégia de identificação proposta incluirá a instrumentalização da decisão de aposentadoria ao modelo de efeito fixo. Essa variável instrumental precisa estar correlacionada com a decisão de se aposentadoria, mas não pode ter efeito direto sobre o estado de saúde do indivíduo. Em outras palavras, esse instrumento só pode impactar a condição de saúde do indivíduo por meio do status de aposentadoria.

A variável instrumental utilizada será a proporção de idosos em cada setor da economia, separadamente para homens e mulheres, utilizando os 17 grupos principais da Classificação Nacional de Atividades Econômicas (CNAE). Os setores da CNAE referem-se a atual ocupação da pessoa ou a última que teve na vida. As proporções foram calculadas com os Censos de 2000 e 2010 e com a PNAD de 2006.

Essa proporção representa a participação de idosos na mão de obra de cada setor da economia, e é uma proxy para a abertura dos distintos setores aos trabalhadores mais velhos. Argumenta-se que essa variável é correlacionada com a decisão da pessoa de participar do mercado de trabalho, ou seja, um indivíduo com 60 anos ou mais, que pertence a um setor com baixa absorção de idosos, tem menor probabilidade de continuar trabalhando ou de retornar ao mercado de trabalho. Além disso, a escolha de uma variável do lado da demanda por trabalho como instrumento para a decisão de parar de trabalhar, baseia-se na alta taxa de participação da PEA aposentada no Brasil. De acordo com Camarano (2001), o alto nível de atividade dos idosos aposentados é a principal característica da inserção laboral de indivíduos mais velhos no Brasil, sendo inclusive maior que em outros países em desenvolvimento na região.

Dessa forma, a estratégia econométrica utilizada nesse capítulo é baseada na função de produção de saúde de Grossman (1972). Foram estimados os modelos MQO, efeito fixo, e 
efeito fixo com variável instrumental, de acordo com a equação (7), separadamente para homens e mulheres:

$$
\text { saúde }_{i t}=\alpha_{1} f\left(\operatorname{apos}_{i t}\right)+\alpha_{2} I_{i t}+\alpha_{3} X_{i t}+\alpha_{3} T_{i t}+\alpha_{4} \mu_{i}+\delta_{t}+\varepsilon_{i t}
$$

Onde

$\mathrm{i}=1, . ., N$ indivíduos

$\mathfrak{t}=1, \ldots, T$ períodos (anos)

saúde $e_{i t}$ - indicadores da condição de saúde

$f\left(\operatorname{apos}_{i t}\right)$ - instrumento para a decisão de aposentadoria (proporção de idosos em cada setor da economia)

$I_{i t}$ - determinantes específicos da saúde (plano de saúde além do SUS)

$X_{i t}$ - anos de estudo, estado civil, número de filhos, número de moradores, nativo no país, morou no campo

$T_{i t}$ - dummy se recebe renda de aposentadoria, posição na ocupação atual ou na última que teve (empregado, empregador, conta própria), número de bens de consumo da família, renda total do indivíduo

$\mu_{i}-$ efeito fixo individual

$\delta_{t}-$ dummy de ano

$\varepsilon_{i t}-$ termo de erro 


\subsection{Base de dados}

A base de dados utilizada nessa investigação é a Saúde, Bem Estar e Envelhecimento (SABE), coordenada pela Organização Pan-Americana de Saúde (OPAS/OMS), cujo principal objetivo é avaliar as condições de vida e saúde das pessoas idosas na América Latina e Caribe (SABE, 2015). A SABE é uma pesquisa única na região, realizada exclusivamente com indivíduos acima de 60 anos de idade, com dados em nível individual sobre saúde, inserção laboral, rede de apoio familiar e social e informações sociodemográficas. A pesquisa foi concluída no ano de 2000 em sete cidades: Buenos Aires (Argentina), São Paulo (Brasil), Bridgetown (Barbados), Havana (Cuba), Montevidéu (Uruguai), Santiago (Chile) e Cidade do México (México). Posteriormente, os inquéritos da SABE tiveram continuidade no município de São Paulo nos anos de 2006 e 2010, acompanhando os mesmos indivíduos e acrescentando novas coortes de 60 a 64 anos de idade em cada onda (SABE, 2015). Como esse estudo optou pelo uso dos dados longitudinais para controlar uma das fontes de endogeneidade entre saúde e decisão de aposentadoria, somente a cidade de São Paulo foi considerada na análise, que utilizou as três ondas disponíveis para o município, 2000, 2006 e 2010.

$\mathrm{Da}$ amostra original foram excluídas as pessoas que nunca trabalharam de forma remunerada na vida, aquelas com 80 anos ou mais de idade, os que participaram de apenas uma entrevista no painel e os que não responderam aos indicadores de saúde utilizados. A amostra final é composta por homens e mulheres, que tinham entre 60 e 79 anos de idade, totalizando 1714 observações. O painel obtido é desbalanceado, uma vez que há indivíduos que foram entrevistados em duas pesquisas, enquanto outros participaram de todas as ondas.

Tabela 10 Painel desbalanceado da amostra selecionada da SABE: total de observações por ano $e$ distribuição dos indivíduos no painel

\begin{tabular}{|c|c|c|c|c|c|}
\hline Ano & Observações & $2000 / 2006$ & $2006 / 2010$ & $2000 / 2010$ & $2000 / 2006 / 2010$ \\
\hline 2000 & 523 & 147 & - & 43 & 333 \\
\hline 2006 & 694 & 147 & 214 & - & 333 \\
\hline 2010 & 497 & - & 214 & 43 & 333 \\
\hline Total & 1714 & & & & \\
\hline
\end{tabular}

Fonte: Elaborado pelo autor com base em SABE (2000, 2006 e 2010)

Nota-se que o número de indivíduos entrevistados mudou ao longo dos anos. Essas modificações foram resultado de óbitos, recusas, não localizações, mudanças e institucionalizações. Ao mesmo tempo, ao longo dos anos, houve reposições de idosos na 
faixa de 60-64 anos, no sentido manter a representatividade da pesquisa nessa faixa etária (SABE, 2015).

\subsubsection{Medidas de saúde}

Uma das dificuldades para avaliar os efeitos da aposentadoria na saúde dos indivíduos mais velhos reside na construção de indicadores confiáveis de saúde a partir dos microdados. De acordo com Coe e Zamarro (2011, p. 79) as medidas objetivas de saúde que constam nas pesquisas abordam doenças específicas e, portanto, fornecem um quadro restrito da saúde dos indivíduos. Já as medidas subjetivas baseiam-se na autopercepção dos respondentes, que ranqueiam o seu estado geral de saúde a partir de uma escala determinada, e possibilitam uma análise mais ampla do seu bem estar. A informação contida nas variáveis subjetivas possui um caráter global e é útil nesse tipo de investigação, na medida em que a natureza do impacto da aposentadoria na saúde ainda não é clara (NEUMAN, 2007, p. 186).

A ampla utilização da saúde subjetiva em pesquisas empíricas gerou um debate sobre as suas potencialidades e limitações. Esse indicador tem se mostrado um preditor significativo para mortalidade, mesmo após a inclusão de medidas objetivas como controle. No entanto, a autopercepção de saúde pode ser endógena à decisão de aposentadoria, pois as pessoas podem justificar a sua não participação no mercado de trabalho devido à saúde ruim, que é uma alegação socialmente aceita. Ou seja, o caráter subjetivo desse indicador superestimaria o impacto da aposentadoria no estado de saúde do indivíduo, hipótese conhecida como viés de justificação.

Com o objetivo de avaliar os efeitos da aposentadoria na saúde dos idosos residentes no município de São Paulo, essa pesquisa utilizará uma combinação de indicadores objetivos e subjetivos. A estratégia utilizada foi baseada em Coe e Zamarro (2011) e Bound et al. (1999), e cria um indicador geral de saúde (IGS) a partir da regressão da autopercepção de saúde sobre todas medidas objetivas de saúde disponíveis. Segundo Coe e Zamarro (2011, p.80), essa estratégia agrega uma variedade de medidas objetivas em um indicador único e abrangente, além de minimizar o viés de justificação presente na saúde subjetiva. O IGS foi criado com base na estimação da seguinte equação:

$$
A P S_{i}=\alpha+\beta S_{i}+\mu_{i}
$$

Onde,

$i=1,2, \ldots, \mathrm{N}$ cross section de indivíduos 
$A P S_{i}$ - autopercepção de saúde em uma escala de 4 pontos, de muito boa (1) a ruim (4) ${ }^{27}$

$\alpha, \beta$ - parâmetros de interesse a serem estimados

$\mu_{i}$ - termo de erro

$S_{i}$ - vetor de indicadores objetivos de saúde, construídos a partir da base de dados da SABE, e que é formado por:

- Atividades básicas da vida diária (ABVD): número de limitações em seis atividades diárias: atravessar um quarto caminhando, vestir-se, banhar-se, alimentar-se, deitar ou levantar da cama, e ir ao banheiro (incluindo sentar e levantar do vaso sanitário) 28

- Atividades instrumentais da vida diária (AIVD): número de limitações em dez atividades diárias: andar uma quadra, subir um andar pelas escadas sem descansar, utilizar transporte, fazer compras, realizar tarefas domésticas leves e pesadas, preparar uma refeição quente, cuidar do própria dinheiro, telefonar e tomar remédios ${ }^{29}$.

- Mobilidade: número de dificuldades em quatro atividades: ficar sentado durante duas horas, levantar de uma cadeira depois de ficar sentado durante muito tempo, curvar, ajoelhar ou agachar e puxar ou empurrar grandes objetos ${ }^{30}$.

- Doenças crônicas: número de relatos em oito doenças crônicas: hipertensão, diabetes, câncer (excluindo câncer de pele), doença pulmonar, problemas cardíacos, derrame, reumatismo/artrose e osteoporose ${ }^{31}$.

- Limitações devido a doenças: número de limitações em atividades diárias (como trabalhar ou fazer tarefas domésticas) devido a quatro doenças: doença pulmonar, doença cardíaca, derrame e artrite/reumatismo/artrose ${ }^{32}$.

\footnotetext{
${ }^{27}$ No questionário da SABE, a autopercepção de saúde possui 5 níveis. No entanto, as perguntas sofreram modificações ao longo dos anos, de modo que para uniformizá-las foi necessário diminuir para uma escala de 4 níveis.

${ }^{28}$ As atividades básicas da vida diária avaliam a capacidade do idoso em realizar atividades cotidianas de autocuidado de forma independente. (DUARTE, 2003, p. 186-187).

${ }^{29}$ As atividades instrumentais da vida diária avaliam a capacidade funcional do idoso em levar uma vida independente dentro da comunidade (DUARTE, 2003, p. 186-187).

${ }^{30}$ Essa dimensão da mobilidade avalia as grandes funções musculares, conforme definido por (NEUMAN, 2007, p. 185). As possíveis respostas aos itens sobre mobilidade são: "sim", "não", "não pode" e "não faz". Em cada quesito, a dificuldade foi considerada se o indivíduo respondeu "sim" ou "não pode". Ver anexo.

${ }^{31}$ As perguntas relativas às doenças crônicas consideram que a existência da doença foi relatada por um médico ou enfermeiro. Ver anexo.

${ }^{32}$ A limitação só foi computada se o indivíduo relatou que a doença impede "muito" as suas atividades diárias.
} 
- Sintomas crônicos: número de sintomas crônicos relatados nos últimos doze meses em uma lista de sete sintomas: dor no peito, inchaço nos pés e tornozelos, falta de ar, vertigem ou tontura, fadiga ou cansaço, tosse persistente e náusea ou vômito.

- Sobrepeso e obesidade: dummies relativas ao índice de massa corporal (IMC): o indivíduo possui sobrepeso se o seu IMC está entre 28 e 30, e é considerado obeso se o seu IMC é seu é maior ou igual a 30.

- Internações: dummy se o indivíduo ficou internado no hospital pelo menos uma noite vez nos últimos doze meses ${ }^{33}$.

- Força de preensão manual: resultado do teste de preensão manual, que avalia a força muscular dos membros superiores ${ }^{34}$.

Para cada indivíduo, o indicador geral de saúde é o valor predito obtido a partir da estimação da equação (8) por um probit ordenado, para cada ano do painel, separadamente para homens e mulheres. A Tabela 11 mostra os resultados dessa estimação, em que os coeficientes positivos indicam uma piora na saúde autopercebida.

Tabela 11. Indicador Geral de Saúde

\begin{tabular}{|c|c|c|c|c|c|c|}
\hline \multirow[b]{2}{*}{ Autopercepção de saúde } & \multicolumn{3}{|c|}{ Homens } & \multicolumn{3}{|c|}{ Mulheres } \\
\hline & 2000 & 2006 & 2010 & 2000 & 2006 & 2010 \\
\hline \multirow[t]{2}{*}{ Atividades básicas } & 0.048 & -0.013 & 0.175 & 0.056 & -0.108 & 0.086 \\
\hline & $(0.188)$ & $(0.087)$ & $(0.127)$ & $(0.114)$ & $(0.081)$ & $(0.073)$ \\
\hline \multirow[t]{2}{*}{ Atividades instrumentais } & 0.171 & 0.036 & -0.002 & $0.143 * * *$ & $0.083^{* *}$ & 0.076 \\
\hline & $(0.111)$ & $(0.059)$ & $(0.060)$ & $(0.055)$ & $(0.040)$ & $(0.067)$ \\
\hline \multirow[t]{2}{*}{ Mobilidade } & 0.163 & 0.113 & $0.164^{*}$ & $0.157 * *$ & $0.121 * *$ & $0.147 * *$ \\
\hline & $(0.114)$ & $(0.081)$ & $(0.088)$ & $(0.066)$ & $(0.053)$ & $(0.065)$ \\
\hline \multirow[t]{2}{*}{ Limitações devido a doenças } & -0.178 & 0.256 & -0.141 & $0.404 * *$ & $0.304 * *$ & 0.193 \\
\hline & $(0.351)$ & $(0.185)$ & $(0.174)$ & $(0.204)$ & $(0.151)$ & $(0.146)$ \\
\hline \multirow[t]{2}{*}{ Doenças crônicas } & 0.092 & $0.114^{*}$ & $0.210 * * *$ & $0.233 * * *$ & $0.221 * * *$ & $0.146^{* * *}$ \\
\hline & $(0.096)$ & $(0.060)$ & $(0.077)$ & $(0.061)$ & $(0.050)$ & $(0.055)$ \\
\hline \multirow[t]{2}{*}{ Sintomas crônicos } & $0.231 * * *$ & $0.126^{* *}$ & $0.188 * *$ & $0.164 * * *$ & $0.115^{* * *}$ & $0.167 * * *$ \\
\hline & $(0.077)$ & $(0.054)$ & $(0.073)$ & $(0.049)$ & $(0.043)$ & $(0.051)$ \\
\hline \multirow[t]{2}{*}{ Sobrepeso } & -0.218 & 0.151 & -0.033 & 0.065 & -0.140 & -0.133 \\
\hline & $(0.214)$ & $(0.238)$ & $(0.245)$ & $(0.196)$ & $(0.155)$ & $(0.198)$ \\
\hline \multirow[t]{2}{*}{ Obesidade } & 0.451 & 0.084 & -0.152 & -0.064 & -0.037 & 0.021 \\
\hline & $(0.291)$ & $(0.236)$ & $(0.235)$ & $(0.140)$ & $(0.125)$ & $(0.141)$ \\
\hline \multirow[t]{2}{*}{ Internações } & -0.027 & 0.306 & 0.047 & 0.061 & -0.232 & -0.304 \\
\hline & $(0.341)$ & $(0.284)$ & $(0.240)$ & $(0.224)$ & $(0.233)$ & $(0.248)$ \\
\hline
\end{tabular}




\begin{tabular}{lcccccccc}
\hline & \multicolumn{3}{c}{ Homens } & & \multicolumn{3}{c}{ Mulheres } \\
\cline { 2 - 3 } \cline { 6 - 8 } Autopercepção de saúde & 2000 & 2006 & 2010 & & 2000 & 2006 & 2010 \\
\hline Força de preensão & $-0.037^{* * *}$ & $-0.017^{*}$ & -0.001 & & -0.004 & $-0.021^{*}$ & $-0.046^{* * *}$ \\
& $(0.013)$ & $(0.009)$ & $(0.014)$ & & $(0.014)$ & $(0.011)$ & $(0.015)$ \\
Observações & 195 & 263 & 182 & & 328 & 431 & 315 \\
Indicador de saúde (média) & -0.838 & -0.05 & 0.705 & & 0.844 & 0.52 & 0.575 \\
\hline \hline
\end{tabular}

Desvio padrão em parênteses. * significativo a $10 \%$; ** significativo a 5\%; *** significativo a $1 \%$

A Tabela 11 mostra que reportar limitações com mobilidade, doenças crônicas e sintomas crônicos conduz a uma piora na autopercepção de saúde em quase todos anos, para homens e mulheres. O indicador de AIVD foi positivo e significativo para as mulheres em 2006 e 2010. Já a força de preensão melhora a autopercepção de saúde.

Além do IGS, que avalia o estado geral da saúde da pessoa, os efeitos da aposentadoria foram investigados em outros seis indicadores, quatro desses já definidos anteriormente: (i) autopercepção de saúde; (ii) atividades básicas da vida diárias; (iii) atividades instrumentais da vida diária; (iii) mobilidade; (iv) doenças crônicas; (v) depressão ${ }^{35}$ e (vi) funcionamento cognitivo ${ }^{36}$. A avaliação do impacto da aposentadoria na autopercepção de saúde continua sendo importante mesmo após a construção do IGS, pois a comparação entre ambos pode ajudar a compreender se a saúde subjetiva reflete as condições objetivas de bem estar ou se há algum viés de relato ${ }^{37}$. Da mesma forma, os indicadores objetivos selecionados podem ajudar a identificar os mecanismos pelos quais a mudança na saúde ocorre. Se algum indicador global (subjetivo e IGS) e objetivo forem significativos e coincidentes em sentido, é possível sugerir que esses indicadores objetivos são responsáveis pela mudança na saúde geral do indivíduo. Neuman (2007, p. 186), no entanto, destaca que o descompasso entre os indicadores subjetivos e objetivos não necessariamente invalida a autopercepção de saúde. É possível que a aposentadoria tenha efeito sobre a saúde geral do indivíduo, captada pela saúde subjetiva, mas não tenha efeitos sobre medidas específicas. A tabela 12 abaixo resume os indicadores de saúde que serão considerados na análise.

Tabela 12. Indicadores de saúde investigados

\footnotetext{
${ }^{35}$ Avalia a existência de sintomas depressivos e é formada pelo número de aspectos negativos relatados, que envolvem satisfação com a vida, energia para a realização de atividades, humor, medo

36 Indicador que teste a capacidade cognitiva do respondente por meio da realização de testes com relação à capacidade de armazenamento de informações, compreensão e resolução de pequenos problemas.

${ }^{37}$ Neuman (2007, p. 186) sugere que essa combinação de indicadores objetivos e subjetivos pode ajudar a controlar outro tipo de viés de relato. $O$ aposentado pode perceber que a sua saúde está melhor sem que tenha, de fato, experimentado melhorias reais. Isso porque ele pode se deparar com menores limitações físicas somente pelo fato de ter uma rotina menos fisicamente demandante do que quando trabalhava, mas não por estar em melhores condições de saúde. Nesse sentido, confrontar o resultado da saúde subjetiva com indicadores objetivos de capacidade funcional poderia ajudar a mitigar essa possível finte de viés.
} 


\begin{tabular}{|c|c|c|}
\hline Indicador de saúde & Dimensão da saúde & Descrição \\
\hline Indicador geral de saúde & $\begin{array}{l}\text { Condição geral de } \\
\text { saúde }\end{array}$ & $\begin{array}{c}\text { Valor predito da regressão da saúde subjetiva em nove } \\
\text { indicadores objetivos de saúde }\end{array}$ \\
\hline Autopercepção de saúde & $\begin{array}{l}\text { Condição geral de } \\
\text { saúde }\end{array}$ & $\begin{array}{l}\text { Saúde subjetiva reportada pelo indivíduo, numa escala de } 4 \\
\text { pontos, de muito boa (1) a ruim (4) }\end{array}$ \\
\hline $\begin{array}{l}\text { Atividades básicas da } \\
\text { vida diária }\end{array}$ & $\begin{array}{l}\text { Capacidade } \\
\text { funcional }\end{array}$ & Número de limitações em atividades diárias (0-6) \\
\hline $\begin{array}{c}\text { Atividades instrumentais } \\
\text { da vida diária }\end{array}$ & $\begin{array}{l}\text { Capacidade } \\
\text { funcional }\end{array}$ & $\begin{array}{l}\text { Número de limitações em atividades instrumentais diárias (0- } \\
10)\end{array}$ \\
\hline Mobilidade & $\begin{array}{l}\text { Capacidade } \\
\text { funcional } \\
\end{array}$ & $\begin{array}{c}\text { Número de limitações com mobilidade, focado em força } \\
\text { muscular }(0-4)\end{array}$ \\
\hline Doenças crônicas & $\begin{array}{c}\text { Prevalência de } \\
\text { doenças crônicas }\end{array}$ & Número de doenças crônicas reportadas $(0-8)$ \\
\hline Depressão & Saúde mental & Número de sintomas de depressão reportados $(0-15)$ \\
\hline Funcionamento cognitivo & Saúde mental & $\begin{array}{l}\text { Resultado em teste cognitivo de memória e aprendizado (0- } \\
19)\end{array}$ \\
\hline
\end{tabular}

Fonte: Elaborado pelo autor com base em SABE (2002, 2006 e 2010)

\subsubsection{Variáveis de controle}

A tabela 13 apresenta as variáveis de controle presentes na equação (7). É importante destacar que o modelo de efeito fixo não inclui as variáveis que são invariantes no tempo: anos de estudo, nativo no Brasil, morou no campo. Essas variáveis somente foram incluídas na estimação por MQO. 
Tabela 13. Variáveis de controle

\begin{tabular}{l|l}
\hline Variavel & Descrição \\
\hline Idade (60-79) & idade do indivíduo \\
\hline Anos de estudo (0-1 ano) & dummy se o indivíduo tem até 1 ano de estudo \\
\hline Anos de estudo (5-8 anos) & dummy se o indivíduo tem de 2 a 4 anos de estudo \\
\hline Anos de estudo (9 ou mais & dummy se o indivíduo tem de 5 a 8 anos de estudo \\
\hline Casado/Amasiado & dummy se o indivíduo 9 ou mais anos de estudo \\
\hline Filhos (0-14) & dummy seo indivíduo é casado ou amasiado \\
\hline Moradores (1-12) & número de filhos \\
\hline Nativo no Brasil & número de moradores \\
\hline Morou no Campo & dummy se o indivíduo nasceu no Brasil \\
\hline Aposentadoria & dummy se o indivíduo morou no campo durante 5 anos até os 15 anos \\
\hline Renda de aposentadoria & dummy se o indivíduo está aposentado \\
\hline Empregado & dummy se o indivíduo recebe renda de aposentadoria \\
\hline Empregador & dummy se o indivíduo é empregado na ocupação atual (ou na última que teve) \\
\hline Conta própria & dummy se o indivíduo é empregador na ocupação atual (ou na última que teve) \\
\hline Bens de Consumo (0-6) & $\begin{array}{l}\text { dummy se o indivíduo é conta própria na ocupação atual (ou na última que } \\
\text { teve) }\end{array}$ \\
\hline Renda total & número de bens de consumo da família (proxy para renda familiar \\
\hline Seguro saúde & renda total do indivíduo \\
\hline \hline Fonte: Elabora pe o indivíduo tem outro seguro saúde além do SUS
\end{tabular}

Fonte: Elaborado pelo autor com base em SABE (2002, 2006 e 2010)

\subsubsection{Estatísticas descritivas}

A Tabela 14 apresenta as estatísticas descritivas das medidas de saúde, das variáveis endógena e instrumental, assim como dos controles incluídos nos modelos de mínimos quadrados ordinários, efeito fixo e efeito fixo com variável instrumental, separadamente para homens e mulheres. A idade média da amostra é similar para ambos os sexos, aproximadamente 68,7 anos. A escolaridade média é baixa (4,7 anos), com os homens mais escolarizados do que as mulheres, e o desvio padrão é alto, evidenciando desigualdades no acesso à educação formal. 
Tabela 14 Média e desvio padrão por sexo.

\begin{tabular}{|c|c|c|c|c|}
\hline & \multicolumn{2}{|c|}{ Homens } & \multicolumn{2}{|c|}{ Mulheres } \\
\hline & Média & Desvio Padrão & Média & Desvio Padrão \\
\hline \multicolumn{5}{|l|}{ Características Demográficas } \\
\hline Idade (60-79) & 68.59 & 4.97 & 68.84 & 5.06 \\
\hline Anos de estudo & 5.10 & 4.20 & 4.43 & 3.84 \\
\hline Anos de estudo (0-1 ano) & 0.17 & 0.37 & 0.21 & 0.40 \\
\hline Anos de estudo (2-4 anos) & 0.53 & 0.50 & 0.52 & 0.50 \\
\hline Anos de estudo (5-8 anos) & 0.12 & 0.32 & 0.13 & 0.34 \\
\hline Anos de estudo ( 9 ou mais anos) & 0.18 & 0.38 & 0.14 & 0.34 \\
\hline Casado/Amasiado & 0.82 & 0.38 & 0.47 & 0.50 \\
\hline Número de filhos & 3.56 & 2.16 & 3.38 & 2.33 \\
\hline Número de moradores & 3.39 & 1.68 & 2.96 & 1.64 \\
\hline Nativo no Brasil & 0.94 & 0.24 & 0.96 & 0.21 \\
\hline Morou no Campo & 0.69 & 0.46 & 0.61 & 0.49 \\
\hline \multicolumn{5}{|l|}{ Emprego e renda } \\
\hline Aposentadoria & 0.54 & 0.50 & 0.79 & 0.41 \\
\hline Renda de aposentadoria & 0.82 & 0.38 & 0.70 & 0.46 \\
\hline Proporção de idosos por setor & 0.03 & 0.02 & 0.03 & 0.02 \\
\hline Empregado & 0.59 & 0.49 & 0.66 & 0.47 \\
\hline Empregador & 0.06 & 0.23 & 0.03 & 0.17 \\
\hline Conta própria & 0.35 & 0.48 & 0.31 & 0.46 \\
\hline Bens de Consumo (0-6) & 4.99 & 1.07 & 4.67 & 1.13 \\
\hline Renda total & 2154 & 2743 & 1183 & 1495 \\
\hline \multicolumn{5}{|l|}{ Medidas de Saúde } \\
\hline Indicador geral de saúde & 0.07 & 0.81 & 0.58 & 0.74 \\
\hline Autopercepção de Saúde (1-4) & 2.49 & 0.68 & 2.57 & 0.74 \\
\hline Atividades básicas (0-6) & 0.24 & 0.74 & 0.45 & 0.96 \\
\hline Atividades Instrumentais $(0-10)$ & 2.63 & 3.05 & 3.53 & 3.34 \\
\hline Mobilidade (0-4) & 0.81 & 1.07 & 1.52 & 1.33 \\
\hline Limitações devido a doenças (0-4) & 0.17 & 0.48 & 0.24 & 0.49 \\
\hline Doenças crônicas (0-6) & 1.44 & 1.18 & 2.02 & 1.35 \\
\hline Sintomas crônicos (0-7) & 1.17 & 1.57 & 1.51 & 1.65 \\
\hline Sobrepeso & 0.15 & 0.36 & 0.13 & 0.33 \\
\hline Obesidade & 0.16 & 0.37 & 0.36 & 0.48 \\
\hline Depressão (0-15) & 2.30 & 2.53 & 3.02 & 3.09 \\
\hline Funcionamento Cognitivo (0-19) & 16.88 & 2.52 & 16.79 & 2.28 \\
\hline Internações & 0.10 & 0.30 & 0.09 & 0.29 \\
\hline Força de preensão (0-60) & 34.07 & 7.72 & 20.24 & 5.26 \\
\hline Observações & 640 & & 1074 & \\
\hline
\end{tabular}

Fonte: Elaborado pelo autor com base em SABE (2015).

Com relação aos arranjos familiares, $82 \%$ dos homens e $47 \%$ das mulheres eram casados ou amasiados. Além disso, os indivíduos da amostra tinham cerca de 3,4 filhos vivos e viviam em residências com 3 moradores no total, aproximadamente. A maioria nasceu no 
Brasil e um contingente importante morou no campo por pelo menos 5 anos na infância, $69 \%$ dos homens e $61 \%$ das mulheres, respectivamente ${ }^{38}$.

A situação dos indivíduos no mercado de trabalho mostra importantes diferenças entre homens e mulheres. Enquanto 54\% dos homens abandonaram suas funções laborais, esse patamar alcança cerca de $80 \%$ das mulheres. No entanto, uma proporção menor de mulheres recebia renda de aposentadoria, $70 \%$, contra $82 \%$ dos homens, evidenciando distintos ciclos de vida entre os gêneros. Conforme discutido anteriormente, a decisão de aposentadoria será instrumentalizada pela proporção de idosos em cada setor da economia, cuja valor médio é de $3 \%$ para ambos os sexos, aproximadamente. Com relação à posição na ocupação atual (ou a última que teve, no caso dos aposentados), a posição de empregado é majoritária, seguida do trabalho por conta própria. O número de bens de consumo possuídos pelo domicílio, que é uma proxy para a renda familiar, e a renda total do indivíduo, mostram que os homens idosos têm uma situação financeira superior às mulheres.

Os valores médios dos indicadores de saúde sugerem que o estado de saúde dos homens é melhor do que das mulheres. Os valores do IGS e da autopercepção de saúde são maiores para as mulheres, indicando um quadro de saúde mais desfavorável. Nesse sentido, a construção do IGS parece coincidir com a saúde subjetiva relatada pelos indivíduos. Quando analisados os demais indicadores de saúde, que capturam efeitos em dimensões mais específicas, os valores médios dos homens são melhores em todas as medidas, com exceção do sobrepeso (embora a obesidade tenha maior prevalência entre as mulheres) e de internações, em que $10 \%$ dos homens e $9 \%$ das mulheres foram internados pelo menos uma vez no último ano ${ }^{39}$.

A análise descritiva pode ser utilizada como um teste preliminar do efeito da aposentadoria em saúde, ao calcular as médias dos indicadores de saúde para aposentados e trabalhadores, separadamente, como proposto por Neuman (2007, p. 188). A Tabela 15 mostra os valores médios dos indicadores de saúde que foram incluídos nas regressões, segundo status de aposentadoria e gênero.

\footnotetext{
${ }^{38}$ Comentário sobre morar no campo. Exposição a doenças etc. Não foi possível controlar para as doenças na infância pois somente a pesquisa de 2000 tinha essa informação.

${ }^{39}$ Explicar que esses indicadores não necessariamente indicam uma vantagem das mulheres nessas dimensões.
} 
Tabela 15. Estatísticas descritivas para aposentados e trabalhadores

\begin{tabular}{|c|c|c|c|c|}
\hline & \multicolumn{2}{|c|}{ Aposentados } & \multicolumn{2}{|c|}{ Trabalhadores } \\
\hline & Média & Desvio padrão & Média & Desvio padrão \\
\hline \multicolumn{5}{|l|}{ Homens } \\
\hline Indicador geral de saúde & 0.17 & 0.85 & -0.05 & 0.74 \\
\hline Autopercepção de Saúde (1-4) & 2.55 & 0.68 & 2.42 & 0.68 \\
\hline Atividades básicas (0-6) & 0.32 & 0.88 & 0.13 & 0.50 \\
\hline Atividades Instrumentais $(0-10)$ & 2.84 & 3.08 & 2.37 & 3.01 \\
\hline Mobilidade (0-4) & 0.95 & 1.14 & 0.65 & 0.96 \\
\hline Doenças crônicas (0-6) & 1.52 & 1.20 & 1.34 & 1.16 \\
\hline Depressão (0-15) & 2.62 & 2.85 & 1.91 & 2.03 \\
\hline Funcionamento Cognitivo (0-19) & 16.63 & 2.62 & 17.17 & 2.36 \\
\hline Observações & 356 & & 284 & \\
\hline \multicolumn{5}{|l|}{ Mulheres } \\
\hline Indicador geral de saúde & 0.62 & 0.75 & 0.44 & 0.68 \\
\hline Autopercepção de Saúde (1-4) & 2.61 & 0.74 & 2.43 & 0.72 \\
\hline Atividades básicas (0-6) & 0.48 & 1.00 & 0.35 & 0.81 \\
\hline Atividades Instrumentais $(0-10)$ & 3.75 & 3.34 & 2.72 & 3.22 \\
\hline Mobilidade (0-4) & 1.58 & 1.34 & 1.26 & 1.26 \\
\hline Doenças crônicas (0-6) & 2.07 & 1.37 & 1.82 & 1.26 \\
\hline Depressão (0-15) & 3.09 & 3.15 & 2.77 & 2.86 \\
\hline Funcionamento Cognitivo (0-19) & 16.71 & 2.34 & 17.06 & 2.03 \\
\hline Observações & 833 & & 241 & \\
\hline
\end{tabular}

Fonte: Elaborado pelo autor com base em SABE (2015)

Para ambos os sexos, as medidas de saúde são piores entre os aposentados do que entre indivíduos que continuam trabalhando, exceto para o indicador de funcionamento cognitivo, que é marginalmente superior entre os não aposentados. Esses resultados podem indicar que a aposentadoria prejudica a saúde dos idosos. No entanto, essa análise pode ser enganadora, pois não inclui variáveis de controle e não há correção para endogeneidade. Os modelos a seguir confirmaram essa hipótese.

\subsubsection{Resultados dos modelos econométricos}

A partir da comparação de médias entre ativos e inativos, que sugeriu que a aposentadoria tem efeitos deletérios sobre a saúde dos indivíduos, a análise econométrica proposta inclui novos elementos que podem confirmar ou rejeitar essa indicação inicial. A Tabela 16 apresenta os coeficientes da aposentadoria para oito indicadores de saúde, obtidos a partir da estimação de três modelos. O modelo básico de mínimos quadrados ordinários incorpora as variáveis de controle à análise de médias, e testa se a indicação de deterioração da saúde ocorre devido à falta de controles. Os modelos de efeito fixo e efeito fixo com variáveis instrumental adicionam, à análise de médias e mínimos quadrados ordinários, o 
controle da endogeneidade da decisão de aposentadoria, e o fazem de distintas formas: o modelo de efeito fixo considera que a fonte de endogeneidade reside nas características individuais invariantes no tempo; já o modelo com variável instrumental mantém o controle para heterogeneidade individual, mas considera a possibilidade de outras fontes de endogeneidade.

Tabela 16. Efeito da aposentadoria nos indicadores de saúde

\begin{tabular}{|c|c|c|c|c|c|c|}
\hline & \multicolumn{3}{|c|}{ Homens } & \multicolumn{3}{|c|}{ Mulheres } \\
\hline & $\begin{array}{c}\text { MQO } \\
\text { (1) } \\
\end{array}$ & $\begin{array}{l}\text { EF } \\
(2) \\
\end{array}$ & $\begin{array}{c}\text { EF-IV } \\
\text { (3) } \\
\end{array}$ & $\begin{array}{c}\text { MQO } \\
(4) \\
\end{array}$ & $\begin{array}{l}\text { EF } \\
(5) \\
\end{array}$ & $\begin{array}{c}\text { EF-IV } \\
(6) \\
\end{array}$ \\
\hline \multirow[t]{2}{*}{ Indicador geral de saúde } & $0.166^{* * *}$ & $0.105^{*}$ & $-1.294^{*}$ & $0.188 * * *$ & 0.065 & -0.657 \\
\hline & $(0.055)$ & $(0.061)$ & $(0.770)$ & $(0.056)$ & $(0.052)$ & $(1.102)$ \\
\hline \multirow[t]{2}{*}{ Autopercepção de saúde } & $0.157 * *$ & 0.157 & -0.127 & $0.141 * *$ & $0.159 * *$ & -0.116 \\
\hline & $(0.063)$ & $(0.097)$ & $(0.714)$ & $(0.058)$ & $(0.079)$ & $(1.263)$ \\
\hline \multirow[t]{2}{*}{ Atividades básicas } & $0.199 * *$ & -0.066 & $-1.960 *$ & 0.093 & 0.014 & -1.253 \\
\hline & $(0.079)$ & $(0.080)$ & $(1.067)$ & $(0.075)$ & $(0.085)$ & $(1.938)$ \\
\hline \multirow[t]{2}{*}{ Atividades instrumentais } & $0.429 * * *$ & $0.329 * *$ & -1.443 & $0.228 *$ & 0.146 & -0.716 \\
\hline & $(0.132)$ & $(0.161)$ & $(1.760)$ & $(0.125)$ & $(0.166)$ & $(3.016)$ \\
\hline \multirow[t]{2}{*}{ Mobilidade } & $0.205 * *$ & $0.269^{*}$ & $-2.782 *$ & $0.312 * * *$ & 0.070 & -1.118 \\
\hline & $(0.099)$ & $(0.137)$ & $(1.650)$ & $(0.106)$ & $(0.129)$ & $(2.302)$ \\
\hline \multirow[t]{2}{*}{ Doenças crônicas } & 0.116 & 0.044 & 0.982 & 0.102 & 0.094 & 0.498 \\
\hline & $(0.114)$ & $(0.112)$ & $(0.931)$ & $(0.107)$ & $(0.102)$ & (1.577) \\
\hline \multirow[t]{2}{*}{ Depressão } & $1.117 * * *$ & $0.848 * * *$ & 1.201 & $0.447 *$ & 0.320 & -0.636 \\
\hline & $(0.256)$ & $(0.323)$ & $(2.555)$ & $(0.254)$ & $(0.223)$ & $(5.000)$ \\
\hline \multirow[t]{2}{*}{ Funcionamento cognitivo } & -0.164 & 0.144 & -2.047 & -0.034 & 0.032 & 1.653 \\
\hline & $(0.233)$ & $(0.329)$ & $(2.684)$ & $(0.152)$ & $(0.207)$ & (3.919) \\
\hline Dummy de ano & $\operatorname{sim}$ & $\operatorname{sim}$ & $\operatorname{sim}$ & $\operatorname{sim}$ & $\operatorname{sim}$ & $\operatorname{sim}$ \\
\hline Observações & 640 & 640 & 640 & 1074 & 1074 & 1074 \\
\hline
\end{tabular}

Desvio padrão em parênteses. * significativo a $10 \%$; ** significativo a $5 \%$; *** significativo a $1 \%$

As colunas 1 e 4 mostram os resultados do modelo de mínimos quadrados para homens e mulheres, respectivamente, e parecem confirmar a indicação da análise de médias. Os coeficientes indicam que a aposentadoria aumenta a probabilidade de piora na saúde dos indivíduos, em todas as dimensões analisadas, com efeitos significativos em oito medidas entre os homens e em cinco entre as mulheres.

O sinal dos coeficientes do MQO pode indicar que a decisão de aposentadoria é endógena. Essa possibilidade é considerada, inicialmente, pelo modelo de efeito fixo. As colunas 2 e 5 mostram os resultados dessa estimação e parece confirmar a deterioração da saúde devido a aposentadoria. É importante observar a mudança dos resultados do EF com relação ao MQO parece seguir um padrão. Analisando somente os coeficientes significativos do MQO, os resultados do EF são mais fracos ou menos significativos, com exceção das 
atividades básicas, para as mulheres. Isso pode sugerir que o EF controlou pelo menos parte da endogeneidade da aposentadoria, relacionada a heterogeneidade individual. Ainda, excetuando-se as atividades básicas, para os homens, e o funcionamento cognitivo, para ambos os sexos, os demais sinais do EF são coincidentes com o MQO, ou seja, de deterioração da saúde.

Ao incluir a instrumentalização da aposentadoria ao modelo de efeito fixo, o padrão de resultados do MQO e do EF se altera. As colunas 3 e 6 mostram que os coeficientes são negativos, com exceção das doenças crônicas e depressão, para os homens e do funcionamento cognitivo e da depressão, para as mulheres. Ou seja, nos demais indicadores, quando a endogeneidade da aposentadoria é controlada via variável instrumental, a condição de saúde melhora com a aposentadoria. Especificamente, o indicador geral de saúde sugere que a saúde global dos homens melhora com a aposentadoria. Além disso, dois indicadores de capacidade funcional (atividades básicas e mobilidade) são marginalmente significativos e negativos, indicando ser o mecanismo pelo qual a saúde geral dos homens melhora após a aposentadoria. Para as mulheres o modelo de variável instrumental não forneceu coeficientes significativos. A Tabela 17 mostra os coeficientes da aposentadoria no primeiro estágio do método de variável instrumental. Nota-que, para os homens, o coeficiente da variável instrumental (proporção de idosos) é significativo e negativo. Ou seja, aumentos na proporção de homens idosos nos diferentes setores da economia conduz a uma diminuição da probabilidade de aposentadoria, como esperado. Ainda para os homens, o teste $\mathrm{F}$ indica que o instrumento é fraco, que pode justificar o desvio padrão relativamente alto para o instrumento. Para as mulheres, a variável instrumental não foi significativa, indicando que o comportamento laboral das mulheres é mais difícil de ser instrumentalizado, provavelmente devido à baixa taxa de atividade nas coortes mais antigas. 
Tabela 17. Primeiro estágio, coeficientes para a decisão e aposentadoria

\begin{tabular}{lccc}
\hline & Homens & Mulheres \\
\cline { 2 - 3 } Proporção de idosos & $-3.082^{* *}$ & 2.025 \\
Renda de aposentadoria & $(1.319)$ & $(1.397)$ \\
& $0.219^{* * *}$ & 0.042 \\
Renda total & $(0.073)$ & $(0.043)$ \\
& -0.000 & $-0.000^{* * *}$ \\
Seguro & $(0.000)$ & $(0.000)$ \\
& -0.008 & 0.000 \\
Empregado & $(0.066)$ & $(0.046)$ \\
& $0.155^{* *}$ & $0.147^{* * *}$ \\
Empregador & $(0.072)$ & $(0.048)$ \\
& 0.176 & 0.078 \\
Casado & $(0.129)$ & $(0.119)$ \\
& 0.049 & -0.045 \\
Bens de Consumo (0-6) & $(0.095)$ & $(0.054)$ \\
& -0.002 & 0.005 \\
Filhos & $(0.028)$ & $(0.017)$ \\
& -0.034 & -0.038 \\
Moradores & $(0.033)$ & $(0.024)$ \\
Teste F & -0.012 & -0.004 \\
Observações & $(0.018)$ & $(0.014)$ \\
\hline \hline
\end{tabular}

\subsection{Considerações finais}

Os resultados dos modelos MQO, efeito fixo e efeito fixo com variável instrumental sugerem que a aposentadoria tem efeitos benéficos para os homens. $\mathrm{O}$ indicador geral de saúde, que captura o estado de saúde global do indivíduo, foi marginalmente significativo. Quando esse resultado é contraposto com as variáveis objetivas de saúde, observa-se que dois indicadores de capacidade funcional também mostraram-se significativos, atividades básicas da vida diária e mobilidade. Esse resultado sugere que a melhoria no estado geral de saúde deve-se a essas dimensões.

Esse resultado pode indicar que o histórico laboral dos homens no município de São Paulo é caracterizado por empregos fisicamente demandantes, ou seja, a saída do mercado de trabalho representaria um ganho em capacidade funcional. Dois dados sugerem que essa interpretação é verdadeira. Em primeiro lugar, a baixa escolaridade média, em torno de 5 anos, pode indicar a existência de trabalhos que necessitam de maior esforço físico. Além disso, 70\% dos homens entrevistados em 2000 disseram que tiveram um trabalho 
predominantemente físico em seu histórico de trabalho, corroborando os resultados alcançados nessa investigação. É importante averiguar se esse resultado marca uma diferença em relação às pesquisas desenvolvidas nos países desenvolvidos, que têm melhor média educacional. 


\section{CONCLUSÃO}

O Brasil é um país que envelhece rapidamente, o que se traduz no aumento da proporção de aposentados na população e na diminuição da relação contribuinte beneficiário. A preocupação principal dos debates em torno da reforma da previdência é com a repercussão sobre as contas públicas, ou seja, os efeitos da aposentadoria sobre o bem-estar individual são negligenciados. Essa tese procurou mostrar que a aposentadoria tem impactos sobre os resultados de saúde e sobre a decisão de mobilidade ocupacional no Brasil.

O capítulo 02 teve como base a investigação dos determinantes da transição do trabalho assalariado para o trabalho por conta própria. O uso da metodologia de pseudo-painel mostrou-se importante, ao permitir o uso de modelos de efeito fixo, levando em conta a possível endogeneidade da decisão de trabalhar, uma vez que a análise das transições foi restrita aos ocupados. Os resultados sugerem que a renda de aposentadoria é uma variável importante para explicar a transição para o trabalho por conta própria entre os trabalhadores mais velhos, especialmente entre os homens, e nos menores quartis de aposentadoria. Já a dummy de aposentadoria não se revelou significativa para essa transição ocupacional. Os demais determinantes sugerem que a natureza dessa decisão mobilidade é distinta entre homens e mulheres. Entre as mulheres, a escolha pelo trabalho autônomo parece vinculada à maior flexibilidade de horário e ao trabalho em firmas pequenas. Já entre os homens, o salário mostrou-se positivo e significativo para a escolha ocupacional de interesse. Colocando os resultados em perspectiva, a transição para o trabalho por conta própria no final da carreira laboral no Brasil metropolitano parece estar vinculada, pelo menos parcialmente, às condições desfavoráveis do assalariamento. Os resultados sugerem que os homens que estão em empregos com alta rotatividade têm maior propensão de trabalhar de forma autônoma, assim como as mulheres que trabalham em firmas pequenas. Esse fato pode sugerir que o mercado de trabalho precisa se adaptar às necessidades de um país que envelhece em um ritmo acelerado. Nesse sentido, é importante que essa pesquisa seja estendida e aprofundada em outras direções, como no papel da escolaridade requerida pela ocupação na decisão de mobilidade das pessoas mais velhas, bem como no estudo da possível discriminação etária no mercado de trabalho.

O capítulo 03 investigou os possíveis impactos da aposentadoria na saúde dos idosos residentes no município de São Paulo. A análise foi conduzida com a SABE, que possui um rico conjunto de informações sobre a saúde e a inserção laboral de idosos e permite identificar não somente o efeito, mas os possíveis canais pelos quais a decisão de aposentadoria impacta 
a condição de saúde das pessoas. A partir da utilização de modelos de efeito fixo e efeito fixo com variável instrumental, foi possível levar em conta a simultaneidade entre a decisão de parar de trabalhar e o estado de saúde das pessoas. Foram encontradas evidências de que a aposentadoria melhora os indicadores de mobilidade, especialmente para os homens. Esse resultado é compatível com o histórico laboral das coortes mais antigas no Brasil, que entravam cedo no mercado de trabalho, tem baixa escolaridade média e estavam ocupados em atividades que exigiam esforço físico. Nesse contexto, a aposentadoria pode melhorar as condições de mobilidade.

Acredita-se que poucos estudos acadêmicos no Brasil investigaram as questões discutidas nessa tese devido à escassez de dados. Nesse sentido, essa tese procurou ultrapassar a barreira da indisponibilidade de dados e contribuir na literatura sobre aposentadoria no Brasil. Mais especificamente, há uma escassez de trabalhos que tratam de mobilidade ocupacional de idosos, em especial, que incluem a renda de aposentadoria. A imputação da renda de aposentadoria da PNAD permitiu investigar a causalidade da aposentadoria em transição ocupacional. De mesma forma, poucos trabalhos em economia no Brasil analisam os efeitos da aposentadoria no bem-estar individual, uma vez que a preocupação central tem sido com os impactos nas finanças públicas e na investigação dos determinantes de aposentadoria. 


\section{REFERÊNCIAS BIBLIOGRÁFICAS}

BENÍTEZ-SILVA, H. Micro determinants of labor force status among older Americans: Yale University, 2000

BLANCHFLOWER, D. G. Self-employment in OECD countries. Labour Economics, v. 7, n. 5, p. 471-505, set. 2000 .

BLANCHFLOWER, D. G.; OSWALD, A. J. What makes an entrepreneur? Journal of Labor Economics, v. 16, n. 1, p. 26-60, jan. 1998.

BONSANG, E.; ADAM, S.; PERELMAN, S. Does retirement affect cognitive functioning? Journal of health economics, v. 31, n. 3, p. 490-501, may 2012.

BORJAS, George J. Labor Economics. New York: McGrw-Hill International Edition, 2008.

BRASIL. Lei no 10.741 , de $1^{\circ}$ de outubro de 2003. Dispõe sobre o Estatuto do Idoso e dá outras providências. Disponível em: $<$ http://www.planalto.gov.br $>$.

BRASIL. Ministério da Previdência Social. Anuário Estatístico da Previdência Social. Brasília: MPS, 2013.

BRASIL. Ministério da Previdência Social. Brasília: MPS, 2015.

BRASIL. Ministério da Previdência Social. Previdência Social: Reflexões e Desafios. Brasília: MPS, 2009. 232 p.

BRASIL. Panorama da Previdência Social brasileira. Brasília: MPS, 2007.80 p.

BRUCE, D.; HOLTZ-EAKIN, D.; QUINN, J. Self-Employment and Labor Market Transitions at Older Ages. Boston College Center for Retirement Research, 2000 (Working Paper, no. 2000-13).

CAHILL, K. E.; GIANDREA, M. D.; QUINN, J. F. Retirement patterns from career employment. The Gerontologist, v. 46, n. 4, p. 514-523, 2006.

CAMARANO, A. A.; MEDEIROS, M. Introdução. In: CAMARANO, A. A. (Org.). Muito além dos 60: os novos idosos brasileiros. Rio de Janeiro: Ipea, 2004.

CAMARANO, A. A.; PASINATO, M. T. O envelhecimento populacional na agenda das políticas públicas. In: CAMARANO, A. A. (Org.). Os novos idosos brasileiros: muito além dos 60? Rio de Janeiro: Ipea, 2004.

CAMARANO, A.A. Estatuto do idoso: avanços com contradições. Rio de Janeiro: Ipea, 2013 (Texto para Discussão, n. 1.840).

CAMARANO, Ana Amélia. O idoso brasileiro no mercado de trabalho. IPEA, Rio de Janeiro, Texto para Discussão n. ${ }^{\circ} 830$, out/2001. 
CLEGG, A.; FIFER, S. Senior Self-Employment and Entrepreneurship - A PRIME Perspective. Public Policy \& Aging Report, v. 24, p. 168-172, 2014.

COE, N. B.; ZAMARRO, G. Retirement effects on health in Europe. Journal of health economics, v. 30, n. 1, p. 77-86, jan. 2011.

CRESSY, R. Credit rationing or entrepreneurial risk aversion? An alternative explanation for the Evans and Jovanovic finding. Economics Letters, v. 66, p. 235-240, 2000.

DAVE, D.; RASHAD, I.; SPASOJEVIC, J. The Effects of Retirement on Physical and Mental Health Outcomes. Southern Economic Journal, v. 75, n. 2, p. 497-523, 2008.

DAVE, D.; SPASOJEVIC, J. The Effects of Retirement on Physical and Mental Health Outcomes. New York: National Bureau of Economic Research, 2008 (Working Paper series, n. 12123).

DUNN, T.; HOLTZ-EAKIN, D. Financial Capital, Human Capital, and the Transition to Self $\square$ Employment: Evidence from Intergenerational Links. Journal of Labor Economics, v. 18, n. 2, p. 282-305, 2000.

EKERDT, D. J. Frontiers of research on work and retirement. The journals of gerontology. Series B, Psychological sciences and social sciences, v. 65B, n. 1, p. 69-80, jan. 2010.

EVANS, D. S.; JOVANOVIC, B. An Estimated Model of Entrepreneurial Choice under Liquidity Constraints. Journal of Political Economy, v. 97, n. 4, 1989.

EVANS, D. S.; LEIGHTON, L. S. Some Empirical Aspects of Entrepreneurship. American Economic Review, v. 79, n. 3, p. 519-535, 1989.

FUCHS, V. R. Self-Employment and Labor Force Participation of Older Workers. New York: National Bureau of Economic Research, 1980 (Working Paper series, n. 584R).

FURTADO, A. C. A. R. A participação do idoso no mercado de trabalho brasileiro. Câmara dos Deputados, Consultoria Legislativa, Série estudo, Brasília. 2005.

GIANDREA, M. D.; CAHILL, K. E.; QUINN, J. F. Self-employment transitions among older American workers with career jobs. US Department of Labor, US Bureau of Labor Statistics, Working Paper, Washington. n. 418, abr. 2008.

GROOT, W.; BRINK, H. M. V. D. Job satisfaction of older workers. International Journal of Manpower, Vol. 20, No. 6, pp. 343-360, 1999.

GROSSMAN, M. On the Concept of Health Capital and the Demand for Health. Journal of Political Economy, v. 80, n. 2, p. 223, 1972.

GRUBER, J.; WISE, D. Social Security and Retirement: An International Comparison. American Economic Review, v. 88, n. 2, p. 158-163, 1998.

HAIDER, S.; LOUGHRAN, D. Elderly labor supply: Work or play? RAND, Labor and Population Program, Working Paper, Santa Monica. n. 2582, abr. 2001. 
HOLTZ-EAKIN, D.; JOULFAIAN, D.; ROSEN, H. S. Entrepreneurial Decisions and Liquidity Constraints. The RAND Journal of Economics, v. 25, n. 2, p. 334-347, 1994.

IBGE. Pesquisa Mensal de Emprego (2002-2007). Rio de Janeiro: IBGE, 2014b

IBGE. Pesquisa Mensal do Emprego. Série Relatórios Metodológicos, v. 23. Rio de Janeiro, 2002.

IBGE. Pesquisa Nacional por Amostra de Domicílios (1981-2013). Rio de Janeiro: IBGE, $2014 \mathrm{a}$

ILO. International Labor Organization. Laborsta Internet, 2015. Disponível em: $<$ http://esa.un.org/unpd/wpp/>. Acesso em agosto de 2015

JOHANSSON, E. Self- employment and liquidity constraints: evidence from Finland. Scandinavian Journal of Economics, n. 102, p. 123-134, 2000.

KALLEBERG, A.; RESKIN, B.; HUDSON, K. Bad jobs in America: standard and nonstandard employment relations and job quality in the United States. American Sociological Review, v. 65, p. 256-278, 2000.

KALWIJ, A.; VERMEULEN, F. Health and labour force participation of older people in Europe: what do objective health indicators add to the analysis? Health Economics, v.15, n.5, p.619-38, 2008

KIHLSTROM, R.; LAFFONT, J. A general equilibrium theory of firm formation based on risk aversion. Journal of Political Economy, n. 87, p. 719-748, 1979.

LEBrão M. L., DUARTe Y. A. O. (org). O Projeto SABE no Município de São Paulo: uma abordagem inicial. Brasília: OPAS/MS; 2003

LIBERATO, V. C. A Oferta de trabalho masculina "pós-aposentadoria" no Brasil urbano 1981/2001. Dissertação (Mestrado em Economia)—Belo Horizonte: Faculdade de Ciências Econômicas, Universidade Federal de Minas Gerais, 2003.

LLOYD-SHERLOCK, P. Ageing, Development and Social Protection: Generalisations, Myths and Stereotypes. In: Living Longer: Ageing, Development and Social Protection. LONDON \& NEW YORK, 2004. p. 1-18.

LLOYD-SHERLOCK, P. Population ageing and international development: from generalisation to evidence. UK: Policy Press, 2010.

LOMBARD, K. V. Female Self-Employment and Demand for Flexible, Nonstandard Work Shedules. Economic Inquiry, v. 39, n. 2, p. 214-237, 2001.

LUCAS, R. E. J. On the Size of Distribution of Business Firms. The Bell Journal of Economics, v. 9, n. 2, p. 508-523, 1978.

MEL, S. DE; MCKENZIE, D.; WOODRUFF, C. Who Are the Microenterprise Owners? Evidence from Sri Lanka on Tokman v. de Soto. The World Bank Development Research Group, Policy Research Working Paper. v. 4635, 2008. 
METE, C.; SCHULTZ, P. Health and Labor Force participation of the Elderly in Taiwan. Economic Growth Center, Yale University, Center Discussion Paper, New Haven. n. 846, jun. 2002.

MOORE, C.; MUELLER, R. The transition from paid to self-employment in Canada: the importance of push factors. Applied Economics, v. 34, n. 6, p. 791-801, 2002.

MOSCARINI, G.; VELLA, F. G. Ocupational mobility and the business cycle. New York: National Bureau of Economic Research, 2008 (Working Paper Series, n. 3.369).

MOUlTON, J. G.; SCOTT, J. C. Good and Bad? An Analysis of Self-Employment at the Older Ages. Public Policy \& Aging Report, v. 24, p. 155-161, 2014.

NARITA, R. Self Employment in Developing Countries: a Search-Equilibrium Approach, 2014

NEUMAN, K. Quit Your Job and Get Healthier? The Effect of Retirement on Health. Journal of Labor Research, v. 29, n. 2, p. 177-201, 31 jul. 2007.

NEUMAN, K. The Health Effects of Retirement: a theoretical and empirical investigation. Notre Dame, Indiana: University of Notre Dame, 2004.

OECD. The Labour Force Participation of Older Workers - The Effects of Pension and Early Retirement Schemes; OECD Economics Department, May 2004

OLIVERIA, A. M. H. C. DE; MACHADO, L. Mobilidade Ocupacional e Incompatibilidde Educaional no Brasil Contemporâneo. Pesquisa e Planejamento Econômico PPE, v. 2, n. 43, 2013.

PALLONI, A.; PELÁEZ, M. Histórico e natureza do estudo. In: LEBRÃO, M. L.;

DUARTE, Y. A O. (Eds.). O projeto SABE no município de São Paulo: uma abordagem inicial. Brasília: Organização Panamerica de Saúde, 2003. p. 255.

PARKER, S. C. The Economics of Self-Employment and Entrepreneurship. Cambridge: Cambridge University Press, 2009.

PEREZ, Elisenda Renteria ; WAJNMAN, S. ; OLIVEIRA, Ana Maria Hermeto Camilo de. Análise dos Determinantes da Participação no Mercado de Trabalho dos Idosos em São Paulo. Revista Brasileira de Estudos de População (Impresso), v. 23, p. 269-286, 2006.

QUEIROZ, V. S.; RAMALHO, H. M. DE B. A escolha ocupacional dos idosos no mercado de trabalho. Economia (Selecta), Brasília. v. 10, n. 4, p. 817-848, 2009.

QUINN, J. F. Labor-force participation patterns of older self-employed workers. Social Security Bulletin, v. 43, n. 4, p. 17-28, 1980.

RIBAS, R. P.; MACHADO, A. F. A Imputação da Renda do não trabalho na Pesquisa Mensal de Emprego. Pesquisa e Planejamento Econômico PPE, v. 39, n. 3, p. 365-396, 2009. 
RIBAS, R. P.; SOARES, S. S. D. Sobre o Painel da Pesquisa Mensal de Emprego (PME) do IBGE. IPEA. Texto para Discussão n.1348, 2008.

SCHNALZENBERGER, Mario; SCHNEEWEIS, Nicole; WINTER-EBMER, Rudolf;

ZWEIMÜLLER, Martina. Job Quality and Employment of Older People in Europe. Department of Economics Johannes Kepler University of Linz. Working Paper No. 1108, July 2011

SIMOES, N.; MOREIRA, S. B.; CRESPO, N. Individual Determinants of Self-Employment Entry - What Do We Really Know? (Working Paper, MPRA Paper n.48403)

UNITED NATIONS. The 2015 Revision of World Population Prospects, 2015. Disponível em: $<$ http://esa.un.org/unpd/wpp/>. Acesso em agosto de 2015

UNITED NATIONS. World Population Ageing 2013. New York: Department of Economic and Social Affairs, Population Division, 2013.

WAJNMAN, S. et al. Os idosos no mercado de trabalho: tendências e consequências. In: CAMARANO, A.A. (Org). Os novos idosos brasileiros: muito além dos 60? Rio de Janeiro: IPEA, 2004. p. 453-480.

WONG, L. L. R.; CARVALHO, J. A. O rápido processo de envelhecimento populacional do Brasil: sérios desafios para as políticas públicas. Revista Brasileira de Estudos Populacionais, v. 23, n. 1, p. 5-26, 2006.

ZISSIMOPOULOS, J. M.; KAROLY, L. A. Transitions to self-employment at older ages: The role of wealth, health, health insurance and other factors. Labour Economics, v. 14, p. 269-295, 2007.

ZISSIMOPOULOS, J. M.; KAROLY, L. A.; RAND. Labor-Force Dynamics at Older Ages: Movements Into Self-Employment for Workers and Nonworkers. Res Aging, v. 31, n. 1, p. 89-111, 2009. 


\section{ANEXO}

(i) Autopercepção de saúde (APS)

"Agora gostaria de lhe fazer algumas perguntas sobre a sua saúde. $\mathrm{O}(\mathrm{a}) \operatorname{Sr}(a)$ diria que a sua saúde é excelente, muito boa, boa, regular ou má?"

(ii) Atividades da vida diária. Indicador composto por seis perguntas, que podem ser respondidas como: sim, não, não sabe (ns) ou não respondeu (nr)

"O Sr(a) tem dificuldades em atravessar um quarto caminhando?"

"O Sr(a) encontra dificuldade para se vestir (incluindo calças, sapatos, chinelos ou meias)?"

"O Sr(a) tem dificuldade para tomar banho? (incluindo entrar ou sair da banheira)"

"O Sr(a) tem dificuldade para comer (cortar a comida, encher um copo, etc)"

"O Sr(a) tem dificuldade para deitar ou levantar da cama?"

"O Sr(a) tem dificuldade para ir ao banheiro (incluindo sentar e levantar do vaso sanitário)?"

(iii) Doenças Crônicas: Indicador composto por oito doenças, que podem ser respondidas como: sim, não, não sabe (ns) ou não respondeu (nr)

"Alguma vez um médico ou enfermeiro lhe disse que o $\operatorname{Sr}(a)$ tem pressão sanguínea alta, quer dizer, hipertensão?”

"Alguma vez um médico ou enfermeiro lhe disse que o $\operatorname{Sr}(a)$ tem diabetes, quer dizer, níveis altos de açúcar no sangue?"

"Alguma vez um médico ou enfermeiro lhe disse que o $\operatorname{Sr}($ a) tem câncer ou tumor maligno, excluindo tumores menores de pele?"

"Alguma vez um médico ou enfermeiro lhe disse que o Sr(a) tem alguma doença crônica do pulmão, como asma, bronquite ou enfisema?"

"Alguma vez um médico ou enfermeiro lhe disse que o $\operatorname{Sr}(a)$ teve um ataque do coração, uma doença coronária, angina, doença congestiva ou outros problemas cardíacos?"

"Alguma vez um médico ou enfermeiro lhe disse que o $\operatorname{Sr}(a)$ teve uma embolia, derrame, ataque, isquemia ou trombose cerebral"

"Alguma vez um médico ou enfermeiro lhe disse que o $\operatorname{Sr}(a)$ tem artrite, reumatismo, artrose?"

"Alguma vez um médico ou enfermeiro lhe disse que o Sr(a) tem osteoporose?"

(iv) Mobilidade. Indicador composto por nove dificuldades motoras, que podem ser respondidas como: sim, não, não pode, não faz ou não respondeu (nr). Foi considerado que o indivíduo possui dificuldade motora se ele respondeu: sim ou não pode.

"Tem dificuldade em caminhas várias ruas (quadras)?"

"Tem dificuldade em ficar sentado(a) durante duas horas?"

"Tem dificuldade em se levantar de uma cadeira, depois de ficar sentado(a) durante longo período?"

"Encontra alguma dificuldade em subir vários lances de escada sem parar para descansar?"

"Tem dificuldade em se curvar, se ajoelhar, ou se agachar?"

"Tem dificuldade para estender seus braços acima dos ombros?"

"Tem dificuldade para puxar ou empurrar grandes objetos, como uma poltrona?"

"Encontra alguma dificuldade em levantar ou carregar pesos maiores que $5 \mathrm{~kg}$, como uma sacola de compras pesada?" 
"Tem dificuldade em levantar uma moeda de uma mesa?"

(v) Depressão. Indicador composto por quinze questões subjetivas sobre a percepção do indivíduo sobre a sua vida, que podem ser respondidas como: sim, não, não sabe (ns) ou não respondeu (nr)

"O Sr(a) está basicamente satisfeito com a sua vida?"

"Tem diminuído ou abandonado muitos dos seus interesses ou atividades anteriores?"

"Sente que sua vida está vazia?"

"Tem estado aborrecido frequentemente"

"Tem estado de bom humor a maior parte do tempo?"

"Tem estado preocupado ou tem medo que alguma coisa ruim vá lhe acontecer"

"Sente-se feliz a maior parte do tempo?"

"Com que frequência se sente desamparado ou desvalido"

"Tem preferido ficar em casa em vez de sair e fazer coisas?"

"Tem sentido que tem mais problemas com a memória do que outras pessoas de sua idade?"

"O Sr(a) acredita que é maravilhoso estar vivo?"

"Sente-se inútil ou desvalorizado em sua situação atual?"

"Sente-se cheio de energia?"

"Se sente sem esperança diante da sua situação atual?"

"O Sr(a) acredita que as outras pessoas estão em situação melhor?"

(vi) Dificuldades Cognitivas: Indicador que se baseia na capacidade cognitiva do respondente.

\subsection{Condição de Atividade do Idoso com base em SABE (2000)}

O indivíduo foi considerado ativo se ele respondeu: Em H.5: 1, 2 ou 3; ou em H.6: 1,2 ou 3

H.5: Na semana passada, o(a) $\operatorname{Sr}(a)$ :

1. Trabalhou?

2.Tinha trabalho porém não trabalhou?

3. Ajudou em negócio familiar, com ou sem pagamento?

4. Procurou trabalho?

5. Dedicou-se aos afazeres domésticos?

6. Aposentado ou pensionista?

7. Está incapacitado temporariamente para o trabalho?

8. Está incapacitado permanentemente para o trabalho?

9. Não trabalhou?

10. Não sabe.

11. Não respondeu"

H.6: "Além dessa atividade, (condição em H.5) na semana passada o(a) Sr.(a):

1. Vendeu algum produto?

2. Fez alguns produtos para vender?

3. Lavou, passou, cozinhou, consertou eletrodomésticos ou realizou qualquer tarefa em troca de pagamento?

4. Ajudou alguém em alguma atividade de plantio ou criação de animais? 


\subsection{Motivação para o trabalho com base em SABE (2000)}

"Qual é a principal razão pela qual o(a) $\operatorname{Sr}(a)$ trabalha?

1. Necessita do ganho

2. Quer ajudar a família

3. Quer manter-se ocupado

4. Necessidade de sentir-se útil, produtivo

5. Gosto do meu trabalho

6. Outro

8. Ns

9. $\mathrm{Nr}$

\subsection{Saúde na Ocupação com base em SABE (2000)}

"Alguma vez um médico ou enfermeira lhe disse que o(a) Sr(a) tinha ou tem um problema de saúde provocado pelas condições dessa ocupação" sim, não, não sabe (ns) ou não respondeu (nr)

Tabela 18. Coortes de nascimento

\begin{tabular}{l|llllll}
\hline idade & $\mathbf{2 0 0 2}$ & $\mathbf{2 0 0 3}$ & $\mathbf{2 0 0 4}$ & $\mathbf{2 0 0 5}$ & $\mathbf{2 0 0 6}$ & $\mathbf{2 0 0 7}$ \\
\hline $\mathbf{5 0}$ & 1952 & 1953 & 1954 & 1955 & 1956 & 1957 \\
$\mathbf{5 1}$ & 1951 & 1952 & 1953 & 1954 & 1955 & 1956 \\
$\mathbf{5 2}$ & 1950 & 1951 & 1952 & 1953 & 1954 & 1955 \\
$\mathbf{5 3}$ & 1949 & 1950 & 1951 & 1952 & 1953 & 1954 \\
$\mathbf{5 4}$ & 1948 & 1949 & 1950 & 1951 & 1952 & 1953 \\
$\mathbf{5 5}$ & 1947 & 1948 & 1949 & 1950 & 1951 & 1952 \\
$\mathbf{5 6}$ & 1946 & 1947 & 1948 & 1949 & 1950 & 1951 \\
$\mathbf{5 7}$ & 1945 & 1946 & 1947 & 1948 & 1949 & 1950 \\
$\mathbf{5 8}$ & 1944 & 1945 & 1946 & 1947 & 1948 & 1949 \\
$\mathbf{5 9}$ & 1943 & 1944 & 1945 & 1946 & 1947 & 1948 \\
$\mathbf{6 0}$ & 1942 & 1943 & 1944 & 1945 & 1946 & 1947 \\
$\mathbf{6 1}$ & 1941 & 1942 & 1943 & 1944 & 1945 & 1946 \\
$\mathbf{6 2}$ & 1940 & 1941 & 1942 & 1943 & 1944 & 1945 \\
$\mathbf{6 3}$ & 1940 & 1941 & 1942 & 1943 & 1944 \\
$\mathbf{6 4}$ & 1939 & 1939 & 1940 & 1941 & 1942 & 1943 \\
$\mathbf{6 5}$ & 1938 & 1938 & 1939 & 1940 & 1941 & 1942 \\
$\mathbf{6 6}$ & 1937 & 1938 & 1939 & 1940 & 1941 \\
$\mathbf{6 7}$ & 1937 & 1937 & 1938 & 1939 & 1940 \\
$\mathbf{6 8}$ & 1936 & 1936 & 1937 & 1938 & 1939 \\
$\mathbf{6 9}$ & 1935 & 1935 & 1936 & 1937 & 1938 \\
\hline
\end{tabular}

